\title{
Rooted in Cultural Expression and Nature's Influence: Interpreting Native American Architecture
}

\author{
By
}

Leslie Kristin Papineau, B.A.S.

\author{
A thesis submitted to \\ The Faculty of Graduate Studies and Research \\ In Partial fulfillment of the requirements for the degree of
}

\section{Master of Architecture}

Carleton University

Ottawa, Ontario

May 2008

Copyright

2008, Leslie Kristin Papineau 


$\begin{array}{ll}\begin{array}{l}\text { Library and } \\ \text { Archives Canada }\end{array} & \begin{array}{l}\text { Bibliothèque et } \\ \text { Archives Canada }\end{array} \\ \begin{array}{l}\text { Published Heritage } \\ \text { Branch }\end{array} & \begin{array}{l}\text { Direction du } \\ \text { Patrimoine de l'édition }\end{array} \\ \begin{array}{l}\text { 395 Wellington Street } \\ \text { Ottawa ON K1A 0N4 } \\ \text { Canada }\end{array} & \begin{array}{l}\text { 395, rue Wellington } \\ \text { Ottawa ON K1A 0N4 } \\ \text { Canada }\end{array}\end{array}$

Your file Votre référence ISBN: 978-0-494-44103-9 Our file Notre référence ISBN: 978-0-494-44103-9

NOTICE:

The author has granted a nonexclusive license allowing Library and Archives Canada to reproduce, publish, archive, preserve, conserve, communicate to the public by telecommunication or on the Internet, loan, distribute and sell theses worldwide, for commercial or noncommercial purposes, in microform, paper, electronic and/or any other formats.

The author retains copyright ownership and moral rights in this thesis. Neither the thesis nor substantial extracts from it may be printed or otherwise reproduced without the author's permission.
AVIS:

L'auteur a accordé une licence non exclusive permettant à la Bibliothèque et Archives Canada de reproduire, publier, archiver, sauvegarder, conserver, transmettre au public par télécommunication ou par l'Internet, prêter, distribuer et vendre des thèses partout dans le monde, à des fins commerciales ou autres, sur support microforme, papier, électronique et/ou autres formats.

L'auteur conserve la propriété du droit d'auteur et des droits moraux qui protège cette thèse. $\mathrm{Ni}$ la thèse ni des extraits substantiels de celle-ci ne doivent être imprimés ou autrement reproduits sans son autorisation.
In compliance with the Canadian Privacy Act some supporting forms may have been removed from this thesis.

While these forms may be included in the document page count, their removal does not represent any loss of content from the thesis.
Conformément à la loi canadienne sur la protection de la vie privée, quelques formulaires secondaires ont été enlevés de cette thèse.

Bien que ces formulaires aient inclus dans la pagination, il n'y aura aucun contenu manquant.

\section{Canada}




\begin{abstract}
In the face of radically changing social and economic conditions, initiated by the impact of the universalizing modernist trends, results indicate little regard towards the local cultural and contextual variations of distinct societies. This thesis will argue that the importance of place and the relationship between man and nature have faded, as distinct characteristics derived from the vernacular slowly lose ground to the modern dominant culture.

Presently, there is an apparent loss of traditional vernacular architecture in First Nations communities, as buildings are developed without a sense of culturally appropriate design. The objective of this thesis is to architecturally express Native American cultural values through the design of an Environmental Learning Centre. The design intent is to encourage and re-establish environmental awareness, culturally significant experiences and relationships with the natural environment, and thereby strengthens the sense of place within the community.
\end{abstract}




\section{Acknowledgment}

To Professor Manuel Baez, thank you for your true dedication, guidance and wisdom over the course of my thesis study.

Special thanks to my thesis committee, Federica Goffi, Titania Truesdale and Thomas Mical for challenging my ideas and providing invaluable criticism, guidance and knowledge.

My deepest gratitude to my family, thank you for teaching me to dream, persevere and accomplish my goals to its fullest potential.

To my Mom and Sister who gave their helping hands, their intellect, enthusiasm and undying support when it was needed. And finally, to Al, for his encouragement, patience and understanding, throughout the many years of my education, this would have not been possible without you. 


\section{Table of Contents}

Title Page

Abstract

\section{Acknowledgements}

Table of Contents

$\begin{array}{lll}\text { List of Illustrations } & \text { IV,V }\end{array}$

\section{Introduction}

\section{Theory}

Attachments to Place

Regionalism, Critical Regionalism and Cultural Identity

The Link Between Past, Present \& Future

The Natural Environment

Traditional Ecological Knowledge

\section{History and Precedent}

Early Native American Building

Native American Vernacular Architecture

The Iroquois Longhouse Dwelling

Social Organization and Function

Climate Conditions

34

Economic Conditions

Religious, Spiritual, Cosmological Beliefs

Two Case Studies:

Two Case Studies: Introduction $\quad 44$

Douglas Cardinal $\quad 45$

Ouje Bougoumou Village 46-55

Busby \& Associates: Nicola Valley Institute of Technology $56-62$

$\begin{array}{lc}\text { Conclusion } & 63\end{array}$ 
The Project: $\quad 64$

The Site: $\quad 65-72$

Design Concept:The Environmental Learning Centre 73

The Description: The visual Journey $\quad$ 74-75

Douglas Kelbaugh:

The Sense of Place $\quad 76$

The Sense of Nature $\quad 77$

$\begin{array}{ll}\text {-The earth } & 79\end{array}$

$\begin{array}{ll}\text {-The air } & 81\end{array}$

$\begin{array}{lr}\text {-Water } & 82\end{array}$

$\begin{array}{lr}- \text { Sun } & 82\end{array}$

-Materials $\quad 82$

-Form $\quad 82$

$\begin{array}{lr}- \text { Wind } & 83\end{array}$

$\begin{array}{lr}\text { The Sense of History } & 84-85\end{array}$

The Sense of Craft $\quad 86$

The Sense of Limits $\quad 86$

$\begin{array}{ll}\text { Cultural Identity } & 87\end{array}$

Model \& Drawings $\quad$ 88-94

$\begin{array}{lr}\text { Final Conclusion } & \text { 95-97 } \\ & \end{array}$

Drawings and Model $\quad 78-81$

Bibliography $\quad 98-99$

$\begin{array}{lr}\text { Appendix A } & 100-102\end{array}$ 


\section{List of Illustrations:}

Fig.1. Random photos of nature, taken by author 16

Fig.2 Response to climate, $1900 \quad 22$

$\begin{array}{ll}\text { Fig.3 Wigwam photo } & 23\end{array}$

Fig.4 Nature \& culture montage by author $\quad 24$

Fig.5 Iroquois 1914 photo $\quad 25$

Fig.6 Exterior view of reconstructed longhouse 26

Fig.7 Traditional symbol for the league of Six Nations 27

Fig.8 Longhouse Palisade 28

Fig.9 Section view of ext. double wall of longhouse 29

Fig.10 Replication of traditional longhouse $\quad 29$

Fig.11 Replication of traditional longhouse $\quad 29$

Fig.12 Lashing frame of longhouse. 1925

Fig.13 Iroquois archeology $1964 \quad 30$

Fig.14 Longhouse plan. 1724

Fig.15 Iroquois longhouse axonometric $\quad 32$

Fig.16 Detail of tying frame. Interior view of traditional longhouse 33

Fig.17 Contemporary traditional longhouse $\quad 33$

$\begin{array}{ll}\text { Fig.18 Solstice and equinox diagram } & 37\end{array}$

Fig.19 Ceremonial longhouse circulation pattern $\quad 37$

Fig.20 Layers of dimension. Drawing by author $\quad 40$

Fig.21 Sacred circle symbol $\quad 42$

$\begin{array}{lr}\text { Fig.22 Axis mundi diagram } & 42\end{array}$

Fig.23 Cosmic tree symbol $\quad 42$

Fig.24 Photoshop montage conceptual study. By author 43

Fig.25 Douglas Cardinal photo $\quad 45$

Fig.26 Oujé Bougoumou map location $\quad 47$

Fig.27 Photo example of typ. House 47

Fig.28 Rendering of Oujé Bougoumou village 48

Fig.29 Village of Oujé Bougoumou plan $\quad 49$

Fig.30 Oujé Bougoumou conceptual site model $\quad 50$

Fig.31 Rendering of the Cree Cultural Institute 51

Fig.32 Replication of traditional Astiyookamak structure $\quad 52$

Fig.33 Traditional rendering of Astiyookamak structure 53

Fig.34 Cree Cultural Institute Elev. Drawing $\quad 54$

Fig.35 Cree Cultural Institute Section drawing 54

Fig.36 Cree Cultural Institute model $\quad 55$ 
Fig.37.The Nicola Valley Institute of Technology photo 56

Fig.38 Nicola Valley site location $\quad 56$

Fig.39 Natural ventilation section detail $\quad 57$

Fig.40 Thermal mass details $\quad 58$

Fig.41 Traditional Pitt house architecture $1900 \quad 58$

$\begin{array}{ll}\text { Fig.42 Site plan layout for Nicola Valley Institute } & 60\end{array}$

Fig.43 Main floor plan for Nicola Valley Institute $\quad 61$

Fig.44 Screen façade detail $\quad 62$

Fig.45 Exterior view of Nicola Valley 62

Fig.46 Exterior view of Nicola Valley $\quad 62$

Fig.47 Site map locating Akwesasne $\quad 65$

Fig.48 Photo of district sign $\quad 66$

Fig.49 Photo of proposed site location 66

Fig.50 Aerial map of Akwesasne $\quad 67$

Fig.51 Location of project photo looking in south east direction 67

Fig.52 Photo of Akwesasne Arena located on west side of project site 68

Fig.53 Aerial view of the City of Cornwall 68

Fig.54 Aerial photo of project site 68

Fig.55 Photo location of project site. Looking in north direction 69

$\begin{array}{ll}\text { Fig.56 River bank at project site } & 70\end{array}$

$\begin{array}{ll}\text { Fig.57 Marshland located east of project } & 70\end{array}$

Fig.58 Photo of Akwesasne Administrative Building,
Mohawk Council of Akwesasne

Fig.59 Photo of Akwesasne Justice Building

Fig.60 Photo of Health Facility Mohawk Council of Akwesasne $\quad 72$

Fig.61 Sun \& wind orientation diagram $\quad 74$

Fig.62. Circulation pattern through building $\quad 75$

Fig.63 Conceptual study using natural material, by author $\quad 78$

Fig.64 Nature Resource symbol of fire, earth, air \& water $\quad 78$

$\begin{array}{ll}\text { Fig.65 Niche wall planter detail } & 79\end{array}$

Fig.66 Earth wall and slip form section $\quad 79$

$\begin{array}{lr}\text { Fig.67 Wood window screen detail } & 80\end{array}$

Fig.68 Typical Post detail, slip form and limestone rock $\quad 80$

$\begin{array}{lr}\text { Fig.69 Water garden plantation } & 80\end{array}$

$\begin{array}{lr}\text { Fig.70 Bioswale detail } & 80\end{array}$

$\begin{array}{ll}\text { Fig.71 Rainwater irrigation system } & 81\end{array}$

Fig.72 Cross ventilation diagram $\quad 81$

$\begin{array}{ll}\text { Fig.73 Sun angle projection } & 81\end{array}$

Fig.74 Air flow diagram around building $\quad 81$

Fig.75 The structural tree, conceptual model by author 83

$\begin{array}{ll}\text { Fig.76 Conceptual montage study by author } & 87\end{array}$

Fig.77 Panel showing preliminary stages of design concept by author $\quad 88$ 
Fig.78 Preliminary structural tree detail model by author 88

Fig. 79 Preliminary structural tree detail model by author $\quad 88$

Fig.80 Top aerial view of site model, photo by author $\quad 89$

Fig.81 Perspective view of site model, photo by author 89

$\begin{array}{ll}\text { Fig.82 Ground floor plan } & 90\end{array}$

Fig.83 Main floor plan 90

Fig.84 Site plan and section $\quad 91$

Fig.85 Elevation drawings $\quad 91$

Fig.86 Section detail of central courtyard $\quad 92$

Fig.87 Section detail of central courtyard indicating scale $\quad 92$

$\begin{array}{ll}\text { Fig.88 Panel diagram } & 93\end{array}$

Fig.89 Conceptual image showing building on site 93

$\begin{array}{ll}\text { Fig.90 Central view of model } & 94\end{array}$

$\begin{array}{ll}\text { Fig.91 Conceptual drawing } & 94\end{array}$

Fig.92 Figure Ground exercise 95 


\section{Introduction}

"Man takes a positive hand in creation whenever he puts a building upon the earth beneath the sun. If he has birthright at all, it must consist in this: that he, too, is no less a feature in the landscape than the rocks, trees, bears or bees of all that nature to which he owes his being." 1

Since antiquity, man has reacted to his environment, using his ability to develop techniques and technologies in intimate balance with nature. Man's creations were natural, built of the materials offered by the landscape. The origins of building structures were designed to take advantage of nature's forces: the wind; the rain; and the sun, and built to address the need for shelter and survival. Over time, these structures became more complex for economic, religious and cultural events in an effort to make sense of our place in the world. Man built his world to symbolize his understanding of and relationship with nature. As Norwegian architect and author Christian Norberg-Schultz explains:

"In general, any understanding of the natural environment grows out of a primeval experience of nature as a multitude of living forces. Man was thus embedded in nature and dependent upon natural forces. The growth of man's mental faculties proceeds from the grasping of such diffused qualities, into more articulate experiences, where the parts and interrelationships within the totality are understood."

Early building methods, defined as traditional vernacular architecture, were the manifestations of mankind's way of living. The origin was the intuitive and learned building methods of local craftsmen, based on knowledge accumulated and passed down through the generations. The vernacular depicted a harmonious relationship with nature, as buildings and landscapes fostered an attachment to place by connecting culture, history, and ecology within a geographical context. Localized time-tested traditions,

\footnotetext{
' Frank Lloyd Wright, "The Nature of the Site," in The Realm of Ideas. Edited by Bruce Brooks Pfeiffer and Gerald Nordland ( Southern Illinois University Press, 1988)
} 
knowledge of techniques, and materials were passed from one generation to the next and varied from region to region, thus creating an internal harmony with the physical surroundings, all contributing to the communities' identities, evolution and growth over time. In this regard, here at the very beginning of this section, it is imperative to explain briefly vernacular architecture. The vernacular is an ongoing influential factor because it included the integration with nature, expressed humanistic associations and provided a sense of continuity. Bernard Rudofsky pointed out in his book Architecture without Architects,

"Instead of trying to 'conquer' nature as we do, Indigenous builders welcomed the vagaries of climate and the challenge of topography."4

Indigenous builders knew how to use the conditions of nature efficiently and developed living conditions in parallel with their natural surroundings. In broadest terms, the independence of vernacular buildings from artificial restraints of influence and style permits us to understand how natural forces shape the built environment, and establish a harmonious relationship with the natural world. As far as human conditions are concerned, the vernacular builder placed man in the centre of his design.

"The true basis for any serious of the art of Architecture still lies in those indigenous, more humble buildings everywhere that are to architecture what folklore is to literature or folk song to music and with which academic architects were seldom concerned.... These many folk structures are of the soil, natural. Though often slight, their virtue is intimately related to environment and to the hearth-life of the people. Functions are usually truthfully conceived and rendered invariably with natural feeling. Results are often beautiful and always instrusive".3

The purpose of this introduction is to demonstrate how the importance of the significant role of man's attitude toward nature is critical to the discourse of today's regional design issues. As we look back in time, what had been a clear vernacular language to learn from

\footnotetext{
${ }^{3}$ Norberg- Schultz, Christian, Genius Loci ( Praeger Publishers: New York, NY, 1971), p. 22.

${ }^{4}$ Rudofsky, Bernard, Architecture without Architects, (New York: Doubleday Company Inc., Garden City, 1964) p 4.

${ }^{3}$ Moholy-Nagy, Sibyl, "Native Genius," in Anonymous, (New York: Horizon Press, 1957) p. 8.
} 
has been replaced by popular trends, global versus local standards, and coveted imported designs. As a result, regional differences are slowly disappearing. Architect and leader in sustainable architecture, Sim Van der Ryn expresses this concern:

Places and cultures are being bulldozed into a planetary geography of nowhere, eroding local and regional differences. 5

Modern technology has greatly accelerated the rate of progress and changes in lifestyle over the last centuries, thus providing the world with convenience, comfort and speed. Through our actions, the effects of progress and technological advances have combined with a greater disconnection between nature and humanity. We have attempted to dominate and control the natural environment, and as a result we are experiencing the effects of an unbalanced ecosystem. Furthermore, with the possibilities imposed by global imperatives, the very idea of what comprises the importance of a specific "place" is slowly losing ground against universal measures.

The heart of this thesis brings into question if there is an importance of modern man's immediacy to the environment outside his door. Architecture should be a built connection to that immediate surroundings so that we can maintain a strong link between people and their local place. Furthermore, the strength of a place-specific architecture is not only important to the inhabitant, but also to the visitor who desires to see the uniqueness and characteristic differences defining each place and environment.

From the beginning, architecture was necessary to provide shelter from the harshness of the natural world and all its elements; however, the development of cultures and societies has changed over the centuries. What was originally more about the connected interaction with nature has now developed into a distant relationship. In this view, the natural world is internalized and can be controlled by man. This creates a belief that human beings are outside the realm of the natural and allows man to cultivate a consumptive attitude with the earth.

In contrast to the above perspective, many groups within North American society have come to recognize that our survival is dependent upon the success of our environment. 
Additionally, it is therefore important to demonstrate the architectural relevance of the vernacular both as a channel for sustainable development for a culture's identity and place, and as the process by which man can build harmoniously with nature. For this reason the thesis investigates the importance of place as a controlling factor of architectural design, as well as one that investigates sustainable environmental design issues specific to place.

For over three hundred years, Canada's First Nations communities in North America have had little opportunity to construct their own indigenous architecture. Western culture's emphasis on change, progress, and novelty became the main priorities within the built environment. However, this left traditional vernacular obsolescent as the Native American peoples embraced notions of continuity and reinforcement, forced to balance traditional ways with contemporary life. Peter Nabokov examines this shift in Native American architecture when he explains, "Early attempts to convert Native American cultures to Christianity in the seventeenth-nineteenth century brought about specific changes to traditional dwellings, and building typologies shifted from culturally established ones to hidden and temporary ones. The need for secrecy led to the disappearance of traditional ceremonial buildings and spaces."

The question then arises "In the face of radically changing social, cultural and economic conditions initiated by the impact of universalizing modernism trends, can one define and design a specific building for a distinct society that has lost their historical vernacular structures?"

Furthermore, what are some possible thematic elements and complexities that might lend themselves to architectural form, function and meaning? What are some good and bad examples of previous attempts to design and incorporate indigenous culture into buildings? What key design issues would be appropriate for an aboriginal community? These are a few of the questions I have sought to answer. I believe the notion is to reveal the cultural context, not as an assemblage of symbols and metaphors, but as the embodiment of intrinsic cultural values. The goal is to create an appropriate site-specific

\footnotetext{
${ }^{5}$ Van der Ryn, Sim and Stuart Cowan, Ecological Design, (Washington, D.C.: Island Press, 1995), p .69.
} 
architecture, designed to capture the essence and character of the people's culture, history and their connected relationship with the natural landscape.

Anthropological research indicates that early aboriginal native structures seemed to grow out of and blend with the environment, demonstrating a deep meaningful relationship between man and nature in the way that these forms were created and constructed. The people of long ago looked to the physical environment, the climate, and their culture, when constructing their dwellings. Amos Rapoport defined these dwellings within vernacular terms as:

Characterized by the intuitive human desire and ability to make architecture that is shaped only by direct influence, through codified imagery, materials and technology, with the concern regard to use, manufacture and meaning of a community that builds it. This is the crucial factor that has led to meaningful architecture for a society that has a strong connection to its roots. ${ }^{7}$

In the following pages, this premise will be explored by reviewing the traditional early vernacular dwellings derived from the First Nations Iroquois of the Eastern Woodlands. It is important to study the form and expression of architecture that has evolved traditionally and in doing so, unlock the social identities, rituals and modes of organization, referencing Iroquois society and their relation to place and belonging. According to Christian Norberg Schulz, quoting Heidegger's Essays on Language and Aesthetics,

The basic intent of the act of architecture or evolving a dwelling for man is to establish his existential foothold at any particular place...man dwells when he can orientate himself within and identify himself within an environment, or in short, when he

\footnotetext{
${ }^{6}$ Nabokov, Peter and Robert Easton, Native American Architecture, ( Oxford University Press: New York, 1989).

${ }^{7}$ Rapaport, Amos, "House form and culture," (University of Wisconsin, Milwaukee. Prentice Hall Foundations of cultural geography series,1969), 47.
} 
experiences the environment as meaningful." 8 Thus "place is the concrete manifestation of man's dwelling, and his identity depends on his belonging to place.

The hypothesis is that for an architectural proposition to represent a true sustainable design solution, reference to the specific cultural domain is implicit. This is a cyclical relationship whereby culture builds the structure and the physical structure reinforces the community's historical link from the past to the present. Revelation of this process means that the architecture identifies with the people and their way of living and thus becomes established as a strong cultural representation. In our global society, I believe we have been caught in the spirit of the age of today's trendy architecture, ignoring recognition of its indigenous response to the challenges presented by the site. Advances in technology and building methods have allowed duplicate buildings to be erected in different ecological conditions. However, this ability to replicate should not become the determining factor in the construction of our built environment. Rather than ignoring the "environment" surrounding a building, it should be integrated and adapted to allow architecture and nature to combine harmoniously. This can be achieved by encompassing the site's contextual landscape, history, culture and climatic conditions, including its vernacular building types. The thesis aims to show ideas that help in modifying the relation between architecture and nature by recognizing the vernacular as an important frame of reference.

Two case studies will be examined, to determine how they dealt with design appropriateness for a First Nations culture. These two explorations are important for a number of reasons. Both projects provide cultural significance to the places in which they were located by choosing to integrate traditional construction methods, contemporary technology and ecological design.

\footnotetext{
${ }^{8}$ Norberg-Schulz, Christian, Genius Loci: Towards a Phenomenology of Architecture (New York: Rizzoli International Publications Inc., 1980), 5.

${ }^{9}$ Norberg-Schulz, Christian. Genius Loci: Towards a Phenomenology of Architecture (New York: Rizzoli International Publications Inc., 1980), 6.
} 
The first case study is the Oujé-Bougoumou project. It is an indigenous First Nations Cree village in northern Quebec, completed in 1992, by architect Douglas Cardinal. Cardinal's aboriginal philosophy towards design issues provide a deep spiritual element of Native American culture, revealing a harmonious balance among nature, culture and architecture that resonates throughout his work, combined with modern practices and technologies.

The second case study is the Nicola Valley Institute of Technology, located in Merritt, British Columbia. The building was designed by Busby and Associates Architects and was completed in 2000-2001. As ancestral stewards of the land and its resources, Canada's First Nations have positioned themselves at the forefront of the environmental movement and are a growing force in contemporary society in re-establishment of their traditional practices of land and cultural sustainability. It is appropriate that First Nations clients should espouse the principles of green building and embrace the use of leadingedge environmental technology. In keeping with this philosophy, the Nicola Valley Institute of Technology has been designed with a fully integrated environmental system using sophisticated energy modeling techniques and state-of-the-art control systems to optimize performance.

This scope of the thesis is the design of an environmental learning center. Focusing on the symbiotic relationships between humanity and nature, the intent is to create an architecture that does not homogenize, but rather localizes and differentiates its particularities by placing the building in context with the natural surroundings. Rooted in the discussion of sustainability, region and tectonics, the environmental learning center will be designed in accordance with and through observation of the local vernacular, drawing upon new technologies, materials, and architectural expressions and enabling architecture to act as a harmonious link between humanity and nature. 


\section{Theory}

\section{Attachments to "Place"}

Architecture facilitates our physical existence. As Christian Norberg Schulz claims, architecture is "the art of place." 10 Place is about our desire to find meaning in our lives and how our natural and man-made environment facilitates and enhances this aspect. Different cultures throughout history have shown different interpretations of place, and this is reflected in their built environment. Two aspects are useful in this observation. First, man constructs his physical environment to provide a sense of place in the world. This ranges from the primitive hut to the pyramids, revealing a spiritual and interpretive existence between others and eternity. Change these interpretations and the resulting built environment will change. For example, a society that does not believe in the afterlife will not derive the same meaning from the pyramids as those who built them. Therefore, the place and situation of a building is intimately related to the interpretation of the building. Additionally, it permits an awareness and understanding of our being.

"The basic intent of the act of architecture or evolving a dwelling for man is to establish his existential foothold at any particular place."

Furthermore, terms like "society", "culture", and "value" also vary by the characteristics of place. A society develops when one belongs to a unique place against the influence of mass culture. This uniqueness is part of the society's memory. Without the grounding of place, this memory does not exist.

The second aspect justifies the manner in which buildings are constructed. This includes the materials used, their arrangement and composition, and the type of craftsmanship. Through time, these buildings form the societal norms by which new buildings are conceived, constructed, and evaluated by that society. The materials utilized for

\footnotetext{
${ }^{10}$ Norberg Schulz, Christian, Architecture: Presence, Language, Place ( Skira Editore: Milan, 2000).

${ }^{11}$ Norberg-Schulz, Christian, Genius Loci: Towards a Phenomenology of Architecture, (New York: Rizzoli International Publications Inc., 1980) 5.
} 
construction form part of the tradition and association with context and are therefore identified as vernacular, providing a deep psychological anchor for the individual and his place in the world.

However, current architecture in today's built environment, particularly for regional communities, seems out of context, and lacks an emphasis on the ecological condition of its place. This stems from the implementing of the principles of the modern movement. A rejection of past practice, according to B.C. Brolin, "was the starting point for modern architecture. The factors underlying the rejection were: $A$ belief in change that made the past and its traditions seem irrelevant. When traditional patterns did not conform to what could occur in the design of buildings, designers ignored them, justifying this supreme approach by the belief that everyone in the world had the same social and physical needs. $" 12$

The goal was to improve the lot of mankind. The means was to standardize the building industry according to a set of principles that would create a uniform modern architecture throughout the world. Architecture was not to reflect cultural differences, but rather to homogenize socially mass-produced technology and prototypical solutions. "After declaring the inevitability of the International style, member of the movement assumed that the universal language of form is the logical outcome of a rational approach to design and people would accept it." 13

The term "placelessness" is borrowed from geographer Edward Relph in his book Place and Placelessness. Relph attributes the loss of place as an "inauthentic" "14 attitude. This loss exists in the way buildings relate to human experience, the landscape and the totality of place. This became an accepted behavior, often found within larger populations or communities. Additionally, they often result from government-imposed regulations or standards that result in environments manipulated for public rather than personal interest.

\footnotetext{
${ }^{12}$ Brolin, B.C., The Failure of Modern Architecture, (New York: Van Nostrand and Reinhold Co., 1976) 57.

${ }_{13}^{13}$ Ibid.,. 58.

${ }^{14}$ Edward Relph. "Place and Placelessness", London: Pion, 1976
} 
These places fail to address the local context and lack originality, becoming socially accepted standards of efficiency and economy.

For the purpose of this study, the relation of man to place has to do with a process of identification by which Christian Norberg Schultz implies "to become 'friends' with a particular environment." 15 Suggested that human identification with a place presupposes "place" has character, which means it distinguishes itself from any other and lends its unique presence (genius loci or "spirit of place"). "..genius loci is a Roman concept. According to ancient Roman belief every independent being has its genius, its guardian spirit. The spirit gives life to places and determines their character or essence. It suffices to point out here that man in the past experienced his environment as consisting of definite characters so man shaped his environment to come to terms with the genius of locality where his life takes place. "16

When applied to the built environment, place must be understood as metamorphic; the design is regional and pays attention to those valued qualities extracted from the total environment, both natural and built, that evolved over time. Christian Norberg Schultz further explains, "The basic act of architecture is therefore to understand the 'vocation" of place. In this way we protect the earth and become ourselves part of a comprehensive totality..... and that man is an integral part of the environment, and that it can only lead to human alienation and environmental disruption if he forgets that. To belong to a place means to have an existential foothold in a concrete everyday sense. " 17

Therefore, architecture should have an identifiable essence with place related to regional context. On the following page, the concept of "Genius Loci" can be understood more clearly within the explanation of the vernacular.

\footnotetext{
${ }^{15}$ Ibid., Schultz, , 6-20.

${ }^{16}$ Ibid., 18.

${ }^{17}$ Ibid., 23.
} 
Around the world, people developed energy efficient building forms suited to their particular climatic location. Traditionally, each region had its prevailing prototypic shelter, each reflecting the diverse climatic conditions. For example, desert dwellers built thick walls of clay and mud, pierced by small window openings designed to maintain cool interior temperatures. Huts in tropical deltas and forests were raised on stilts to provide breezes and protection from the wet ground. Igloos were built of snow blocks to insulate against cold, harsh climatic conditions. Each method of construction noted expresses a need to provide shelter from the elements, built from natural materials found within their specific regions while maintaining a harmonious relationship to nature. These were the traditional and natural ways by which communities lived. They served as historical remnants that recorded and conserved the traditional core of man's existence while maintaining an expression of the world's cultural diversity.

The vernacular paid attention to context through:

1) The sensitivity of site,

2) A responsiveness to the restrictions of local climate,

3) The correct use of local materials, and

4) A fit between cultural needs and form.

"By building in accordance with the nature of the ecosystem in terms of material, site, climate and cultural norms, the vernacular dweller created a new micro-environment and established a dialogue between himself and nature. This dialogue reflects a state of equilibrium in the energy budget of the house and environment." 18

\footnotetext{
${ }^{18}$ Turan, Mete, Architectural and Environmental Adaptation. Edited: G.Golany, (New York: Norstrand Reinhold Company, 1983), 146.
} 
In addition, Author Victor Olgyay explained:

The people possessed a remarkable ability to adapt their dwellings to their particular environmental difficulties. An awareness of climate was integrated with innate craftsmanship to solve problems of comfort and protection. The results were building expressions of true regional character. 19

\section{Regionalism, Critical Regionalism and Cultural Identity:}

The lessons learned from regional architecture should be considered and incorporated in building design. Uniqueness and differentiation in architecture are vital to preserving local cultures and customs while creating a sense of place.

The term regionalist architecture refers to a contemporary response to the vernacular, and is a reaction against the universality and the uniformity of Modernism and Globalism. Theorist Kenneth Frampton stated that the Modern movement passed over two essential elements of traditional architecture: tectonics and the site-specific response to place. Frampton did not advocate the incorporation of traditional stylistic elements but rather espoused the concepts behind them. Tectonics mattered because they represented an awareness of local building materials and methods, both of which contributed to an environmentally and culturally sustainable architecture. Furthermore, Frampton did not believe that regionalist architecture should necessarily reject outside influences. Rather, he believed that designers needed to be conscious in their decisions in adopting or not

adopting a particular innovation or design methodology. Moreover, when they did incorporate such an item, they sensitively combined the new with the old, each benefiting and informing the other. This design approach encouraged sensitivity towards local issues as well as environmental, cultural and economic means. 
In 1991, Authors, Liane Lefaivre and Alexander Tzonis introduced a new form of regionalism called critical regionalism. This was a "theoretical framework to describe the work of architects who turned away from the orthodox of modernist and post modernist design principles. "20

According to Lefaivre and Tzonis, critical regionalism shared historical qualities relevant to regionalism in architecture. This concept concerned the specifics of place and the use of regional design elements in combating universalizing architecture. The difference that set it apart from its precedent relations was the "willingness to be critical of regional traditions as well as universalizing trends" ${ }^{21}$ According to Frampton, "regionalism was primarily concerned with the ability to use architecture as a communicative sign and the substitution of information for genuine experience."22 For example, a gabled roof serves as a sign of domesticity, and columns on a public building signify civic importance. Frampton insisted that critical regionalism is neither a style nor a mere revival of the vernacular. It was an "architecture of resistance and a culture of building that sought to balance technology and global cultural issues with individual identity and place. ${ }^{23}$

Building on the framework advanced by Lefaivre, Tzonis and Frampton, Douglas Kelbaugh supported place differentiation when he explained, "Rather than transforming differences into formal types devoid of their original context, critical regionalism seeks to avoid universalizing the vernacular. ${ }^{24}$ In other words, critical regionalism is composed of two primary components: the architectural features unique to a particular region, and the concerns common to regional architecture throughout the country, such as climate and condition.

\footnotetext{
${ }^{19}$ Olgyay, Victor, "Design with Climate," Bioclimatic Approach to Architectural Regionalism, Ed., (Princeton University Press: Princeton, New Jerse NJ 1974), 4-6.

20 Lefaivre, Liane and Alexander Tzonis. "Critical Regionalism : Architecture And Identity In A Globalized World," Architecture in Focus Series: Prestel, 2003., pg.10

${ }^{21}$ Lefaivre, Liane and Alexander Tzonis., "Why Critical Regionalism Today?" In Theorizing a New Agenda for Architecture: An Analogy of Architecture Theory, Ed. Kate Nesbit., (New York: Princeton Architectural Press, 1996), 486, 488

${ }^{22}$ Frampton, Kenneth, Towards a Critical Regionalism: Six Points for an Architecture of Resistance, in the Anti-Aesthetic: Essays on Postmodern Culture, Ed. by Hal Foster, ( Port Townsend, WA: Bay Press. 1983), 21.

${ }^{23}$ Frampton, Kenneth, "Place, Form, Cultural Identity," Arcade 20, no. 1., 2001, 16-17.
} 
Douglas Kelbaugh further adds additional characteristics to this understanding:

The Sense of Place: This is characterized as a preference for "local climate, topography, vegetation, building materials, and building practices," and "local authenticity" over "sophisticated imitation." This sense of place must strike a delicate balance between preference for the local and an outright resistance to any changes.

The Sense of Nature: This is where "Buildings and cities, like plants and animals, can be viewed as vital rather than as inert and denatured. They can be treated as organisms which are conceived, grow, flex, adapt, interact, age, die, and decay - always rooted in their habitat." ${ }^{25}$ A building is not a static object that remains unchanged once it is physically completed. It is constantly changed and adapted by its occupants and neighboring structures.

Sense of History: History should not be treated "as a grab bag of forms." Rather, "rhyme" is the most desirable word when reusing historical types. In this conception, rhyme is "likeness tempered by slight variation." The use of rhyme yields results that are particularly attractive to proponents of critical regionalism, because "when design rhymes across time it demonstrates a sense of history, and when is rhymes across space, it reinforces a sense of place. ${ }^{26}$

Sense of Craft: Excessive reliance on cheap and flimsy materials results in buildings that look and feel cheap and do not age well. "Buildings should be an investment rather than an operating expense.",27

Sense of Limits: A sense of limits reflects the need for "physical and temporal boundaries to frame and limit human places and activities." This is the desire to denote

\footnotetext{
${ }^{24}$ Kelbaugh, Douglas. "Repairing the American Metropolis, Common Place revisisted: Critical Regionalism: An Architecture of Place", Washington: University of Washington Press. 2002, P.53.

${ }^{25}$ Ibid., pg.82

${ }^{26}$ Ibid, pg.82, 84

${ }^{27}$ Ibid., pg. 84,87
} 
particular uses for distinct space. Such boundaries "make life more understandable and negotiable" and "differentiates place from raw place." 28

As the framework described above suggests, structures that claim adherence to the principles of critical regionalism - or that seek to avoid the pitfalls of slavish imitation must consider a range of concerns. These concerns include formal as well as functional elements of building design and all are equally important.

Focusing on the relationship with all aspects of the buildings setting, and its surrounding context and local materials, inspires the need for design solutions deeply associated with place. The marriage between the lessons of indigenous design and sophisticated new ecological technologies is critical when achieving balance and harmony between man and nature. Distinct climate conditions, indigenous vegetation and vernacular architecture can be informative in providing ecologically sensitive solutions for contemporary architecture.

\footnotetext{
${ }^{28}$ Ibid., pg. 87,89
} 

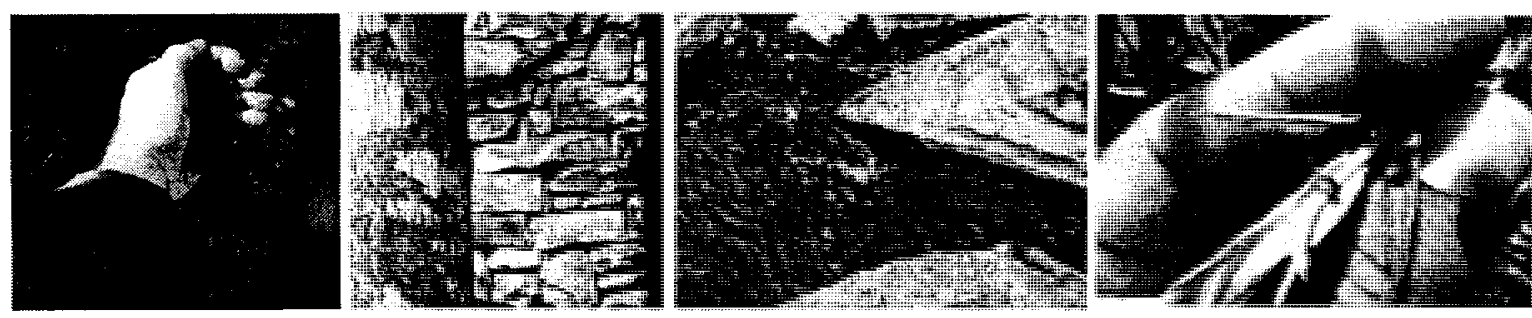

Fig. 1 Photos by Author. 2007

\section{The Link Between Past, Present and Future:}

The purpose of studying the past is to seek and communicate a fuller understanding of the forces shaping the way we live today. This study reveals a link between past, present and future, as expressed through built form. Architectural dwellings afforded basic protection from environmental forces, themselves eventually becoming part of the natural environment subject to the laws of nature and synchronized with natural patterns. Therefore, man's understanding of nature and its role in environmental design, along with the establishment of a balance between natural factors, were important to the cultural, economical and biological survival of societies.

We as a society need to understand the natural environment. We live in an ecosystem where all living things exist, interrelate and depend on each other. Nature's processes need to be integrated into building designs without negatively affecting the balance of the ecosystem itself. 


\section{The Natural Environment}

Architecture is a physical expression of culture, influenced by nature. When we talk about the environment that humans dwell in, we see our physical surroundings --trees, rivers, animals, etc.-- that existed alongside civilization as we know it.

"The man-made world is ...born as a human reflection of the wonder we find in the natural world the heavens, the seasons, landscapes and seascapes, plants and animals. "29

Imitation of nature is a motif constantly appearing in architectural design from Greek and Roman times and continuing through the Middle Ages, the Renaissance, the Industrial Age, and Modernism. Therefore, the impact architecture has on the natural environment is obvious: our built environment sprawls into nature; selected designs of buildings are influenced by nature; tectonic materials come from natural resources; and we use natural energies to operate our buildings. Therefore, the direct connection with sustainable issues is important to this thesis, emphasizing the relationship of man and nature as a connected ecosystem variable.

Today, we are now much more concerned about climate change, global warming, and environmental degradation. This concern has elevated environmental consciousness toward green, natural, organic and vernacular design solutions. These are often based on existing local characteristics taken from site, the surrounding context, local climate and topography.

The pure simplicity of vernacular architecture is reawakening the imagination of responsible practitioners as being inspirational and effective approach towards sustainable measures. Passive design is thus the common denominator for a responsible and sustainable architecture, an understanding by no means implicit of regression, but indeed a principle upon which great systems can exist. This supports a relationship of coexistence and balance between man, built form, and environment that will ultimately benefit all. Context thus becomes one of the preeminent factors in an architecture that is

${ }^{29}$ Crowe, Norman, Nature and the Idea of a Man-Made World., (Cambridge, Massachusetts: MIT Press, 1995$) 7$. 
responsible and responsive to its geographic, cultural, and temporal surroundings in achieving this balance.

In 1987, the World Commission on Environment and Development (WCED) published a report entitled "Our Common Future." The document, known as the Bruntland Report, initiated strategies to address vital global issues and provided guiding principles for sustainable development as it is generally understood today.

"Sustainability" is a development strategy aimed at achieving a balance among natural, cultural and technological relations in reference to a region's physical conditions and characteristics of traditional vernacular building. The definition of "sustainable" differs among cultures, climates and landscapes, and relates to the ecology, economics, heritage and aesthetics of a particular place. Design solutions sustainable in one place are most likely to be inappropriate if applied to another. Author Brian Edwards defines sustainability as;

Not universal, but like classicism, is modified by regional circumstances. It is an order of process and thought necessarily adjusted by local circumstances- the rightness of sustainability and its cultural relevance relies upon the celebration of difference. 30

Because sustainable architecture is context based, it offers the opportunity to reinforce a sense of identity in a place. Architectural responses need to return to the passive unified approach that is grounded in environmental design.

World history offers many examples of societies with environmentally sustainable structures that have prospered for thousands of years, and others that have pursued other paths which have led to ecologically unsustainable ways. For the development and improvement of humankind, it is imperative to renew our relationship with nature, and commit to living as part of the earth by understanding development and growth as sustained processes, not as exploitation to impractical degrees.

\footnotetext{
${ }^{30}$ Edwards, Brian, Green Architecture, (London: Wiley Academy, July 2001. vol. 71, no. 4), 7.
} 


\section{Traditional Ecological Knowledge:}

Throughout the world, indigenous cultures exhibit similarities and differences of language, geographic situations and climatic zones. They also share similar beliefs, values, and cosmological views of the universe, including a thorough knowledge of their natural environment and a profound respect for all creation.

This respect is understood to be predominantly one of symbiosis, with no concept of ownership towards the land, water, plant life, etc., and without a notion of improving over the natural environment by human intervention. This knowledge is the prerequisite for maintaining cultural diversity for a local region against the extreme of universalism. "Without local knowledge places erode." 31

To elaborate on the previous paragraph, it is commonly conveyed that aboriginal peoples have a conservation ethic - "philosophies and practices that help them manage the environment and sustainable issues." ${ }^{\prime 32}$ This ethic is perceived to have manifested itself in "customary laws" ${ }^{33}$ and "institutions" that aboriginal peoples historically used to restrict their resource use. "This existence of a conservation ethic in aboriginal cultures, in fact, is proposed as the major reason why the native population was able to live in relative harmony with the environment for thousands of years before European contact". ${ }^{34}$

The most common forms of evidence employed to support the existence of a "conservation ethic" are the testimonials, or "oral histories," of aboriginal peoples. Author Winona LaDuke maintains that all aboriginal peoples in North America have "knowledge in living sustainably" and this "is something which would be valuable for the rest of society". Such knowledge includes the principles of reciprocity and cyclical thinking, which are "predicated on finding balance". 35

\footnotetext{
${ }^{31}$ Van der Ryn, Sim and Stuart Cowan. Ecological Design,. (Washington, D.C.: Island Press, 1995), 65. 32 Callicott, J. Baird and Michael P. Nelson, 2004. American Indian environmental ethics: An Ojibwa case study Upper Saddle River, N.J.: Pearson-Prentice-Hall.

33 Ibid

34 Knudtson, Peter and David Suzuki. 1993. Wisdom of the Elders New York: Bantam Books. RCAP, 1:86-7p.658

35 LaDuke, Winnona. 1993. "Social Justice, Racism and the Environmental Movement", www.zmag.org/zmag/articles/barladuke.html.
} 
The principle of reciprocity within Indigenous cultures is based on not taking without giving, and to taking what one needs. The associated cyclical thinking involves the perception that all living natural things are cyclical, which is in accordance with traditional ecological knowledge (natural law). Time, the sun and moon, the seasons, and humanity are a few factors. It is perceived that what you do now will affect you in the future because the present and the future are a cyclically related continuum. Thus, the Indigenous people living on the land and maintaining its resources have an intimate knowledge of the distribution of resources, the functioning of ecosystems, and the relationship between the environment and their culture. In most indigenous societies balance is something that needs to be maintained.

This natural environmental perception, known as traditional ecological knowledge (TEK), represents an ecological and environmental wisdom inherent in traditional cultures. "Indigenous cultures are closely bound to a particular piece of land, their actions are local rather than global consequences. In the late twentieth century, there is a deep desire to regain a balance between culture and nature, to put certain pernicious technologies back in the bottle, and to question every aspect of the contemporary landscape. We cannot do this without making bridges to the ecological wisdom inherent in the practices of traditional cultures." 36

Traditional knowledge is part of the collective memory of a native community, and is passed on orally through songs and stories, as well as through actions and observations. This holistic view of the environment is based on underlying values that support sustainability, which includes providing for the well-being of the community without jeopardizing the integrity of the environment. "These values, and basic tenets made it possible for indigenous peoples to maintain their economic, political, religious, and other institutions for generations in a manner which would today be characterized as 'sustainable development'." 37

\footnotetext{
${ }^{36}$ Van der Ryn, Sim and Stuart Cowan. Ecological Design. Washington, D.C.: Island Press, 1995. pg. 61.

37 Scott, Colin. Knowledge Construction: Metaphors and Literal Understanding. In Naked Science: Anthropological Inquiry into Boundaries, Power, Knowledge, ed. Laura Nader. New York: Routledge, 1996. pg.193-208.
} 
The following table reveals the similarities and differences of TEK and Western scientific knowledge and how they regard the relationship with the natural environment. ${ }^{38}$

\begin{tabular}{|l|l|}
\hline Traditional Ecological Knowledge & \multicolumn{1}{|c|}{ Scientific Ecological Knowledge } \\
\hline $\begin{array}{l}\text { Collected through observation and } \\
\text { experience. }\end{array}$ & Experimental and abstracted from context. \\
\hline $\begin{array}{l}\text { Holistic- although individuals have } \\
\text { specializations. }\end{array}$ & Specialized and reductionism \\
\hline $\begin{array}{l}\text { Culturally compatible: the knowledge is } \\
\text { developed in a social context. }\end{array}$ & $\begin{array}{l}\text { Cultural disjunctions- hierarchies and } \\
\text { compartments. }\end{array}$ \\
\hline Oral & Written \\
\hline Mostly qualitative & More quantitative \\
\hline Collected by resource users & Collected by specialist researchers \\
\hline $\begin{array}{l}\text { Diachronic- Knowledge based on } \\
\text { collection over a long time, in a relatively } \\
\text { small area. }\end{array}$ & $\begin{array}{l}\text { Synchronic information gathered in a short } \\
\text { time, but over a large area. }\end{array}$ \\
\hline $\begin{array}{l}\text { Explanation can be a spiritual cumulative } \\
\text { collective experience. }\end{array}$ & Science avoids dealing with the spiritual. \\
\hline Not equipped to test or verify & \begin{tabular}{l} 
Incorporates a system of hypothesis testing \\
\hline Slower to accumulate \\
subjective certainty \\
Table 1 Comparison of Traditional and Scientific Ecological Knowledge. (Dewalt 1994, Johnson 1992)
\end{tabular} \\
\hline
\end{tabular}

\footnotetext{
${ }^{38}$ DeWalt, Billie R., Using Indigenous Knowledge to improve agricultural and natural resource management. Human Organization, Vol.53., No.2. pg. 123-131.

Johnson, Martha,, Research on Traditional Environmental Knowledge: Its Development and its Role. In Martha Johnson (ed.) Lore: Capturing Traditional Environmental Knowledge. Dene Cultural Institute and the International Development Research Centre. Ottawa. 1992.
} 


\section{History \& Precedent}

\section{Early Native American Building}

Early traditional Native American peoples, before colonization, produced distinctive most durable examples of architecture, both temporary and permanent. They built structures that followed topographic contours deeply rooted within the land, utilizing natural elements to build their structures in relation to their local climate, materials, landforms, and customs. Constructed from limited local resources, they addressed environmental concerns by revealing the importance of maintaining equilibrium with the natural cycles of life, as well as with the relationship and connection between man, nature and the environment. They considered their dwellings complete when the natural and the spiritual came together and thus became "one." As art historian Vincent Scully explained:

"Native American peoples ritualized their relationship to the natural world around them. This symbiosis was fundamental to their architecture for the environment, and was an implacable catalyst in the kind of shelter they created for themselves. The balance between the artificial and the natural can be clearly seen in the architecture of their settlements." 39

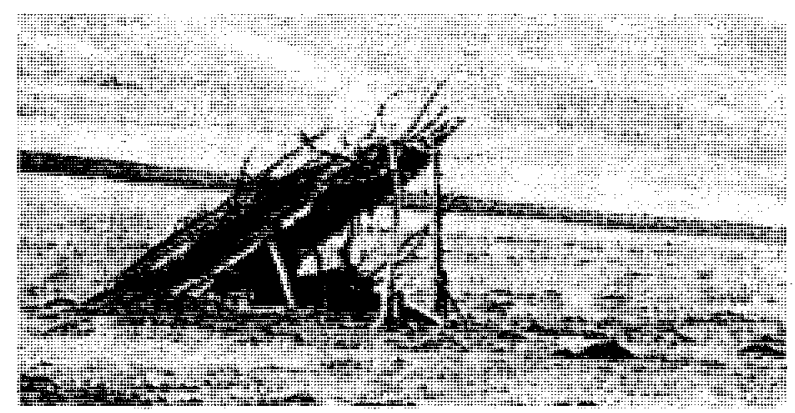

Fig.2 Native American Architecture. Pg.28 Response to climate. 1900

39 Highwater, Jamake.The Primal Mind, Vision and Reality in Indian America. Meridian NAL, New York American Library, Inc. New York. 1982. p.23. 


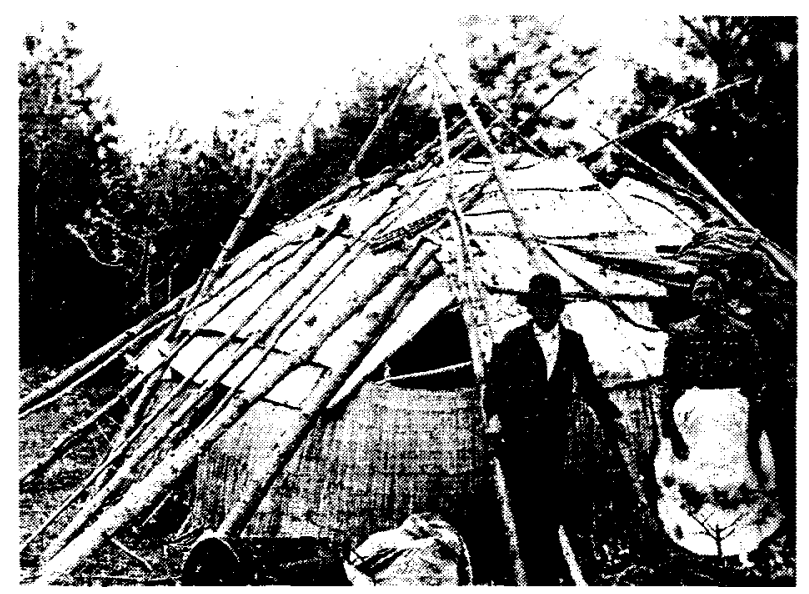

Fig.3 1761 Photo Wigwam. Native American Architecture. P.60.

The traditional understandings mentioned above formed the foundation for a spiritual connection with nature. These are the ethics, morals, values, beliefs and philosophy of the Native American people.

In 1977, at a United Nations conference held in Geneva, Switzerland, the Native Mohawk Iroquois offered a message about their people and beliefs to the rest of the world. This document was called "A Basic Call to Consciousness: The Haudenosaunee Address to the Western World." The primary objective was to:

...call for a consciousness of the sacred web of life in the universe. "40 This document was a means of helping non-Native Americans understand the true meaning and depth of the native spiritual connection to the rest of creation. Within its pages were several points that support and emphasize the thesis of this paper. In the initial paragraph of the document they acknowledge that they are using the Original Instructions as the source for their beliefs. They recognize their role in the interconnected web of life, pointing to their responsibility as spiritual guardians of their land. "We believe that man is real, a part of the Creation, and that his duty is to support Life in conjunction with the other beings. 41

\footnotetext{
${ }^{40}$ Haudenosaunee Council. "A Basic Call to Consciousness The Hau de no sau nee Address to the Western World". Geneva, Switzerland, Autumn 1977. Akwesasne Notes (1978). (Retrieved October 8, 2003) from $<$ http://www.ratical.org/many_worlds/6Nations/BasicCtC.html $>$

${ }^{41}$ Ibid
} 
In the beginning, we were told that the human beings who walk about the Earth have been provided with all the things necessary for life. We were instructed to carry a love for one another, and to show a great respect for all the beings of this Earth. We are shown that our life exists with the tree life, that our well-being depends on the well-being of the Vegetable Life, that we are close relatives of the four-legged beings. In our ways, spiritual consciousness is the highest form of politics. 42

This statement affirms the Native people's belief that spiritual connection among all living things is not limited to philosophy but pervades every aspect of life and culture. It is pointed out that "World Creation" 43 is sacred, and it is suggested that gratitude and affection should be paid to nature and the natural environment as it supports and creates life. Based on this relationship, there is an emphasized need for the "protection and liberation of all things that support the sacred web of life, the trees, the sun, the wind, the water, and the air." 44

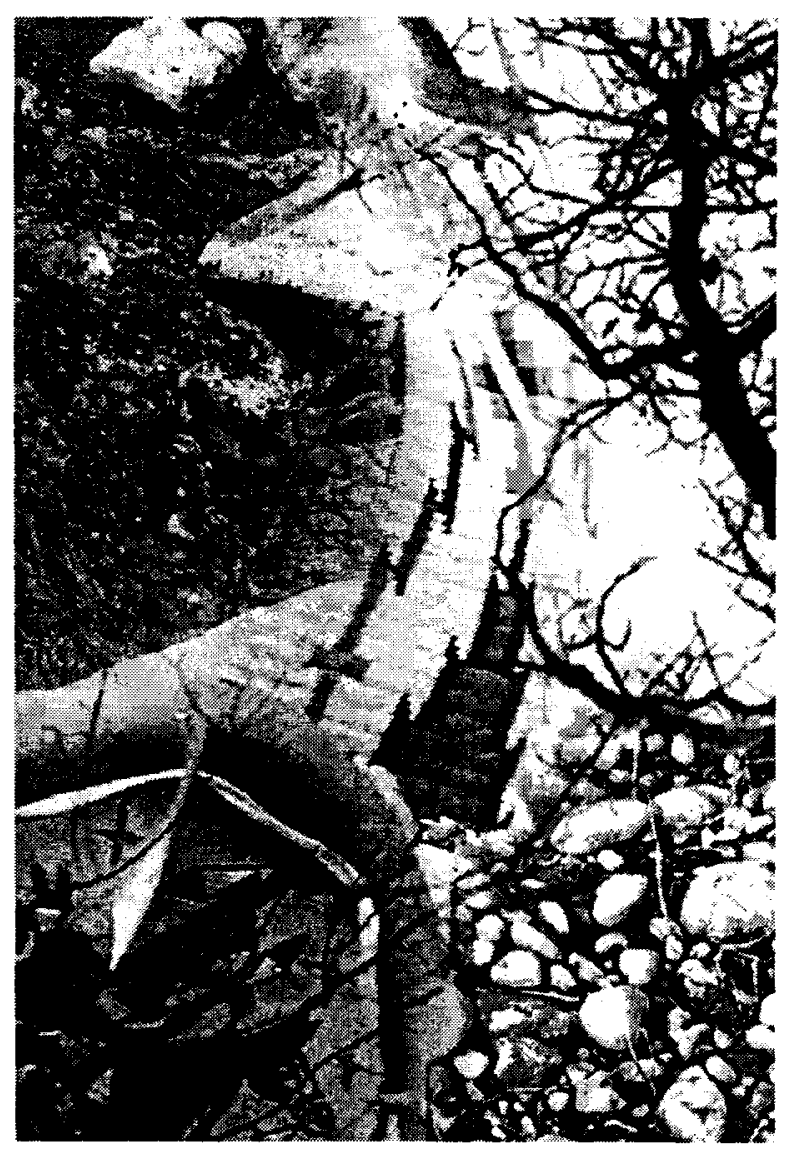

Fig.4. Nature \& Culture Montage by Author. 2007

\footnotetext{
42 Ibid

${ }^{43}$ Haudenosaunee Council. "Basic Call to Consciousness The Haudenosaunee Address to the Western World". Geneva, Switzerland, Autumn 1977. Akwesasne Notes (1978). Retrieved Nov.,2007.

${ }^{44}$ Haudenosaunee Council. "A Basic Call to Consciousness The Haudenosaunee Address to the Western World". Geneva, Switzerland, Autumn 1977. Akwesasne Notes (1978). Retrieved Nov.,2007.
} 


\section{Native American Vernacular Architecture}

Traditional Native American architectural forms were responses to local climate, the use of natural materials, and designing around inherent social organizational patterns, seasons, religions, and historical measures. The materials of the traditional dwellings were wood, bark, leaves, grass, reeds, snow, stone, and clay. Their principal types of construction were (1) tensile or bent frame with covering, (2) compression shell, and (3) post and beam (joined) wood frame with various materials. The support structure was tied, wrapped and knotted together. These dwellings were not conceived as permanent, for some tribes relocated according to seasonal changes, and the building materials they used slowly corroded through time. The primary goal was to make sure the structure functioned well in all aspects of their lives.

In the following pages, I will describe the longhouse structure specific to the early dwellings from the Iroquois of the Eastern Woodlands. I will explain how this early structure was conceived and developed, and how it once stood as a representation of the Iroquoian culture before its disappearance. What remains is a memory which still resonates in the oral traditions, visual artifacts and remnants of culturally symbolic ideals. A new Native American structure is required to represent and signify meanings, values and principles of the culture through built form. Architecturally, one can re-establish cultural identity, social relationships, and re-instate a sense of place based on regional values. Thus, it is important to study architectural forms and expressions that have

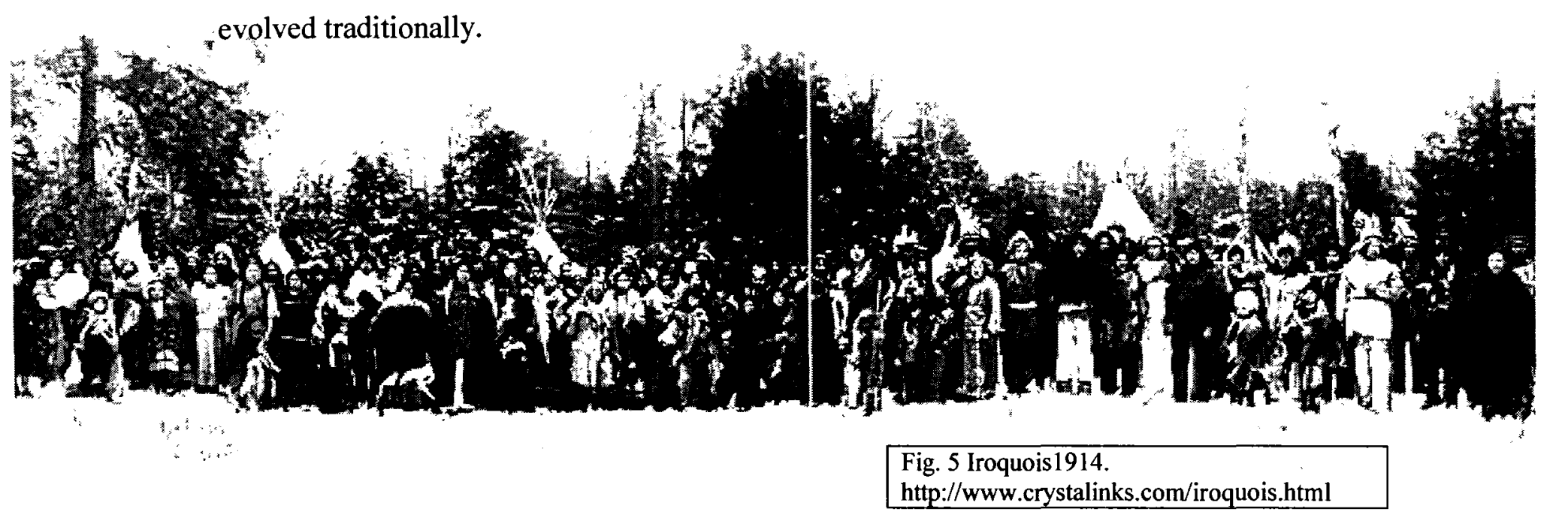




\section{The Iroquois Longhouse Dwelling:}

The Iroquois call themselves "Haudenosaunee" which means: "People building an extended house" or more commonly referred to as "People of the Long House" 45

It was this longhouse dwelling that became the dominant symbol providing social solidarity to their culture. The structure was developed based on ancestral teachings that reflected their culture in the built form.

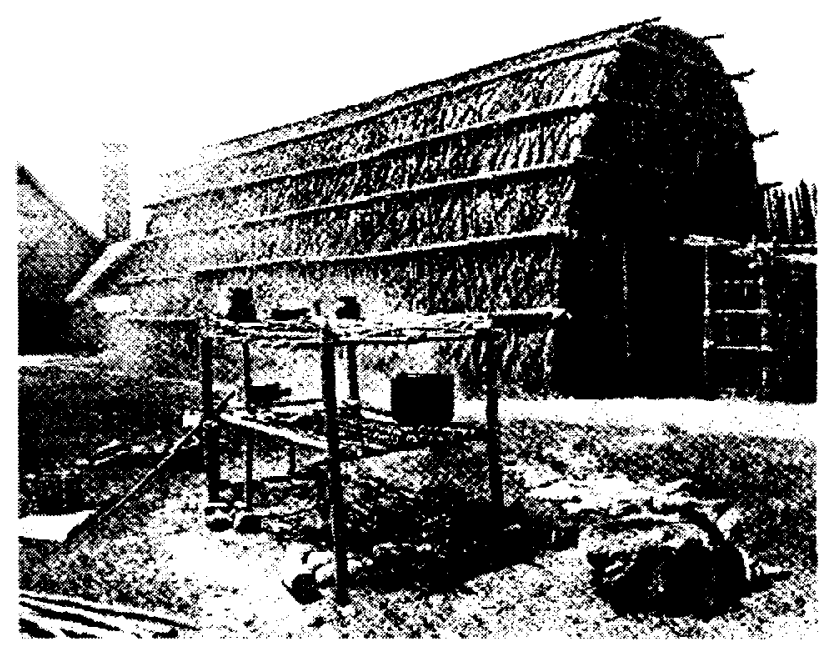

Fig.6. Exterior of Reconstructed Longhouse, Built in 1640. Ste-Marie Among the Hurons. The Canadian Encyclopedia.

http://www.thecanadianencyclopedia.com

Archeological evidence indicates that the Iroquois lived in upstate New York for at least 500 years before the Europeans arrived. Longhouse construction dates back to at least 1100 C.E. Historically, the Iroquois and other Native American communities possessed a deep sense of identity as a society, with strong ties to family, clan, and cultural beliefs. The longhouse stood as the dominant symbol of social solidarity becoming the unifying political symbol of a confederation league of five nations in 1570, adding a sixth in 1772 .

45 Published in Akwesasne Notes New Series, Fall October/November/December1995, Volume 1 \#3 \& 4, pp. 62-63. 


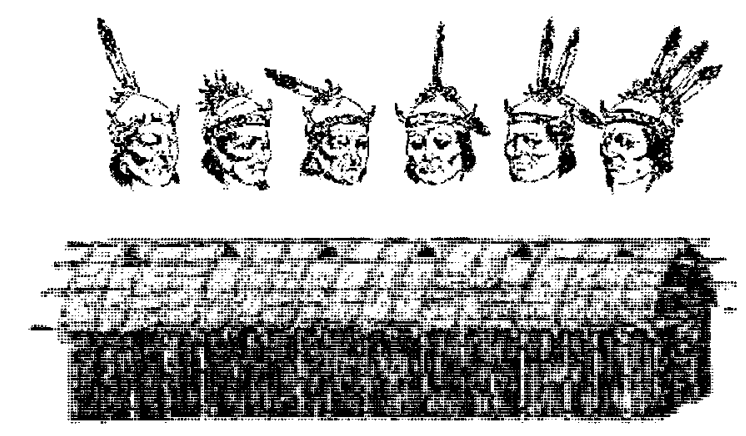

Fig.7. Traditional Symbol for the League of the Six Nations Confederacy. North American Travelling College. Web Access. 2007

Addressing this issue, Norman Crowe in The Idea of a Man Made World, states:

"The present is always shaped by the past. Cultural values evolve and are nurtured in a certain place and they forever bear the stamp of that place." 46

The traditional longhouse was built following information transmitted through oral narratives, developed through cosmic orientation, materiality, values and ceremonies that contributed and communicated a spiritual heritage and sense of place between the natural world and the Iroquois people. The ancient dwelling was multifunctional, serving as a ceremonial structure that depicted divine wholeness. "Buildings were transformed from solid objects into gateways through which the soul can manifest itself." 47

46 Crowe.Norman, "Nature and the Idea of a Man-Made World: An Investigation into the Evolutionary Roots of Form and Order in the Built Environment". MIT Press. Cambridge, Massachusetts.1999.pg.8 47 Hirschfelder, Arlene and Paulette Molin. "Encyclopedia of Native American Religion. Roundhouse". Publishing. New York. N.Y.1992.pg.162. 


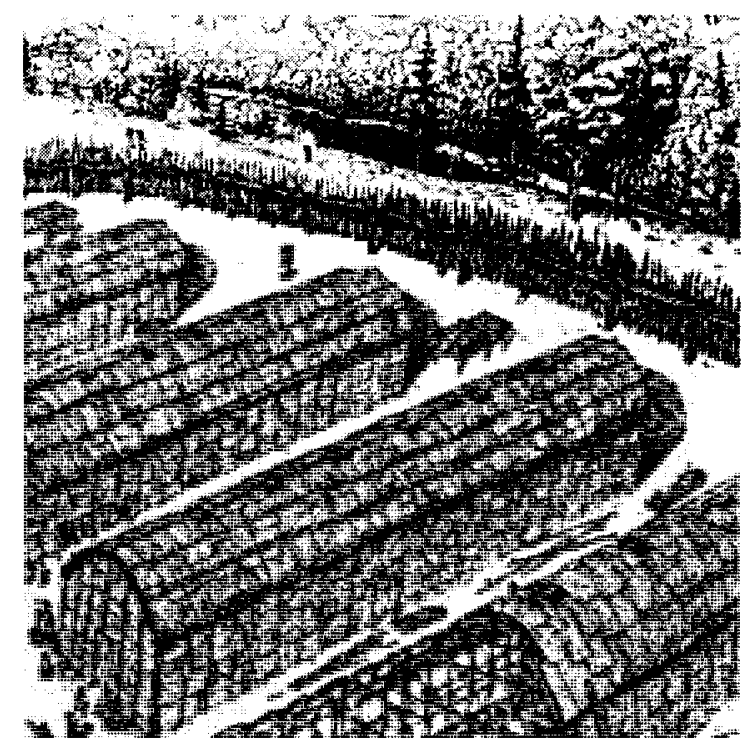

Fig.8.Longhouse Palisade The Canadian Encyclopedia. $\mathrm{http}: / / \mathrm{www}$.thecanadianencyclopedia.com

The longhouse structures were grouped together in large palisade communities. The forms of these dwellings were long, narrow and rectangular, placed on an east-west axis, with two doors placed at each end. The context and orientation of the longhouse symbolized religious beliefs that were important in the framing of the structure and its ceremonial functions.

The inspiration for this type of structure was based on local materials and climate. The bark from the birch tree and other abundant wood resources formed the structure. The cold climate with heavy snows and strong winds inspired the architectural form.

The relationships of structure to ground and ground to surrounding spaces were carefully controlled, providing a comfortable relationship and sensitivity to the natural environment. 


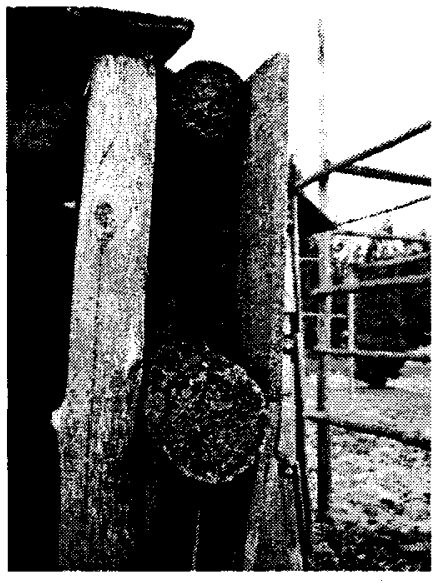

Fig. 9. Section view of exterior double wall of longhouse. Replication structure from the North American Travelling College. Photo by author. 2007

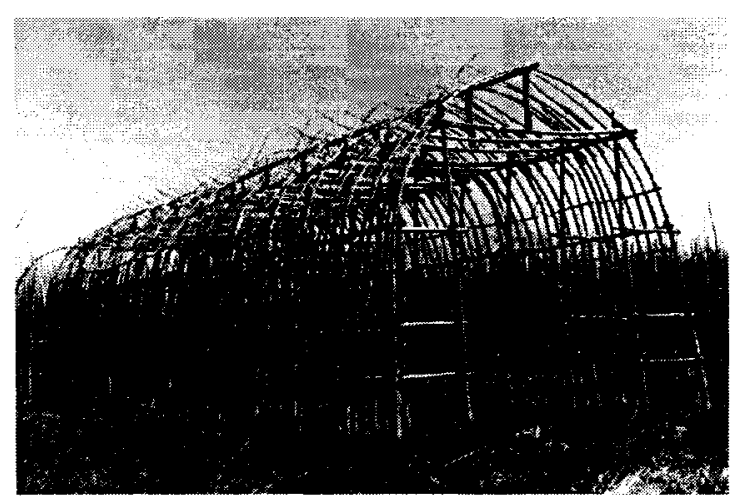

Fig. 11. Replication of traditional longhouse structure. Ganondagan. A Bridge between yesterday and today. Summer, 2001.J. Underhill
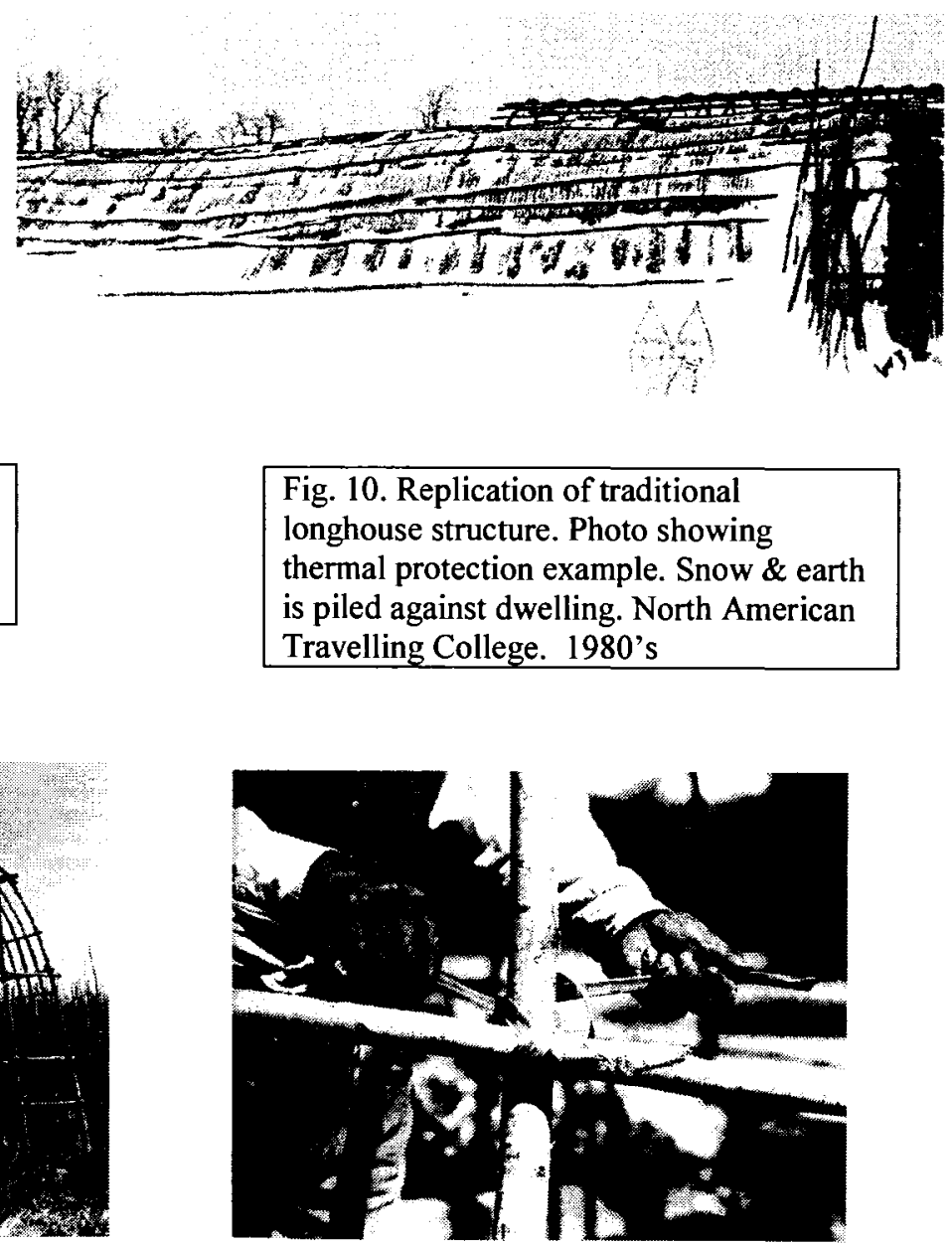

Fig. 10. Replication of traditional longhouse structure. Photo showing thermal protection example. Snow \& earth is piled against dwelling. North American Travelling College. 1980's

Fig.12. Lashing frame of longhouse. 1925. Native American Architecture. P.17 


\section{Social Organization \& Function:}

The remains of four traditional longhouse dwellings were found and excavated by archeologist in 1964. These dwellings are believed to have been occupied around 13801400. The largest longhouse was 334 feet long and 23 feet wide. The outer wall of the longhouse was framed with three-inch poles set into the ground about a foot deep. Two rows of vertical poles, eight to ten inches in diameter, defined the inside central corridor and supported both the sleeping bunks and roof. Archeologists have assumed that this building housed a total of between 150-200 people.

The dwellings were extended to accommodate newly-married couples within a singular clan house. The longhouse size became a rough indicator of how many families it had acquired and how long it had stood in the village. In each structure, the eldest women held sway as the reigning longhouse "mother." The Iroquois preferred the elm tree as a choice of material for their structures: this was noted and celebrated in their legends.

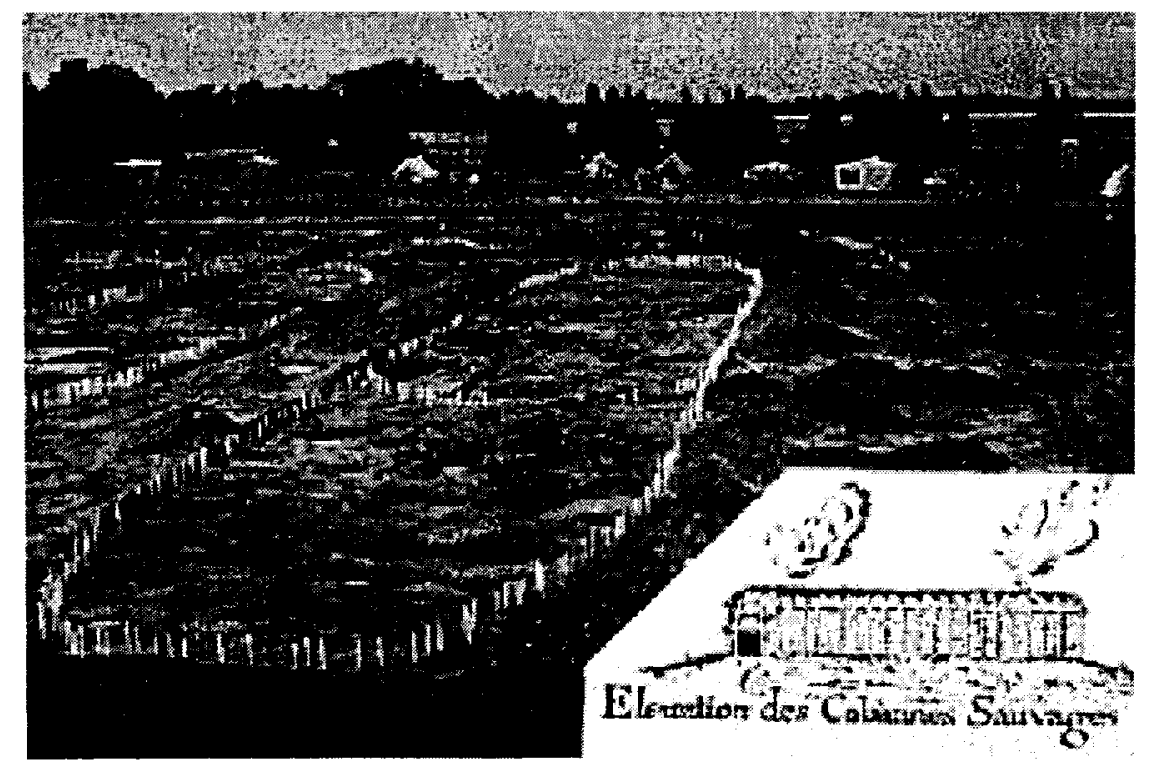

Fig.13. Iroquois Archeology.1964. Native American Architecture.p.79 
"The bark peeled from the trees between May \& July when the sap was rising, the sheets were flattened under rocks and kept moist to prevent warping and cracking as they dried. Punctured with bone awls, the bark was criss crossed and tied to the frame with strips of green basswood or slipper elm inner bark. An external frame of poles for the sides and the rafters for the roof were then adjusted to hold the bark shingles in place. The interior of the house was separated into chambers with a continuous passage through the center from end to end. Upper and low bunks were lashed to the wall posts and the uprights, which extended from floor to roof. Each family's 'room' was considered private space. Beneath the sleeping platform, was storage space for personal effects. Located at each end was a doorway covered with suspended hides. Between each compartment was a firepit that provided heat followed by a hole in the roof that permitted ventilation and allowed smoke to escape."48

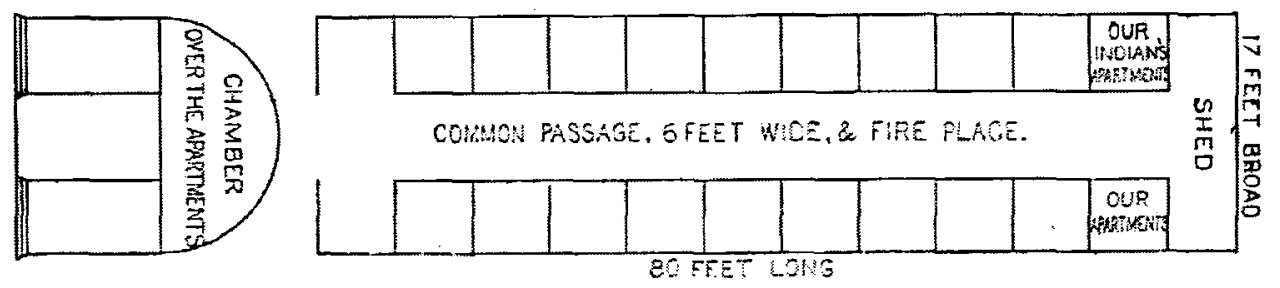

Fig. 14. Longhouse plan. 1724 approx. Native American Architecture. P.82

The social organization significantly influenced the size of the dwellings and living arrangements, as well as local resources and methods of gathering food. This not only affected the size of the community, but also the social rules which governed who lived together. The way in which the tribes arranged their spaces and used their dwellings reflected the organization of their society.

\footnotetext{
${ }^{48}$ Nabokov, Peter and Robert Easton. "Native American architecture". Oxford University Press, New York : 1989 , pg.84
} 
In the Iroquois longhouse there may have been twenty or more families, which were all related on the mothers' side, along with their relatives. All these families belonged to the same clan each clan in a village having its own longhouse. The clan was the basic social and economic unit in Iroquois society.

"Architecture, then, was a principal tool for socialization- a means by which members of a tribe learned rules of behavior and a particular world view." $" 49$

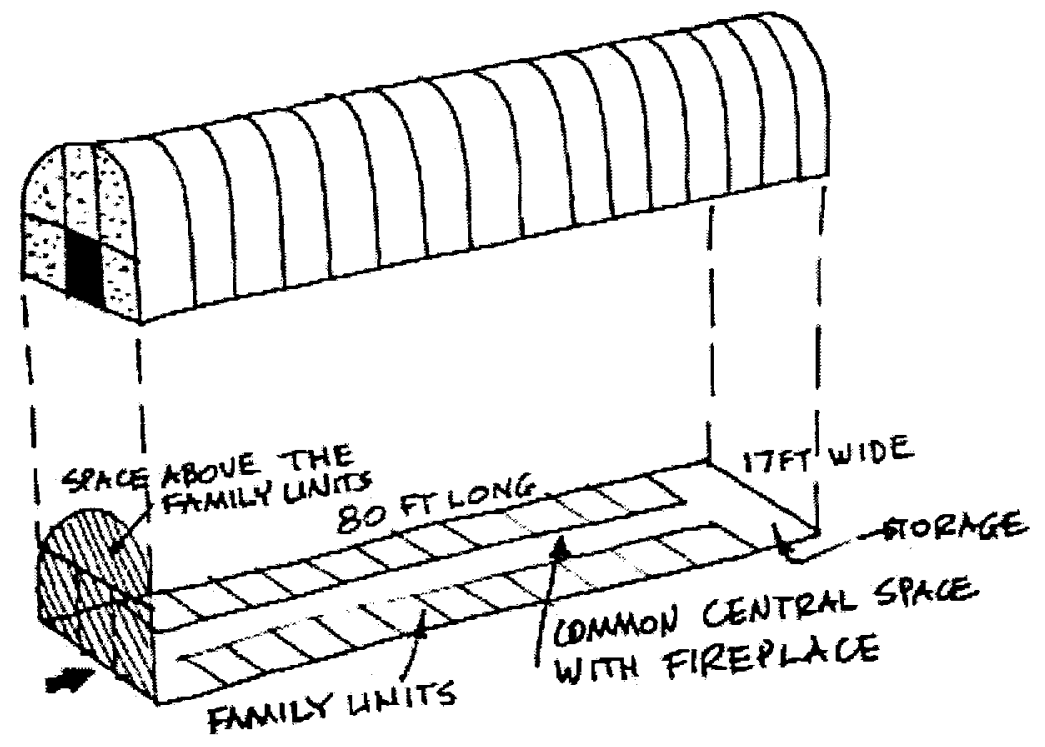

Fig.15. Iroquois longhouse axonometric. The North American Travelling College.

\footnotetext{
${ }^{49}$ Nabokov, Peter and Robert Easton. Native American architecture Oxford University Press, New York : 1989, pg.30.
} 


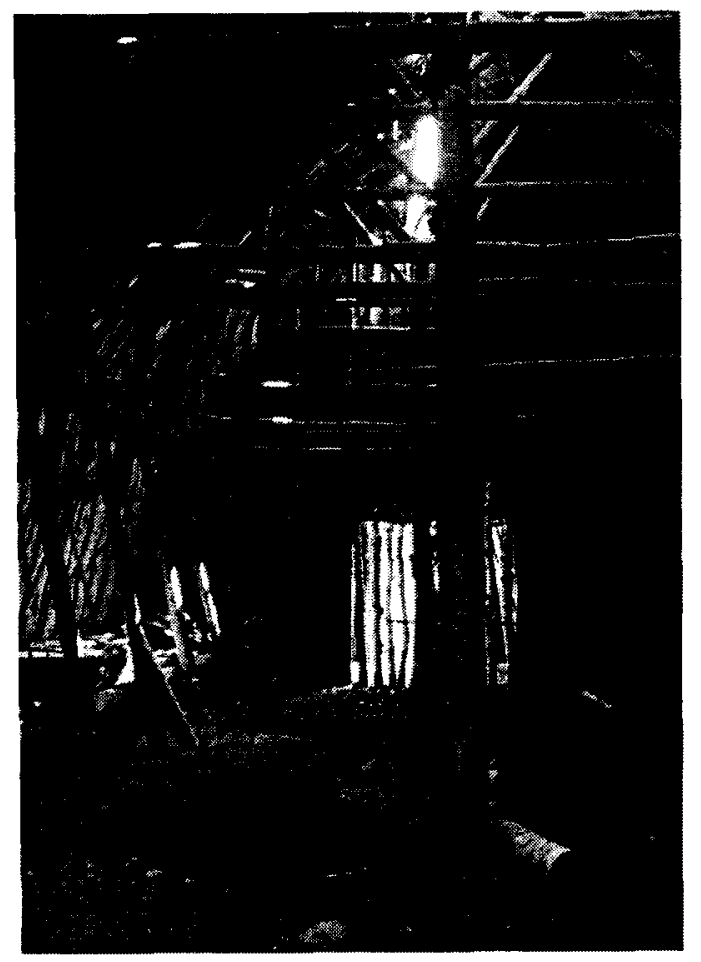

Fig.16. Detail of tying frame: Interior View of Traditional Longhouse Dwelling.

Replication North American Indian Traveling

College. Photo by Author 2007

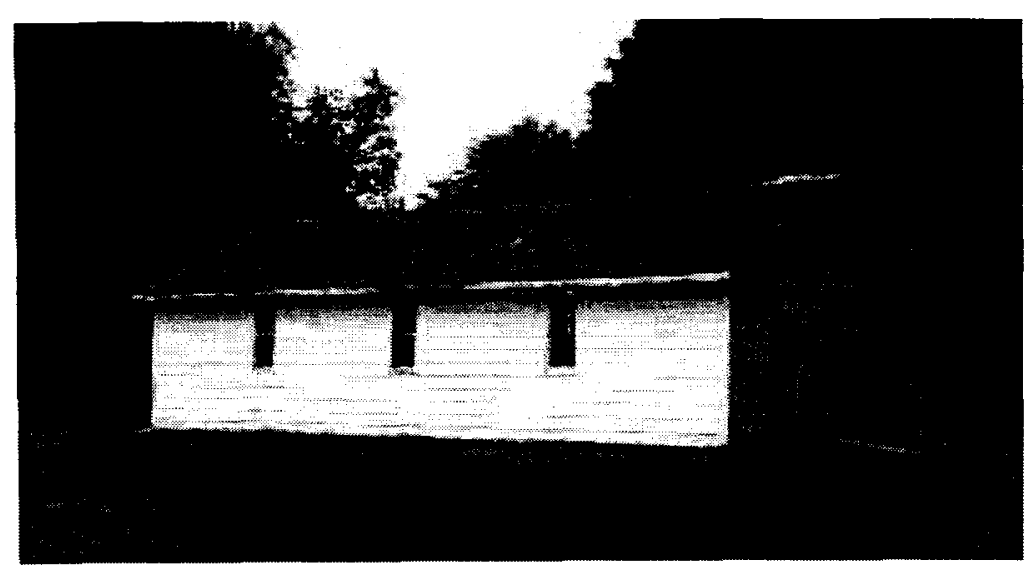

Fig.17. Iroquois Longhouse at Tonawanda

1980s.http://www.iroquoismuseum.or g/longhous.htm 


\section{Climate Conditions:}

The primitive builders were skilled in dealing with the harsh climatic problems and had the ability to use minimum resources for maximum comfort, appropriate for a small population. These builders and craftsmen learned to solve their problems by collaborating with nature.

"Primitive man builds more wisely than we do, and follows principles of design which we ignore, in this sense the container whose main purpose is to shelter and protect the occupants and contents protects him from the undesirable effects of his surroundings."50

Warming the structures was accomplished by heating the interior corridor with centrally located hearths approximately every twenty feet. Other thermal factors included recessing the structure into the ground and then mounding a snow or earthen berm against the outside perimeter shell. The exterior walls were doubled with a central core to provide ventilation, while the interior side was insulated with grass. On the exterior, thin pliant branches were interwoven over flattened bark to keep out the rain and cold. The main entrance had a small porch that deflected the wind and snow from entering. In the summer months, the grass was removed from the interior walls, leaving a perforated structure that provided cool ventilation through the interior.

\footnotetext{
${ }^{50}$ Rapoport, Amos. Socio-cultural factors and house form, House Form and Culture, Englewood Cliff, NJ: Prentice - Hall, Inc. 1960. p 85.
} 


\section{Economic Conditions:}

According to L.H. Morgan, "An Iroquois longhouse was described as a house of 'five fires' or 'seven fires' to indicate the number of families living together and the rough dimensions of the building. Platforms along the sidewalls served for sleeping and storage. Over time longhouses could be extended as needed, with new family sections added at each end. Excavations of former Iroquoian town sites have revealed traces of longhouses measuring as long as $120 \mathrm{~m}$ (400 ft). Raised bunks were constructed along the walls for beds. Spaces were contrived for storage."51

Most native tribes had two seasonal dwellings suited for a specific climate. They relied on different food sources for summer and winter while occupying different camps in fall and spring. But for more sedentary people like the woodland Iroquois, intense occupation of a single site often exhausted local building supplies and soil. Every ten or fifteen years, when their building materials became sparse, the Iroquois would resettle the entire community not far from the original site. Rapoport argues the reason for the architecture being built in a particular manner was based on the values of the group or culture in question. "The socio-cultural factors are the primary concern when choices effecting how a group builds. Developed through the vision a culture has over the perfect life.... and once shelter is provided, the particular architecture or settlement patterns develops as well, because they suit a very specific way of life." 52 What is critical about Rapoport's inquiry is his demonstration that the "desire to improve a particular culture's quality of life involves in part developing building forms and settlement patterns that are able to sustain the lives of their inhabitants within the context of local ecological systems without excluding other factors. "53

51 L.H. Morgan. Houses and House life of the American Aborigines originally published in 1881; republished Chicago: University of Chicago Press, 1965,p.128

${ }^{52}$ Rapoport, Amos. Socio-cultural factors and house form, House Form and Culture, Englewood Cliff, NJ: Prentice - Hall, Inc. 1960. p 46-82.

${ }^{53}$ Rapoport, Amos. Socio-cultural factors and house form, House Form and Culture, Englewood Cliff, NJ:

Prentice - Hall, Inc. 1960. p 46-82. 


\section{Religious, Spiritual and Cosmological Beliefs.}

Every civilization has propounded its own philosophies and connections to one another, and thus some mysticism and religions are similar in context to other cultures around the world. By using symbols to reflect religious beliefs and cosmology, it teaches people about the origins of their own culture and strengthens the roots of individual ethnic identities. "Architecture has certain physical characteristics that appeal to our senses, creating intimate sacred spaces that encourages the investigation of the unknown and the worship of 'energetic qualities' that manifest in dimensions beyond the familiar and constitute the basis of most religions and belief systems."

The word for "religion" does not exist in many Native American nations who follow the traditional ways. It is their beliefs and spirituality, integrated with nature's elements, that seemed analogous to religious doctrines. "For many indigenous peoples spirits permeate matter -- they animate it. This led the early anthropologists to refer to such beliefs as animist - Animism is described as a philosophy rather than a religion. "55 Thus, native peoples undertook every action with respect for the environment, nature and all living things within a state of balance and harmony because they believed all things contain spiritual forces. They believe that the universe contains a fixed social and structural order that encompasses the physical and spiritual realms in its organization and in its relationship to all living things.

"The Native American belief system and the way they built their structures permeated through their mythologies, their pictorial representations, which emerge from the attempt to recreate the universal structures on earth in communication to the divine. The way to represent the divine is through the alignment of their structures. Alignments and characteristics corresponded to the rising and setting moon and the sun's position. The rotation of the earth around its polar axis creates day and night, the seasons, and the summer and winter solstice." 56

\footnotetext{
54 Rapoport, Amos . "House form and culture", University of Wisconsin, Milwaukee. Prentice Hall Foundations of cultural geography series. 1969. p. 40

55 Burger, Julian. "The Gaia Atlas of First Peoples: A Future for the Indigenous World”. London: Gaia Books Ltd, 1990. p.64

56 Nabakov, Peter. "Native American Architecture: Preserving Social Religious Life", Four Winds, Vol.1, No.5. Spring-Winter, 1981: pg.43-47.
} 


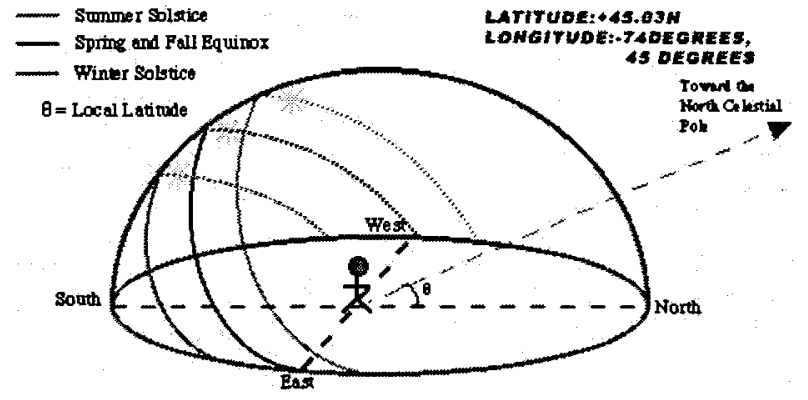

Fig.18. Solstice \& Equinox diagram.

The Iroquois longhouse structure was a traditional dwelling that arose from a specific historical, demographic, ecological and cultural circumstance. The creation of the dwelling corresponded between dwelling and the cosmos. The Cosmos refers to the universe; and the knowledge of our existence.

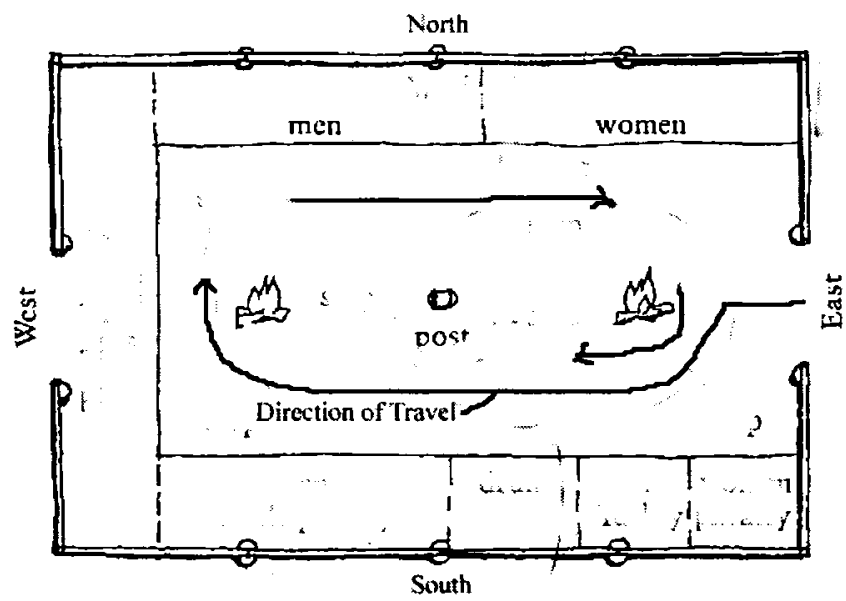

Fig.19. Ceremonial longhouse circulation pattern Native American Architecture, P. Nabacov. P.89

"The two egress doors on either end of the building, symbolically entering and exiting of celestial bodies, was configured by the direction of the sun and moon entering the sky world from the east and to exit in the west, therefore the people enter in that same recreated cosmological direction." 57

57 L.H. Morgan. Houses and House life of the American Aborigines originally published in 1881; republished Chicago: University of Chicago Press, 1965,p.34. 
The ceremonies of the Iroquois reflected their interconnectedness with the natural world and were performed and celebrated to thank the Creator. Ceremonies were held throughout the year and corresponded to the cycles of nature. For example "the Iroquois held a Maple ceremony in March when the maple sap began to flow, a Strawberry ceremony was held in June when the strawberries began to ripen, and a Harvest ceremony was held in the September/October period when all crops were harvested and stored" 58 Before and after each ceremony, but not limited to just ceremonies, the Iroquois acknowledged all life forms that made up the world in a Thanksgiving Address. This address is a prayer of great importance as it contains the teachings of how one is to conduct one's self in harmony with the natural world. The address also focuses on mutual respect, conservation, love, generosity, and the responsibility to understand that what is done to one part of the Web of Life, affects our being. It is composed of policies, principles, moral duties, laws, ceremonies, and other religious and political aspects that the Iroquois were given on how to live in harmony with each other and with the Natural World. (Refer to Appendix A- for the Thanksgiving Address) 


\section{The Oral Tradition \& Symbolism:}

Indigenous architecture is a language: it tells the story of people and of the organization of their existence. Culture and history are two intertwined in the development of architecture with each playing a distinct role in molding the architectural expression of a region. Not only are they verbal communication methods, but also encompass theoretical, visual and symbolic entities, associated with belief and spirituality. It was believed that early "Structures carried discernible meanings, which were consciously or unconsciously built into them by their designers."

These buildings expressed their cultural values and ways of life, and were maintained through their oral narratives and symbolic forms.

"Architecture is 'read,' conveyed and organized through its society, through materiality, and metaphysical.... architecture is like a book that a culture "writes" for other members of that culture; it is a culture talking to itself about the meaning and organization of the life of that culture." 60

The oral tradition is an important communication mechanism for ensuring a culture's continued existence. These narratives depict the cultural history, sacred myths, and beliefs, thus providing a portrait of the intimate life of that community. Additionally, it is a means of representing the collective cultural identity, capturing the sacred in ordinary life and the links among past, present, and future. "Oral tradition is not just speaking and listening, (it is) the whole process which involves a lifestyle, history, its culture, its language, values, and subsequently, its literature. So it's not merely a simple matter of speaking and listening, but living that process....it is the importance of your identity, what your heritage is, and how that forms, formulates itself in creative expression...." 61

\footnotetext{
${ }^{58}$ Cornelius, C. "Iroquois Corn in a Culture-Based Curriculum: A Framework for Respectfully Teaching about Cultures". (New York: State University of NY Press).1999.p.92

59 Nabokov, Peter and Robert Easton. "Native American architecture". ( Oxford University Press, New York) 1989, p. 38.

60 Preziosi. Donald. "Architecture, Language and Meaning. The Origins of the Built World and Its Semiotic Organization". (Moutin Publishers. New York). 1979,p.103.

61 Coltelli, Laura. "Winged Words. Article by Simon Ortiz. Winged words: American Indian writers speak".(University of Nebraska Press).1992. p. 104
} 
Their creation story gave them a model for organizing their living spaces and surroundings. It was a guide that explained the buildings purpose and was understood semiotically through signs and symbols inscribed through the longhouse's conception, construction, and use.

"The Origin myth told them to build a house that would re-create the cosmos," the myth transformed the house into a symbol. In the form of the longhouse, the concept of "house" acquired meaning beyond that of its individual existence in and of itself." 62

The people viewed the creation of the world as the creation of a dwelling, further strengthening the metaphoric correspondence between earth, dwelling and the cosmos. As author Mircea Eliade explained:

"The longhouse is considered a symbolic representation of a three partite cosmos. Heaven, earth and the underworld, which appear in the symbolic meaning attributed to the roof, the main level and the base...The house thus forms a miniature cosmos, microcosmos."63

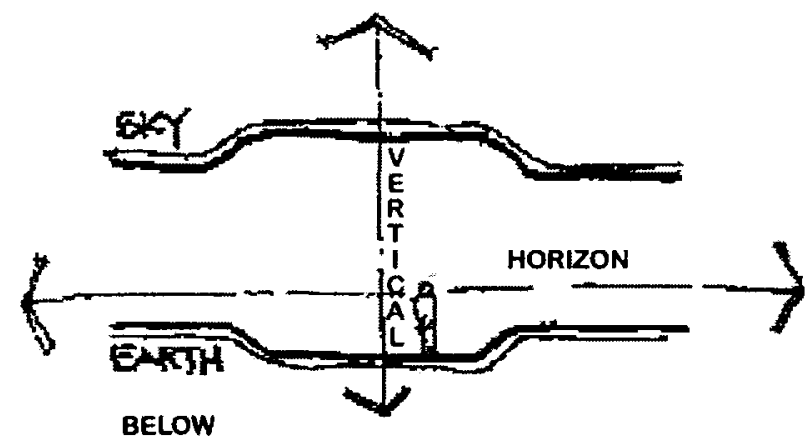

Fig.20. Layers of Dimension. Drawing by author.2006

Thus, it is necessary to define the term "symbols" and "symbolism" in application to indigenous culture. Symbols are generally defined as things that represent other things. They can be "sounds such as spoken words or they can have a physical manifestation, such as artifacts of a cross, a flag or the Vatican" ${ }^{\text {64 }}$ In the words of Victor Turner,

62 Preziosi, Donald. "The Semiotics of the Built Environment: An Introduction to Architectonic Analysis". Bloomington: Indiana University Press, 1979, p.63.

63 Eliade, M. "Symbolism, the Sacred, and the Arts. Crossroad", New York. 1986. p. 116.

${ }^{64}$ Levy, Janet. E. Metals. "Symbols, and Society in Bronze Age". In Material Sysmbols:Culture and Economy in Prehistory, edited by J. Robb, 1999.p.205-223 
Symbols are more than they seem, and are often a good deal more. ${ }^{65}$ The multiple meanings of symbols depend on their context and use, including individuals using the symbols. All human societies use physical symbols and language. Humans are symbolic creatures, and symbols are in fact one of the fundamental components of human psychological structure. Humans perceive the world through pictures and sounds, many of which become symbols in mind. We also organize, categorize, and interpret our world through symbols. Learned symbolic codes, such as languages, enable us to understand and react to the world around us. Consequently, symbols permeate every aspect of the human experience and primarily serve as instruments for communication.

Many societies both past and present, distinguish between the natural and the supernatural worlds. As Richard Townsend states, the diverse system of signs and symbols speak of an ancient dialogue that can be read by individuals who understand the group's cultural knowledge.. ${ }^{66}$ In these societies, natural and spiritual forces are intertwined and set the stage for myths, rituals, and ceremonies, affecting how the environment is perceived and built upon, and for more mundane aspects of life including subsistence strategies. For example, the Native American people turned to nature to find symbols representing their cultural beliefs. These symbols were transmitted through oral traditions and ritual performances that reinforced an interdependent relationship. This was manifested and displayed through their visual expressions, tools, and architecture. Thus, a visual language has emerged which shows the sacred and spiritual, as a metaphysical connection between the universe and cultural expression. Author Peter Nabocov expands upon this concept:

"Indigenous architectures constructed duplicates of mythic homes described in origin stories... Such myths functioned as zoning codes, blueprints, and labor unions. When people rebuilt a house or started a new one, they were renewing

\footnotetext{
${ }^{65}$ Turner, Victor. "The Ritual Process", Aldine, Chicago. 1969.p.14.

${ }^{66}$ Townsend, Richard. "Landscape and Symbol. In the Ancient Americas: Art From the Sacred Landscapes". The Art Institute of Chicago. Chicago.1992. p.29.
} 
their links to the timeless moment when they were born on earth. Architecture was identity to them." 67

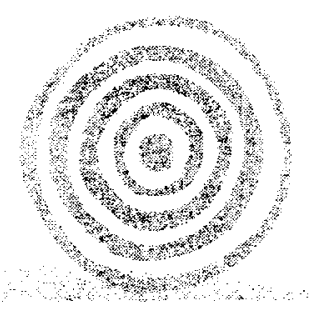

Fig.21. Sacred circle symbol New Organic Architecture The Breaking Wave, D. Pearson

The Circle is the oldest symbol of the world. The Circle is a reminder of our connections to Mother Earth. The sun, moon and planets travel in circles. All life, all creatures, and all living things, move about in the circle of life. They all depend on each other to survive.

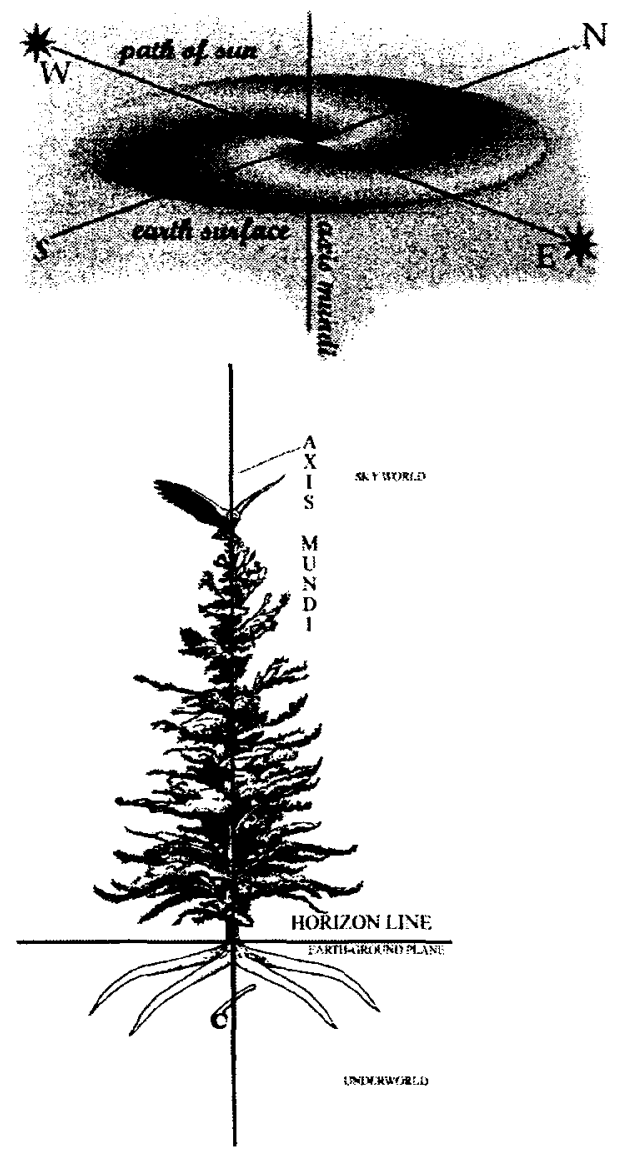

Fig.22. Cosmic Tree Axis Mundi Detail. Symbolism, the Sacred, and the Arts. Crossroad, New York. 1986. p. 116.

Fig.23. Cosmic tree axis-mundi detail http://www.championtrees.org/yarrow/Tree ofPeace.htm 5/21/2008

\footnotetext{
${ }^{67}$ Nabakov, Peter. "Native American Architecture: Preserving Social Religious Life", Four Winds, Vol.1, No.5. Spring-Winter, 1981. p.43-47.
} 
It is thus quite evident that the designs of Indigenous buildings need to be culturally sensitive and appropriate. The vernacular presents a natural perspective, a different view of the world, an inherited alternative ways of doing things, and a different value systems that sustain, balance and strengthen the relationship with nature. In addition, the union of climate, form, and function reveals specific dwelling characteristics and spaces. This is evident in the methods of construction, available materials, and level of technology --all demonstrating that architecture can play both a practical and symbolic role in the identity of a culture.

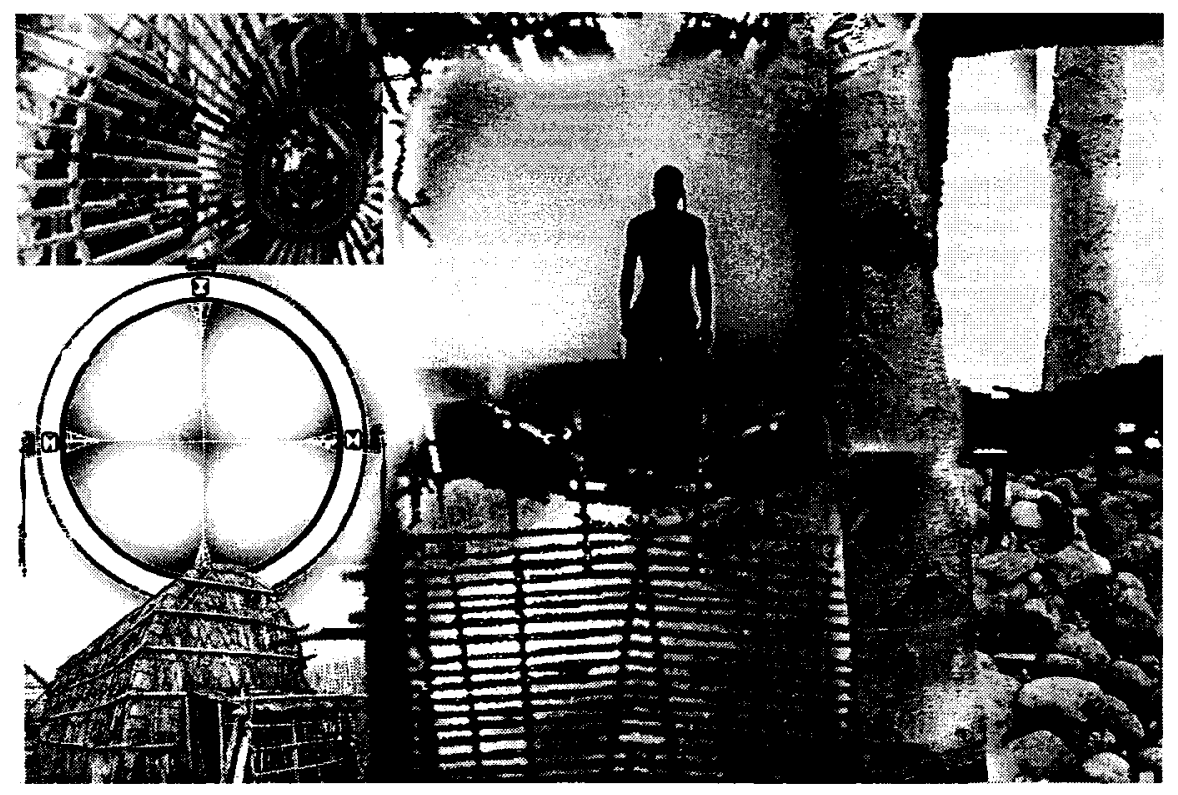

Fig.24 Photoshop montage conceptual study by author. 2008 


\section{Two Case Studies: Douglas Cardinal \& Busby and Associates}

Canada's First Nations are a growing force in contemporary society. As ancestral stewards of the land and its resources, they have positioned themselves at the forefront of the environmental movement. It is appropriate, therefore, when commissioning new facilities for First Nations people, that the designs should reflect the principles of green building. This chapter will present two case studies: Douglas Cardinal's 'OujeBougoumou Village'; and Busby and Associates 'The Nicola Valley Institute of Technology'. Each project is considered in terms of its programmatic and conceptual framework with regard to its site and the opportunities presented by available resources. Additionally, both examples support different architectural solutions with strong ties to the past, while ensuring a strong bond with the natural environment. 


\section{Douglas Cardinal Architect Inc.:}

The buildings of Canadian architect Douglas J. Cardinal are well known nationally and internationally by their undulating curves and sculpted forms. His buildings exhibit a recognizable and innovative design approach that has been called an indigenous Canadian style of architecture.

His attraction to freeform curvilinear shapes echoes the natural

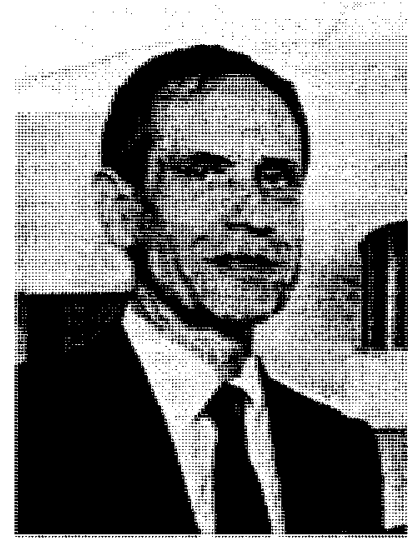
landscape and provides a unique design approach towards ecological concerns for the Canadian landscape. $5 / 19 / 08$

"His architectural ideas, influenced by the natural landscape and the elements, cannot be understood without reference to the native world view. " 68

Douglas Cardinal understands the importance of maintaining culture as the underlying principle in the emergence of a new architecture that reflects the values of First Nations people. Initially, contemporary architecture in aboriginal communities was non-existent. The buildings were often constructed with no input from the aboriginal community.

By joining forces with community leaders during the design process, the communication and relationship between architect and client was strengthened. And as a result, the design for a building captures the sense of pride, reflection and identity of its people that contributes to the future development of a healthy and functional community.

" The buildings must be part of nature and must flow out of the land; the landscape must weave in and out of them so that, even in the harshness of winter, we are not deprived of our closeness with nature. . This is the paramount factor in planning and executing our

68 Trevor Boddy. "The Architecture of Douglas Cardinal". NeWest Press. Edmonton.1989.pg.1 
vision of the human community. Our vision is in sympathy with the land and will be opposed by the short sighted and exploitive values of the dominant society. We will use knowledge and technology compatible with our culture to contribute to our rebirth as a viable contributing group in society. The artificial environment we construct must reflect the natural world and be in sympathy with our heritage. "69

The architecture developed through his philosophies, methodology, and design concepts produces a strong relationship between nature, culture and architecture.

\section{The Oujé-Bougoumou Village}

Oujé-Bougoumou is an indigenous Cree First Nations' village, which is home to a population of 650 people. It is located on Lake Opemiska in the James Bay Region about 400 miles north of Quebec City. Although the Oujé Bougoumou people have lived in the region for a very long time, their village is relatively new. The story of its development illustrates how tradition, architecture and nature can be woven together for the benefit of the overall community. Through perseverance and determination, this community has developed solutions that combine conventional technologies with innovation and traditions.

This community has won recognition and awards for its modern concepts combining economic sustainability, environmental conservation, and design and has set the standard for additional initiatives within existing native communities. Canadian Geographic (July/August 1994) described the new community in the following way:

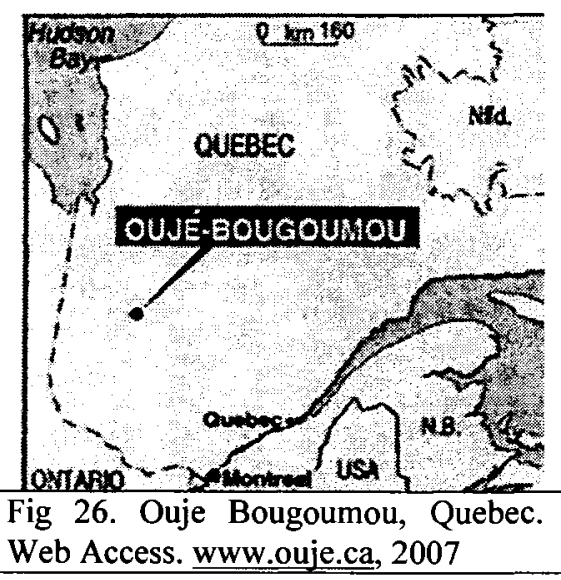

${ }^{69}$ Boddy, Trevor. "The Architecture of Douglas Cardinal." Edmonton NeWest Press, 1989. pg.116.. 
"An achievement never before seen in Canada - a native settlement with architectural coherence and integrity... a blend of modern technique and traditional shapes, modern technology, and traditional philosophy; and the traditional practices and way of life of the Cree people."70

The history of the Oujé-Bougoumou Crees throughout the better part of this century is a sad story of abuse, dispossession, and neglect from the combined efforts of mining and forestry companies, as well as at the hands of governments at both the provincial and federal levels. Oujé Bougoumou experienced decades of repeated relocations. Moreover, the people were poverty stricken and lived for decades in shacks and tents scattered along the Chibougamau area of Northern Quebec.

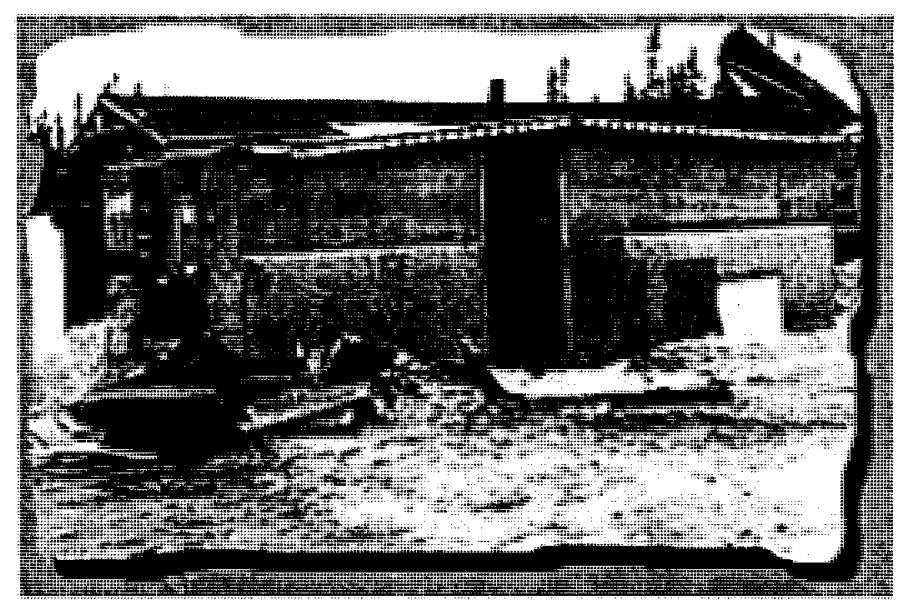

Fig.27Example of typical house before village retrofit. http://www.ouje.ca/. Web Access.2007

"Over the past 60 years the people had to forcibly relocate due to mining discoveries, until they found land that no one wanted, between the highway and the railway tracks. After a long and gritty fight with the Canadian government- the Oujé-Bougoumou Crees finally received land for a 2-square kilometer reserve, in recognition by the Canadian Government as a Native entity. " 71

70 Goddard, John, "In From the Cold." Canadian Geographic (July/August, 1994).p. 38-47. 


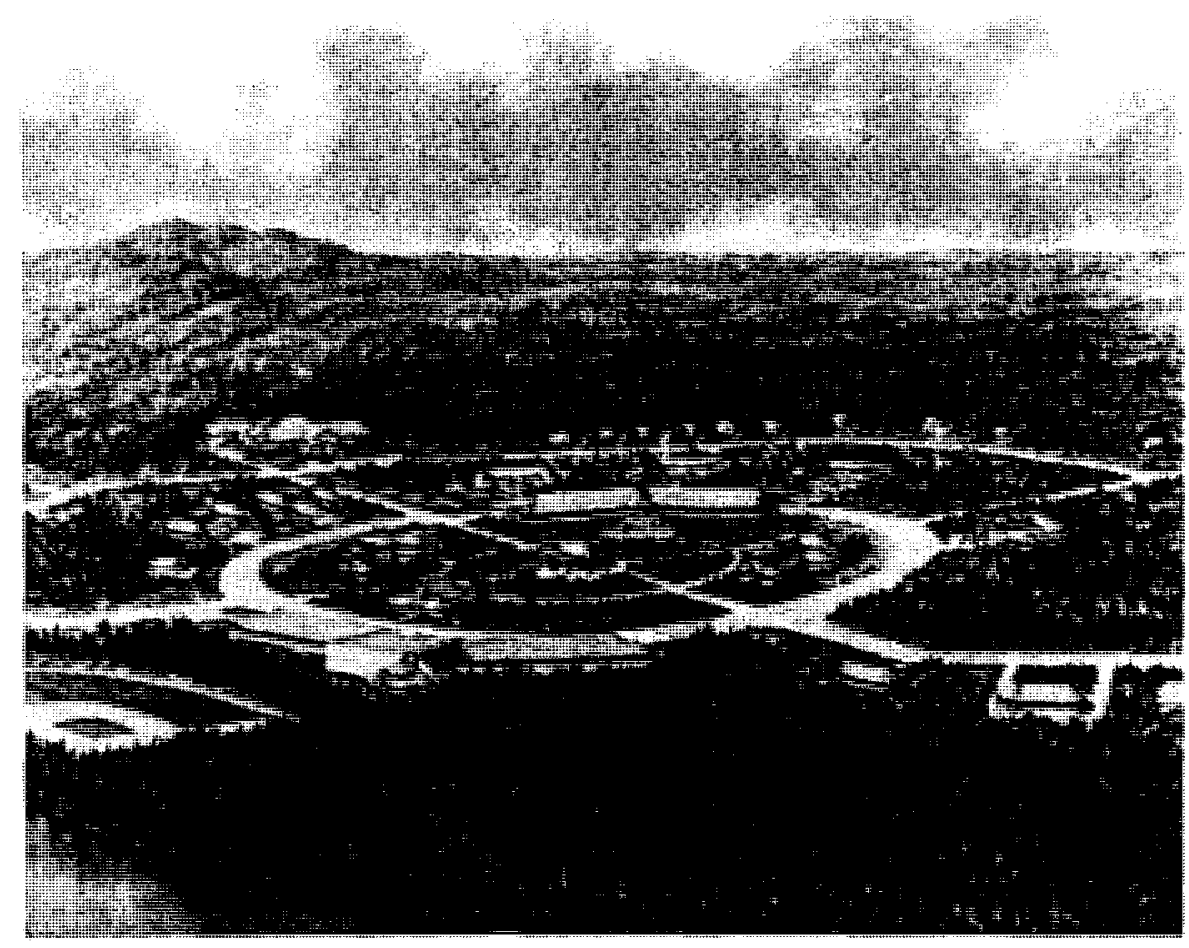

Fig.28 Render of Oujé Bougoumou Village

by Douglas Cardinal Architect Inc. 2007

The firm of Douglas Cardinal, along with Oujé -Bougoumou community members, designed the village based on three principles:

1. Economic efficiency and sustainability;

2. Environmental conservation and harmony;

3. Aesthetic beauty.

${ }^{71}$ http://www.ouje.ca/ 


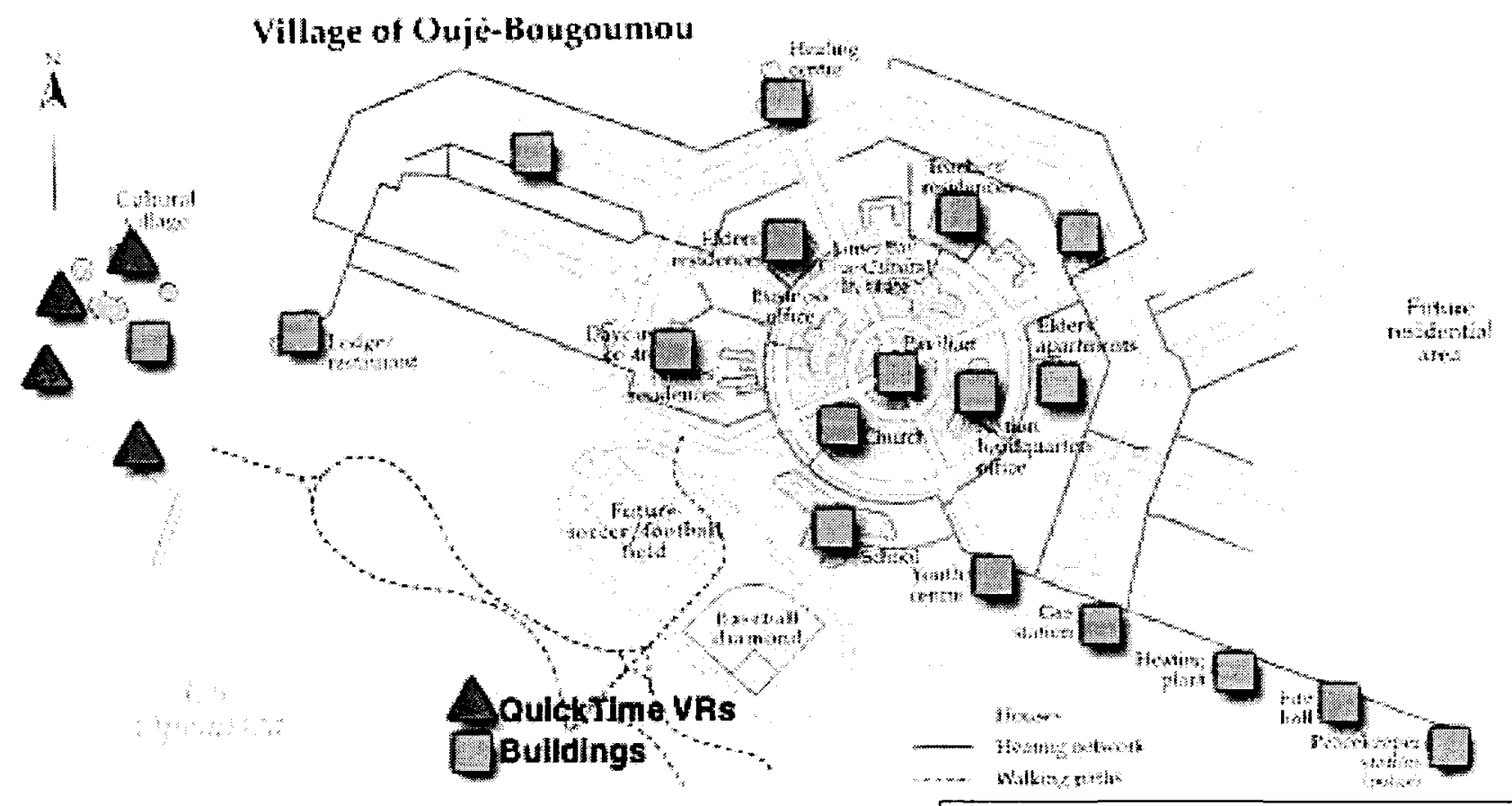

Fig.29Village of Oujé Bougoumou plan. Accessed from Douglas Cardinal Architect Inc. 2007

The village was designed to be in harmony with its natural environment and with the traditional Cree philosophy of conservation.

"To provide an environment in which the people truly feel at home, where they freely express their lifestyles and their cultural values. To reflect on their culture by incorporating the traditions of the past and provide a proper setting for the future, a home for future generations to flourish and develop, and have an opportunity to make a contribution."72

72 Oujé Bougoumou Village Architectural Concept Oct. 2, 1991). Douglas Cardinal Architect Ltd..p.1. 


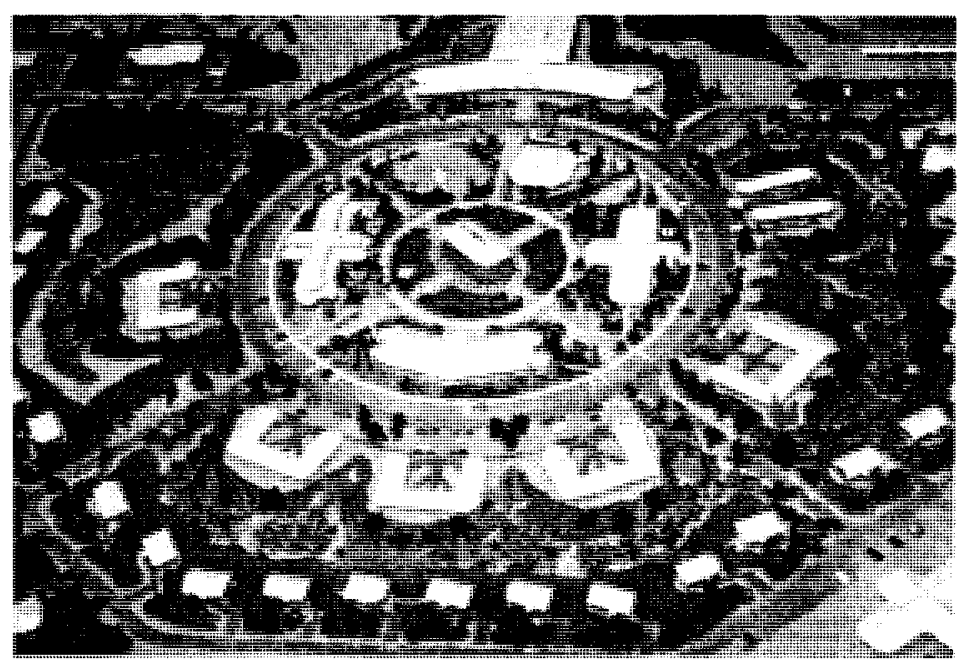

Fig.30 Ouje Bougoumou conceptual site model. Accessed from Douglas Cardinal Inc. 2007

The features of the project included a daycare and community center, a healing lodge, a youth center, and a sports facility. Ecologically innovative aspects of the village included an economic, self-efficient energy heating system that converted sawdust from sawmills operating in the region into useful energy, providing heat and hot water for the entire village. The design of the village is circular in plan. As the focal point, the traditional vernacular building is placed in the center of the village, surrounded by an outer perimeter of community buildings and clusters of residential homes, which is reminiscent of the old camps.

From the Oujé-Bougoumou experience, architecture and its relationship to a particular place is more than simply the adaptation of specific vernacular elements. The built project demonstrates a successful, community-driven process that provides a place for a native community and reflects its culture and lifestyle. As Christian Norberg-Schultz explains,

"Architecture and place are more than just the built environment that one constructs to dwell within. To retain meaning and enable the connection to place, architecture cannot separate from collective memory developed from the past as shared by a group of individuals who share the same experiences. In addition in order to move into the future, architecture cannot erase its past." 73

73 Norberg-Schultz, Christian. "The Concept of Dwelling". Rizzoli International Publications. New York.1993.p. 16 


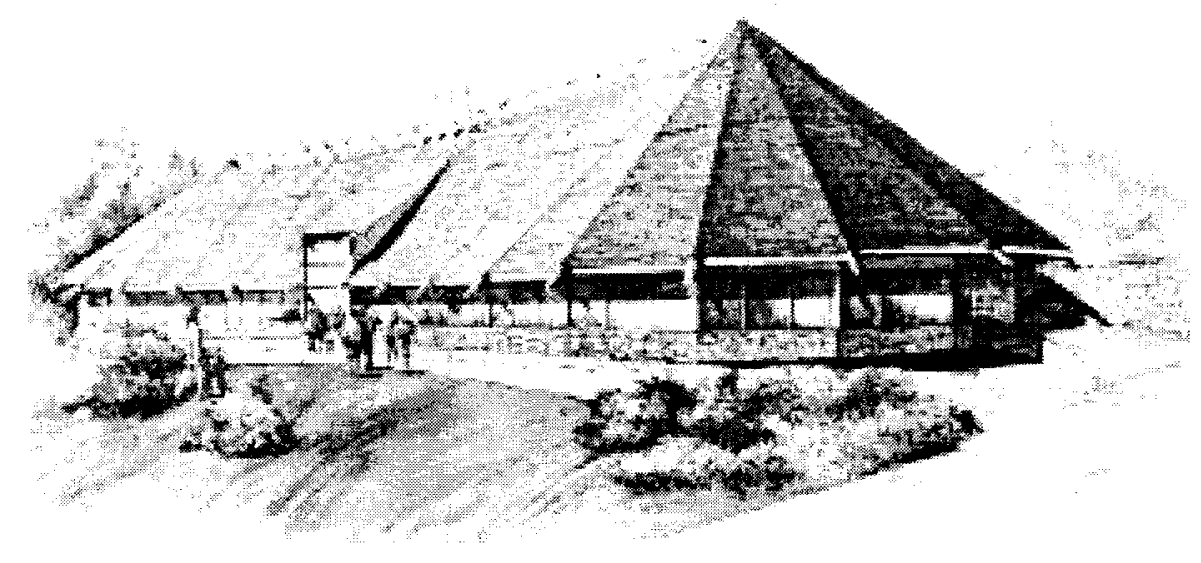

Fig.31 Rendering of the Cree Cultural Institute. Ouje Bougoumou. Accessed from Douglas

Cardinal Architect Inc. 2007

" My buildings are designed to fit into their environment, to appear as if they have always been there. The materials interact with each other, and their surroundings.." 74

This admiration for the vernacular resulted in the perpetuation of an authentic architectural language that ensured historical continuity. Therefore it was essential that the new designs follow the traditions of the vernacular dwellings that served the needs of the people for generations.

During one meeting, Douglas Cardinal met in the traditional Cree Astiyookamak dwelling structure with the community in order to discuss and generate concepts for the project. This process provided inspiration, taken from the examination of the traditional dwelling and by listening to the community. 


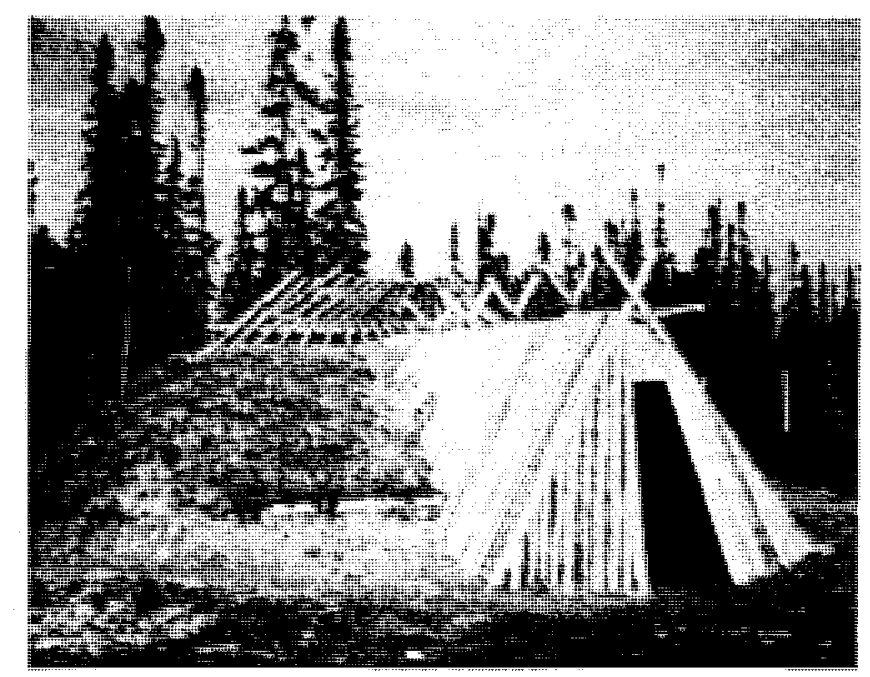

Fig.32. Replication of Traditional Astiyookamak structure . Accessed from Douglas Cardinal Architect. Inc. 2007.

Cardinal explains:

"There was a feeling of well being in this space. The walls consisted of a sloped 4 foot thick bermed dirt wall. Natural light came from the skylight directly above the fire area. Being part of the earth and of nature was overwhelming and was reinforced by the awareness that only natural materials were used. There was a feeling of being rooted, of being sheltered, of being in harmony with nature and with the natural environment."75

Cardinal developed a conceptual idea from a description of the traditional Cree structure's description Astiyookamak, which means 'moss house', described as having a ceiling that reaches 'from the sky to the earth.'

"To construct the traditional dwelling, a depression was dug into the ground, and the wooden skeleton of the house was then erected with poles. On these poles, which were exposed on the inside, were slabs of wood and moss. An opening to the sky was located over the central fire and was noted for the poles protruding through into the sky. The

74 Douglas Cardinal. http://www.library.ualberta.ca/subject/education/k12/a web access. 6.15.06

${ }^{75}$ Douglas J. Cardinal Architect Ltd. "James Bay Cree Cultural Institute, Schematic Design Proposal". OujéBougoumou Village. Sept.16, 1992. 
doorway opened to the east. It did not incorporate any steps; rather one walked directly into the dwelling by stepping over a short barrier of earth." 76

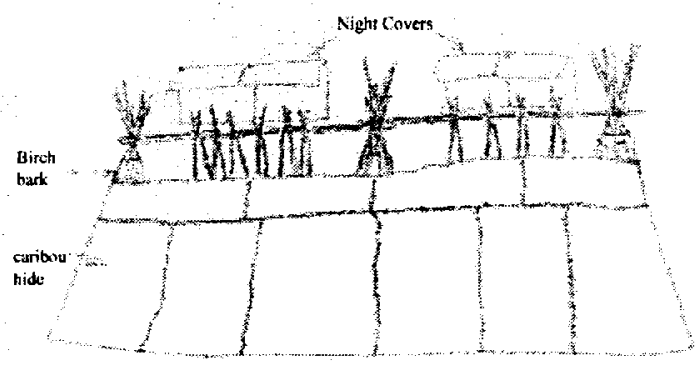

Fig.33. Traditional rendering of Astiyookamak structure . Accessed from website: http://www.ouje.ca/ 2007

The proposal's objective was to connect to the past by acknowledging Cree history while responding to the future with an environmental agenda. What was subtly different from other 'green' and modern designs was that the energy performance was not an accentuated leading-edge technologically driven feature. The design approach was orientated towards a more humanistic and holistic content that combined the design with culturally historical measures. In this manner, Cardinal used contemporary architecture to comment on the architecture of the past.

Traces of the traditional vernacular structure is evident in the design of all the buildings at Oujé Bougoumou. One example is the Cree Culture Institute. Centrally located, this building is a multi-purpose, two-storey, 48,000 square-foot structure. The building's program consists of a modern lounge, restaurant and exhibition area, visitor services, and a 300-seat theatre. Cardinal proposed a series of integrated environmentally sensitive strategies for his design. The most important of these were (1) focusing on the buildings' form, (2) the use of natural materials, (3) natural sources of light and ventilation; and (4) the use of clean renewable energy. It was constructed using a natural wood post and beam system and was reinforced with a steel-framed inner base.

\footnotetext{
${ }^{76}$ Nabakov, Peter. "Native American Architecture: Preserving Social Religious Life", Four Winds, Vol.1,
} 
The building's sloped roofs and high ceilings allowed for an abundance of windows and skylights, imparting an

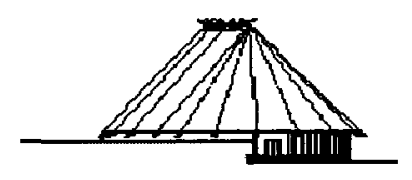
interior feeling of spaciousness, airiness and brightness.

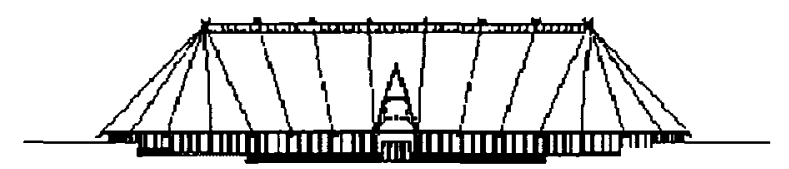

Fig.34 Cree Cultural Institute Elevation Drawing. Ouje Bougoumou. Info. By Douglas Cardinal Architect Inc. 2007.

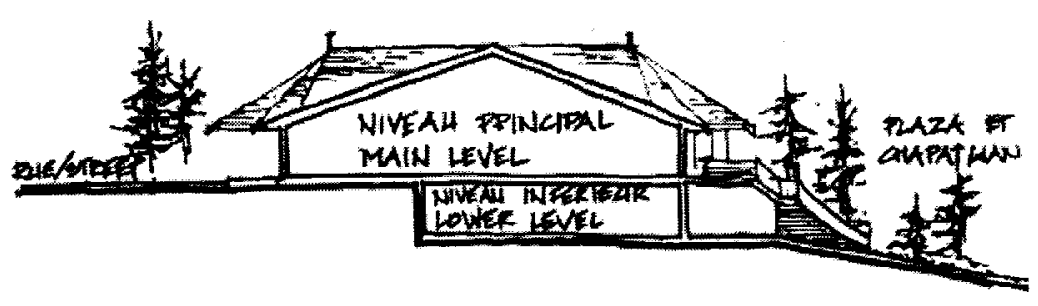

Fig.35 Cree Cultural Institute Section Drawing. Ouje Bougoumou. Info. By Douglas Cardinal Architect Inc. 2007.

Cardinal comments:

"Every dwelling had a large bay window, exposed beams and skylights, and all doors faced east reminiscent to the dwellings of their ancestors. To emphasize the gathering spaces, traditional conical shapes were used. The village development was therefore a clustering of traditional forms in a circular pattern with single storey structures relating to the ground."77

No.5.( Spring -Winter, 1981). p.43-47.

${ }^{77}$ Douglas J. Cardinal Architect Ltd. "James Bay Cree Cultural Institute, Schematic Design Proposal". OujéBougoumou Village. Sept.16, 1992. 


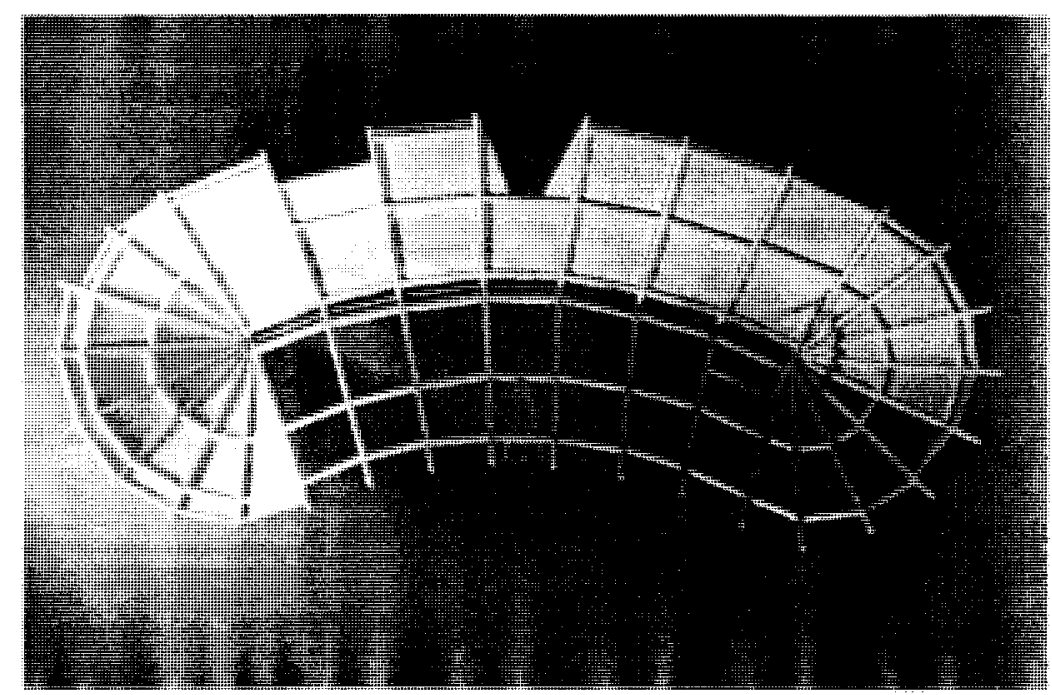

Fig.36 Cree Cultural Institute model. Top elevation. Ouje Bougoumou. Info. By Douglas Cardinal Architect Inc. 2007.

The skylight provided an effective use of natural ventilation. Fresh air was drawn in from a vent duct located on the west side and distributed throughout the building without consuming much energy.

Through consideration of traditional native ideologies of the site, Douglas Cardinal successfully infused new design strategies with a unique sense of cultural connection. Therefore, when it comes to environmental design, technology should not become the prevailing factor. There are alternative ways to design new environments holistically, as we shall see in the next case study. 


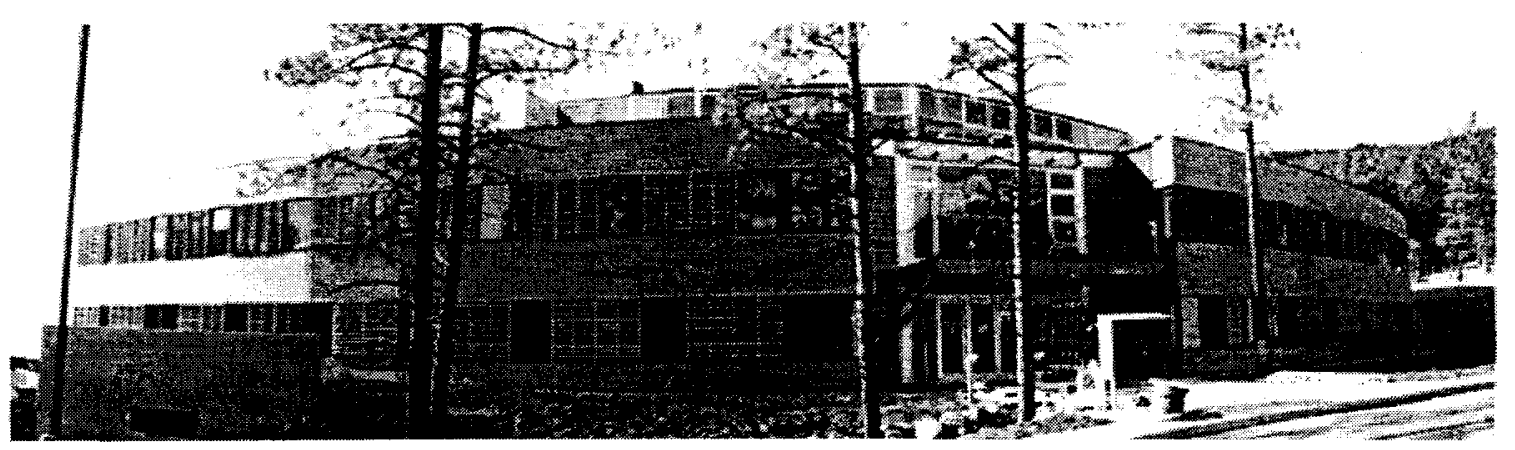

Fig.37. The Nicola Valley Institute of Technology: front elevation. 2007. Canadian Architect, Aug. 2002. p.16.

\section{The Nicola Valley Institute of Technology - Merritt, British Colombia}

The Nicola Valley Institute of Technology is designed to function as a fully integrated environmentally sensitive project that uses sophisticated energy state-of-the-art equipment and control systems to optimize performance.

The building has won numerous design awards, including those noted below:

-2002 Vancouver Regional Construction Association Awards of Excellence, General Contractors Award of Merit

-2002 The Wood Design Awards, Citation Award

-2002 Lieutenant Governor of BC, Medal for Excellence

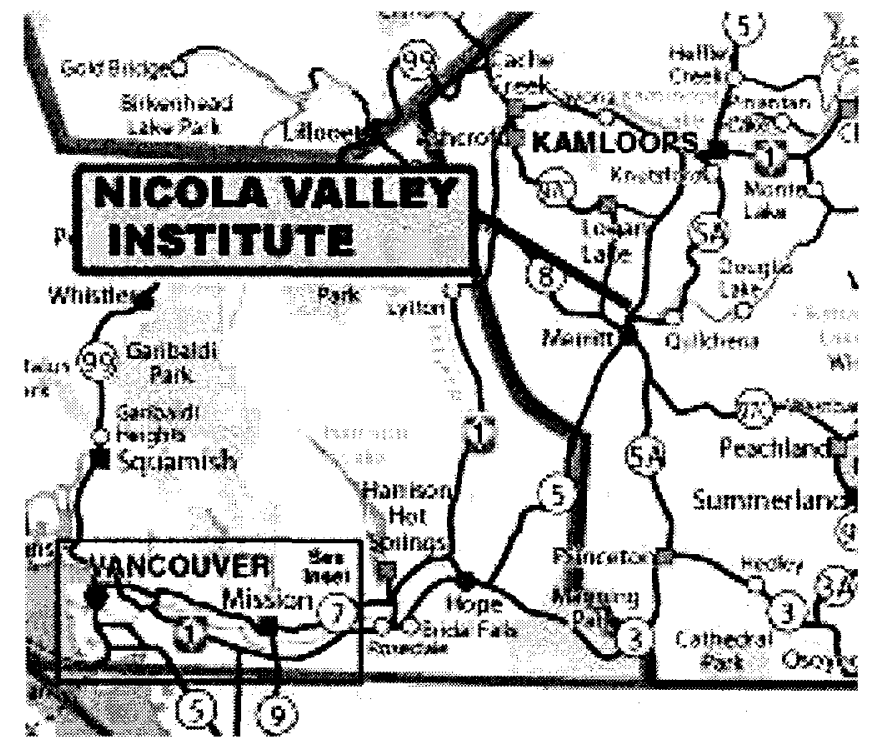

-2002 International Green Building Challenge

Fig.38 Nicola Valley Institute site location

www.mapquest.com. 2007 
It was designed by Busby + Associates Architect's from Vancouver British Colombia and was constructed in 2000 . This 45,182 sq.m First Nations learning facility, called The Nicola Valley Institute of Technology, is the first phase of a 43 -acre academic campus.

This building was designed to reflect the characteristics of the native culture, while respecting and responding to the natural environment through a sustainable design solution. The building is connected to its landscape, and is technologically advanced, though regional, in character. Located on the outskirts of Merritt, British Columbia, the new building shares the site with the existing College of the Caribou. Following First Nations ideals, the architecture draws heavily on traditional forms and building techniques while respecting and responding to the natural environment. The result, is a building that functions as a gathering and learning space, reflecting native themes and ideologies through a modern sustainable vernacular.

Busby + Associates Architects consulted extensively with the community members in order to address the needs of the modern academic institution. The project design philosophy stressed the importance of maintaining the relationship between man, nature and the community, while acknowledging the significant features of the site and the cultural heritage of the people.

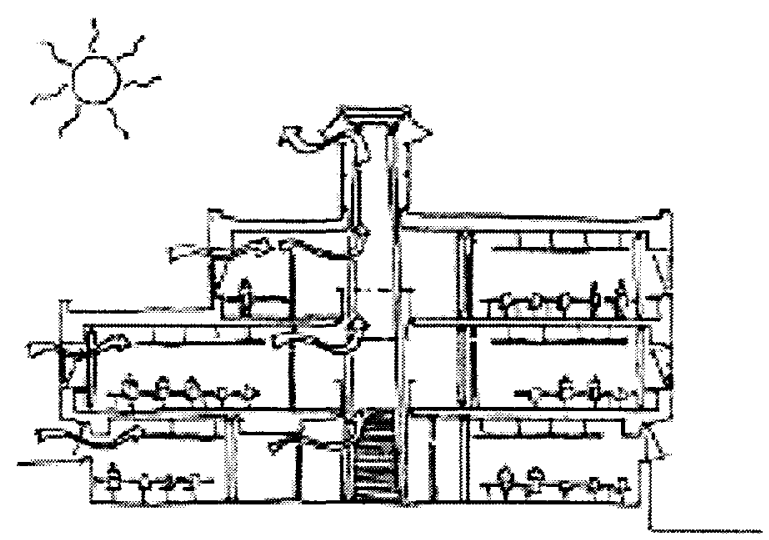

Natural Ventilation: user operated and sensored motorized operable windows in the ventilation atrium reduce cooling loods during spring and fall.

Fig.39. Ventilation -Section detail. Canadian Architect. Aug. 2002.pg.18

"The Nicola Valley experiences hot, dry summers and moderately cold winters. In response to these conditions, the institute has been designed as a cold climate green building, with a strong commitment to environmental sustainability and the integration of new technologies." 78

${ }^{78}$ Taggart, Jim, “Modern Vernacular." Canadian Architect. Vol. 47 no.8 (August 2002). Jim Taggart p.18. 


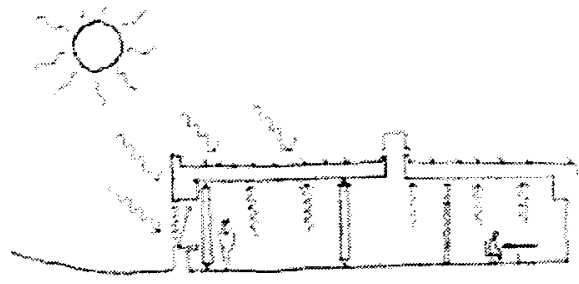

THERMal Mass: heat sink during the day.

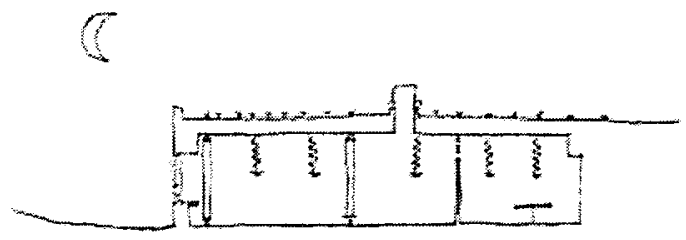

THERMAL Mass: night time flushing of stored heat.

Fig.40. Thermal mass details for day \& night temp. Canadian Architect. Aug. 2002.pg.18

Native historical vernacular structures and environmental principles were assessed for design inspiration. The concept came from two examples: (1) the tepee form, a simple and efficient ventilation structure that promoted cooling by convection in the summer months; and (2) the pit house, a south-facing, earth-sheltered structure that minimized heat loss in the winter months. By incorporating both of these functional systems into its overall environmental strategy, the new building exploits environmental principles without replicating the conical form of the tepee or the domed shape of the pit house.

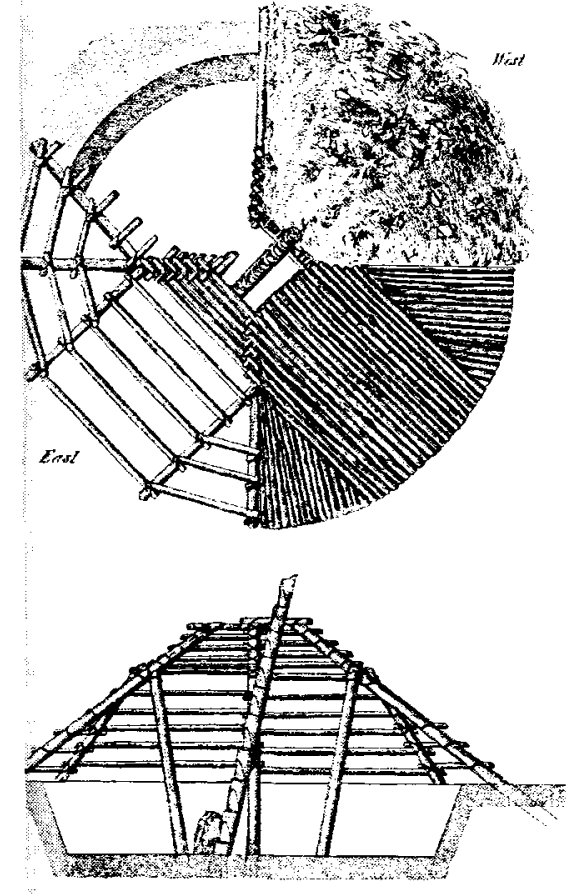

Fig.41. Native American Architecture Traditional pit house architecture ca. 1900. Native American Architecture.p. 177

"The inner strip of the semicircular rooftop is planted, reinforcing the sense that the building has grown out of the landscape and supporting the minimization of disruption to the surrounding area. In addition, tensioned fabric is used in the ventilation stack for shading; a reference to stretched skins in traditional aboriginal design, this technique is also used for the front entrance canopy. "79

\footnotetext{
${ }^{79}$ Sustainability Now: http://www.sustainability.ca/Docs/Busby-NicolaValleylnst.pdf
} 
Environmental considerations influenced the site design, construction process, the selection of materials, and the selection of systems for water and energy conservation. Siting was carefully planned in order to minimize impact on the forest as well as to be integrated with the landscape.

Water efficiency required a planted roof system. Energy and atmospheric principles applied to this roof system reduced heating and cooling loads. The exterior wall systems stored thermal mass in the winter and maintained cool interior temperatures in the summer months. Under ideal conditions, mechanical economizers were used to draw fresh outdoor air for ventilation. Solar control strategies and sliding cedar sunshades, were used to control the amount of sunlight that is admitted to the building.

Material choices and resources to minimize consumption, resulted in the selection of Eco-smart fly-ash concrete in order to reduce potential emissions, yellow cedar for its durability, facetted glue laminate wood columns for economy and strength and sustainable methods as a potential renewable resource of assembly. Indoor environmental quality control principles incorporated natural ventilation by using operable windows, relief grills between rooms and censor motorized windows in the atrium. Additionally, the building's orientation on the site accentuates the cardinal points of the compass, an east-facing main entrance and a non-hierarchical arrangement of functional spaces within the building. According to project architect Alfred Waugh,

"The project responds to the building forms of local aboriginal culture. It does so with thorough planning leading to creative engineering and use of materials, and low energy consumption over the life of the building. "80 


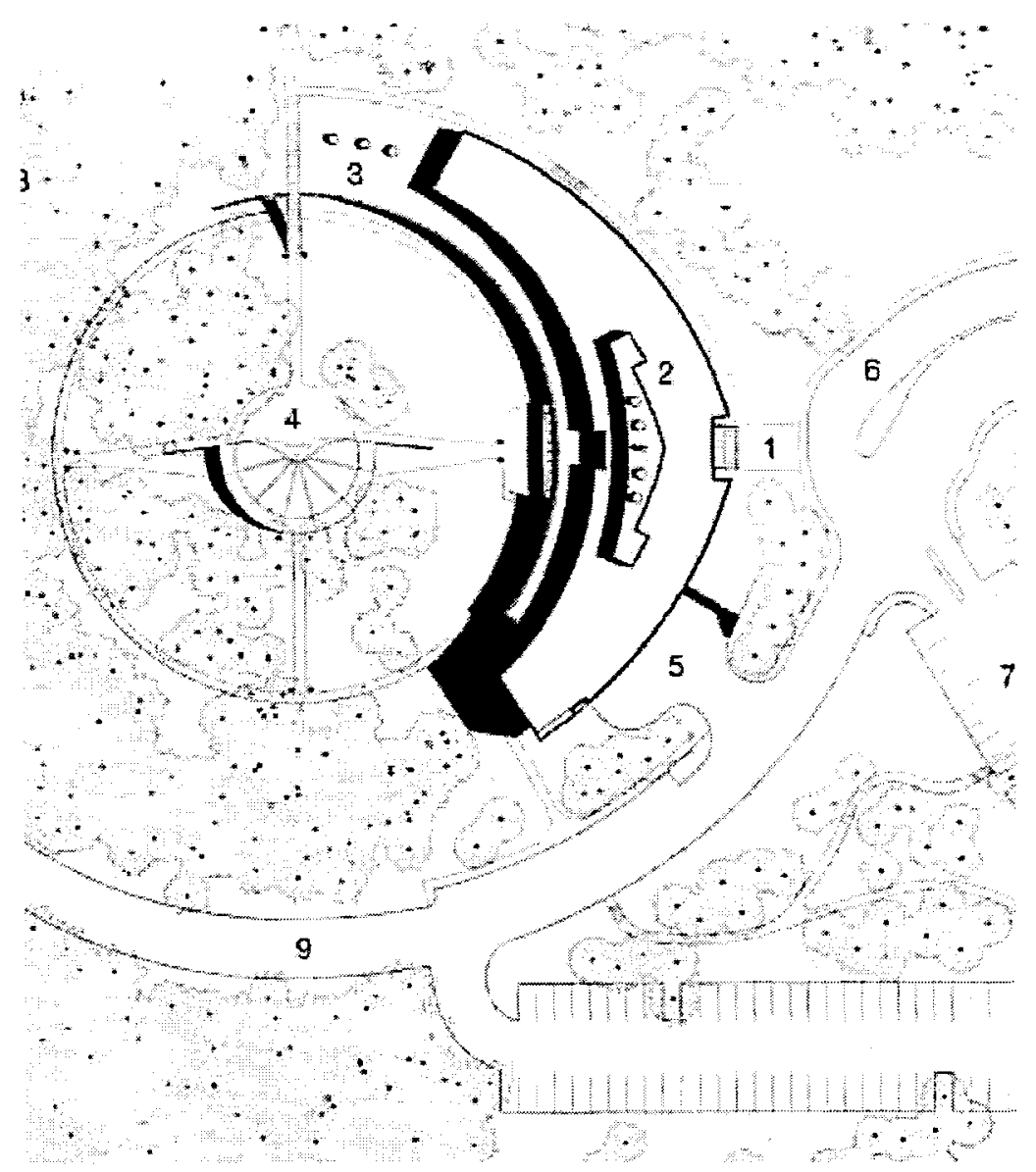

Fig. 42. Site plan layout. Canadian Architect. Aug. 2002.pg.18

1. Entry plaza

2. Ventilation atrium

3. Planted Roof

4. Future ceremonial arbor

5. Loading dock

6. Drop-off

7. Parking

8. Forest

9. Future access road.

${ }^{80}$ Taggart, Jim. "Modern Vernacular." Canadian Architect. Volume 47 no.8 August 2002.p.18. 


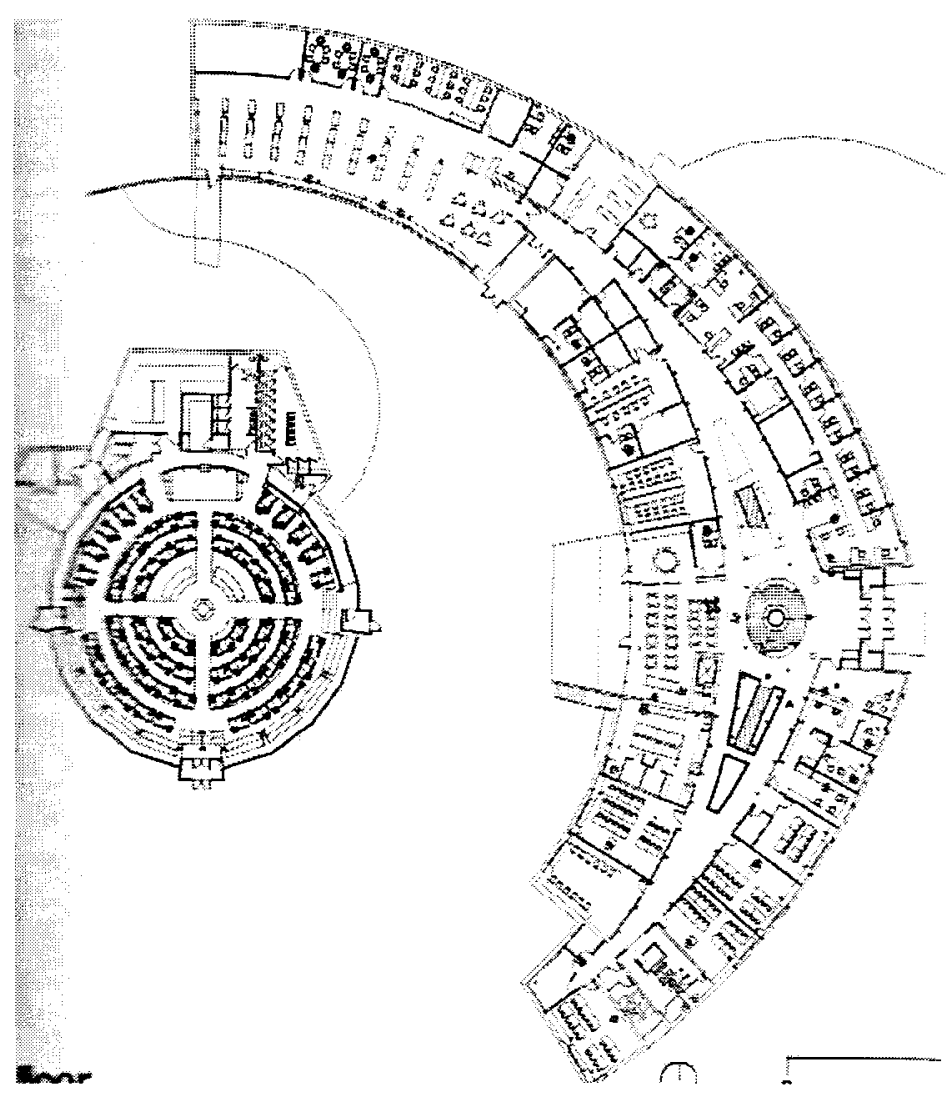

Fig.43. Main floor plan. Canadian

Architect. Aug. 2002.pg.18

Expanding on the above commentary, the primary construction materials were selected based on local availability, environmental qualities and structural capabilities.

"More than 50\% of the material for the structure and envelope of the building being sources from the local region." 81

These materials consisted of concrete for the floor slabs and retaining walls, the selection of wood glue-lam columns that "visually represented the pit house poles rising up through the interior space., 82

\footnotetext{
${ }^{81}$ Sustainability Now: http://www.sustainability.ca/Docs/Busby-NicolaValleyInst.pdf.
}

${ }^{82}$ Sustainability Now: http://www.sustainability.ca/Docs/Busby-NicolaValleyInst.pdf 
Yellow cedar was chosen as a wood of natural abundance and was used on the exterior skin of the façade as a horizontal rain screen band.

"The rain screen acted to shelter the inner materiality and insulation of the building by providing a screen that filtered the rain, allowing it to drip down the skin and exit the building. And with time the cedar will age to a silver grey colour." 83

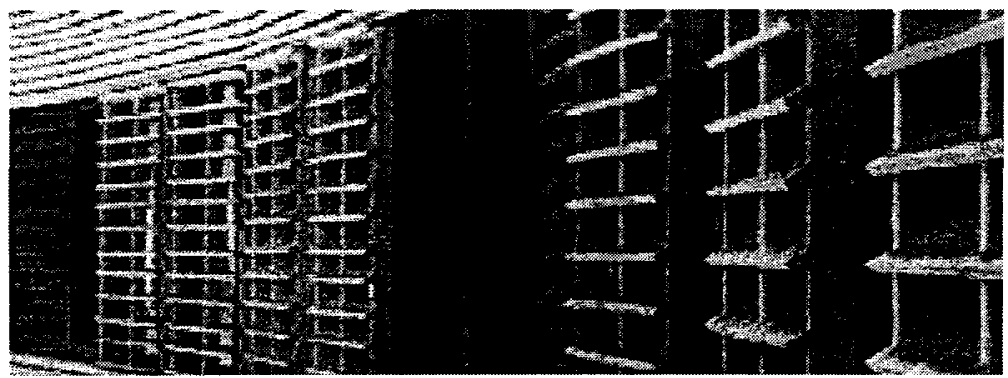

Fig.44 Screen façade detail. Canadian Architect. Aug. 2002.pg.19

The Nicola Valley Institute associates with its landscape, reflecting its place amidst the natural environment and its origins through its modern vernacular, materiality, form and expression.
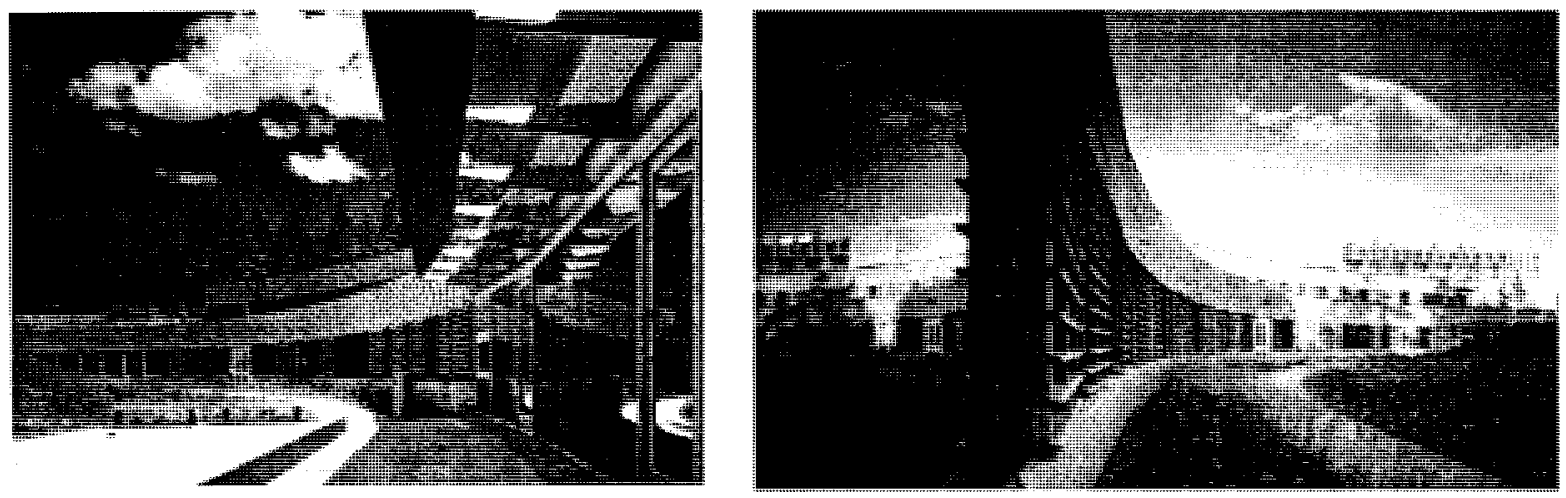

Fig.45 Exterior detail. Canadian Architect. Aug. 2002.pg. 17 Fig. 46. Exterior detail . Canadian Architect. Aug. 2002.pg. 17

\footnotetext{
${ }^{83}$ Sustainability Now: http://www.sustainability.ca/Docs/Busby-NicolaValleylnst.pdf.
} 
In conclusion, the strategies employed in the two featured case studies include considered opportunities that successfully incorporating traditional and contemporary First Nations cultural ideals and natural elements within the building's design. The relationship between 'the old way' and 'a new way' of producing a vernacularly sensitive architecture is a complicated negotiation to achieve with in design. To be harmonious and consistent with older designs does not necessarily mean that new architecture has to be traditional. At the same time however, the new buildings should not be disrespectfully confrontational.

The history of architecture covers all aspects of the built environment, from progress in construction methods and use of materials, to the emergence of popular styles and trends and the historic contribution of individual architects to the advancement of architecture. It is a gradual process where by each new generation bases new ideas on old ones, with some elements added and some eliminated. Even if the forms are different, the basic tectonic rules are the same. Architectural designs and ideas, although evolving from one generation to the next, offer some degree of consistency in scale, height, material, texture, and ornamentation. In addition, and just as important, architects should use a different, but equally relevant strategy towards incorporating traditional elements, while retaining a sense of contemporary methods. The quest for an ecological understanding and approach in all of man's endeavors and activities has become a challenge to all who care about nature and a more healthy, sustainable earth. It is a call that should be answered by all professional disciplines, because one un-ecological activity can prove disastrous to the efforts of so many. Since architecture contributes to the making of the built environment, ecologically sustainable measures should be employed as one of the vital tools of the architect and is a key element in architectural design. Designing and building in harmony with nature is the one concept that works towards integrating the elements of balance between the built environment and nature. 


\section{The Project}

The Native American culture resides among the past, present and future ideals. Their built forms need to represent these links as distinctive elements in their identity. This project seeks to design an environmental learning facility intended to provide a sense of place for its people.

The design proposal incorporates methods by which the surrounding community and the general public can experience cultural activities within the program area's interior and exterior. Rooted in sustainability and regionalism, the building is designed in accordance with the local vernacular, new technologies, and the use of natural forms, materials, and elements of architectural expressions.

The building's functional program addresses environmental and inherent Native American philosophical concerns. In addition, experiential and visual features are developed that enable the architecture to act as a communicative space between man and the natural environment and thus reflecting the community's identity. 


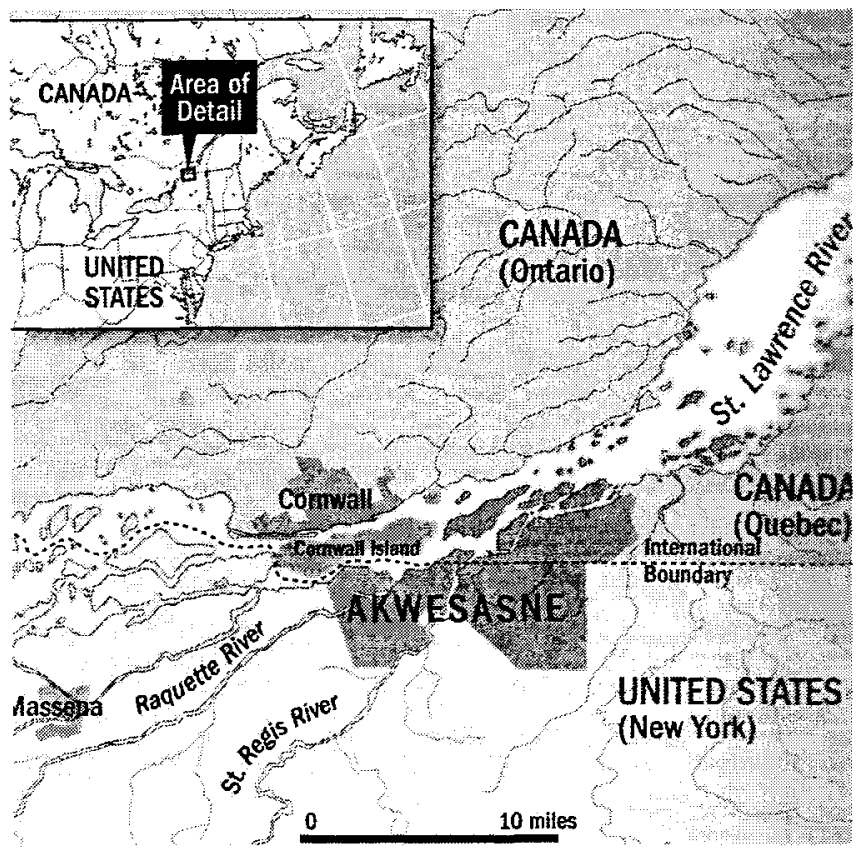

Fig.47. Site Map locating the Akwesasne Mohawk Reservation.

www.akwesasne.ca,2007.

The Site:

The site in question is located on a First Nations reserve called Akwesasne. This community can trace its history to the early Iroquoians of the St. Lawrence River and Great Lakes Basin. The Territory of Akwesasne is approximately 26,000 acres in area with a population of 13,000 . It is an international community, straddling the border between Canada and the United States, two countries in the Canadian Provinces of Ontario and Quebec and the State of New York in the United States. Akwesasne is a rural community comprised of four residential districts: the St. Regis Village, the Chenail (Snye) Districts in Quebec, Cornwall Island in Ontario and the town of Hogansburg in New York State. Governed by three Native government bodies representing the Canadian and the United States, the area has a very complex legal situation. However, despite the uniqueness of this multi-jurisdictional situation, the residents have amalgamated themselves into one community. Over the years, dynamic changes have provided this Mohawk community the opportunity to become self-sufficient and to manage its built environment. It is committed to honoring its community heritage and establishing the foundation for a prosperous, secure and self-sustainable future. Based on thousands of years of history, this community strives to retain and preserve its land and culture for future generations. 


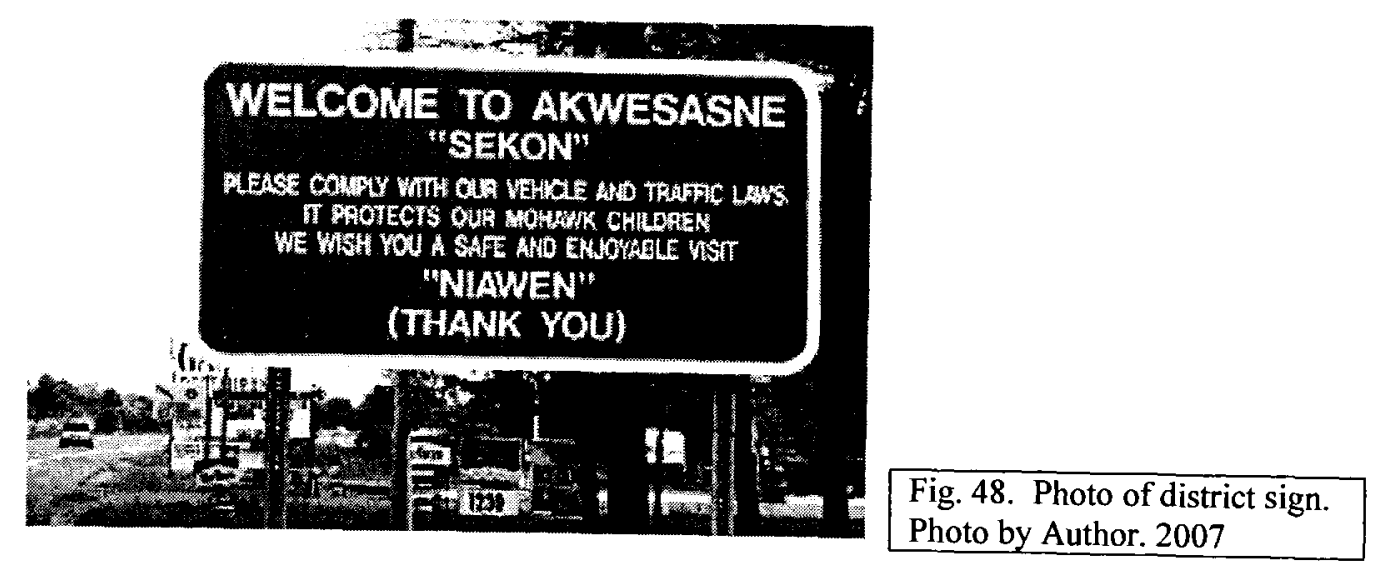

I have chosen the district of Cornwall Island Ontario, as the principle location for this project. The three-acre waterfront property shares its territory with an existing arena located to the south of the property. Adjacent to the site, across the St. Lawrence River and nestled in the eastern most part of the province of Ontario is the city of Cornwall and the Seaway Valley region.

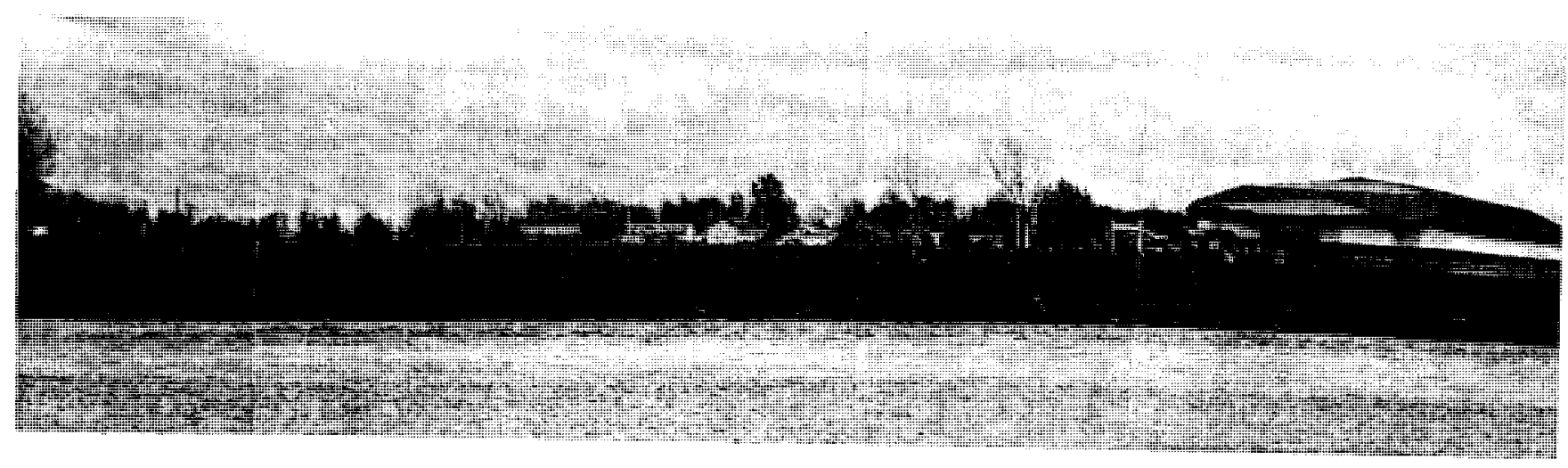

Fig. 49 Proposed site location on Cornwall Island, Ontario. Akwesasne. Photo by author.2007 
AKWESASNE AND VICINITY

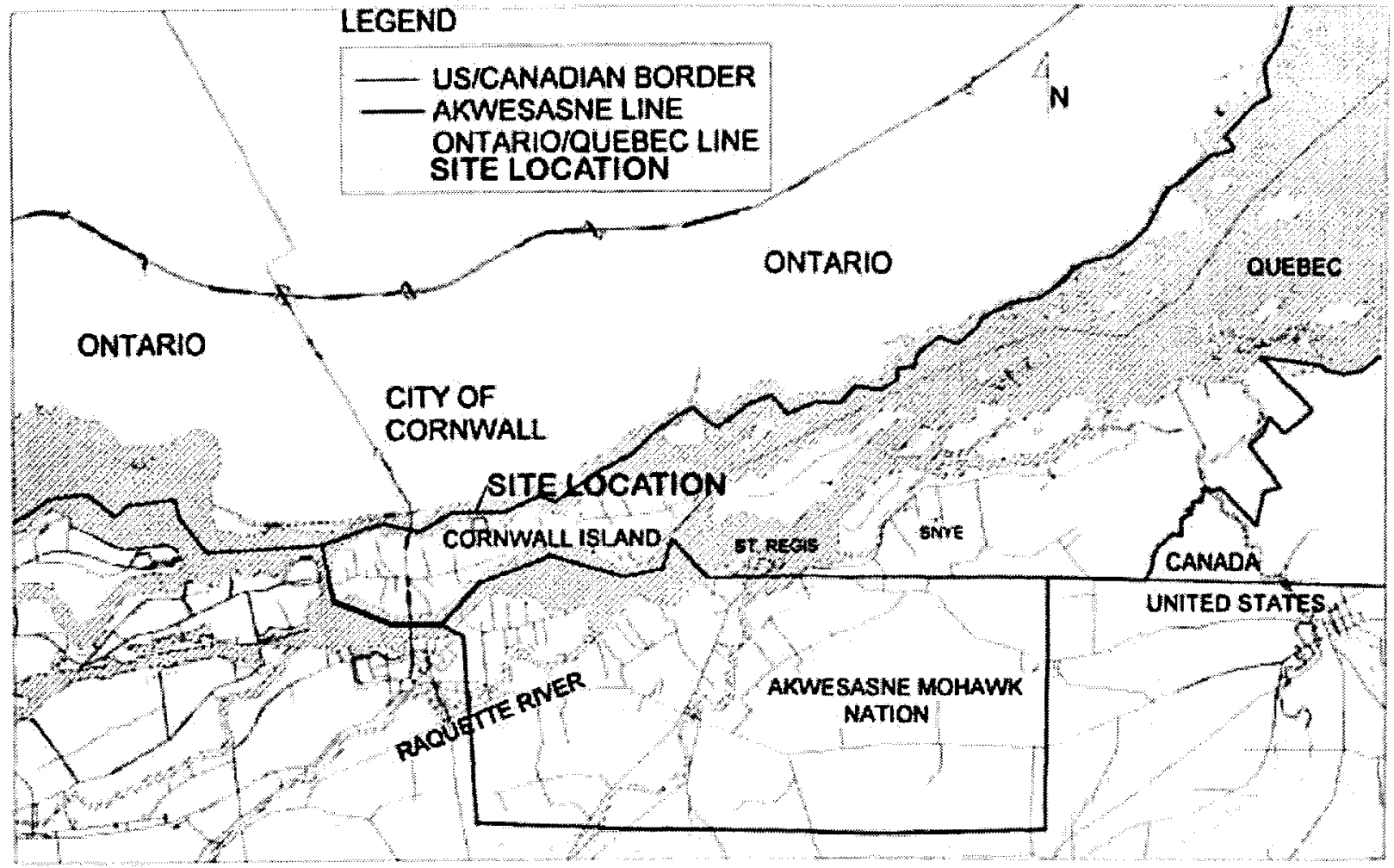

Fig.50. Aerial Map. www.akwesasne.ca, indicating site location. 2006

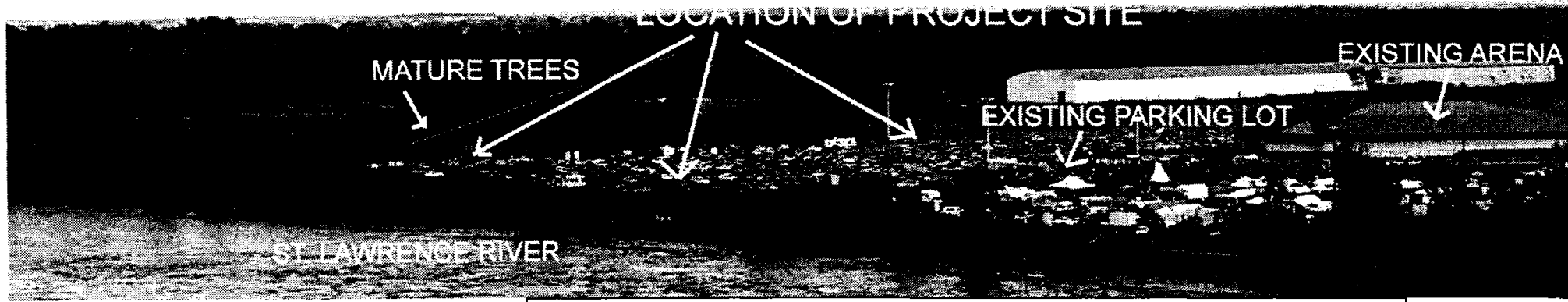

Fig.51. Location of Project - Looking in south-east direction. Photo by Author 2007 

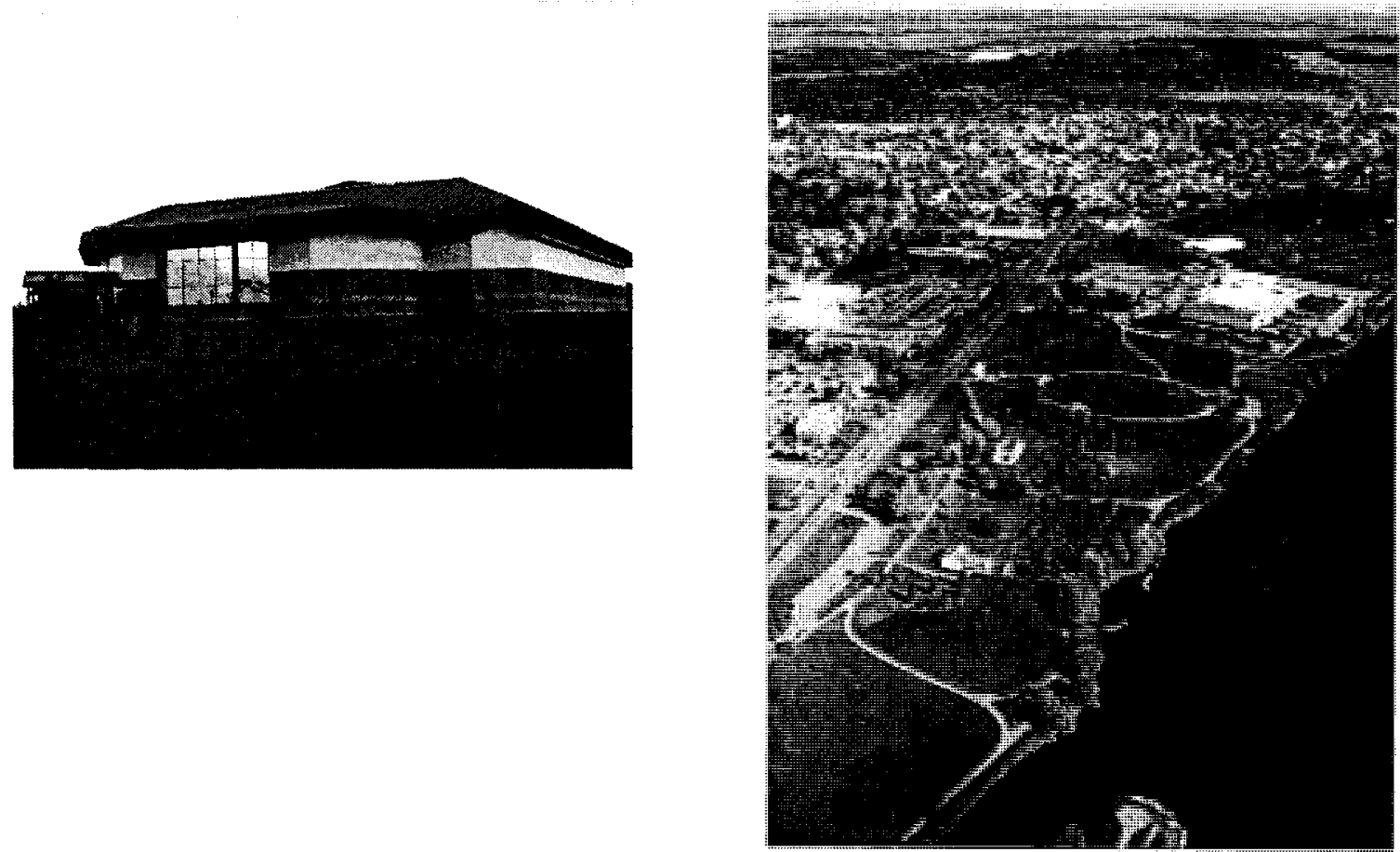

\begin{tabular}{lll|l}
\hline Fig.52 Akwesasne Arena located on west side of & Fig.53. Aerial view of the city of Cornwall, Ontario.
\end{tabular} property. Photo by Author. 2006 www.cornwall.ca. 2007

Fig.54. Aerial photo of project site. www.GoogleEarth. 2007

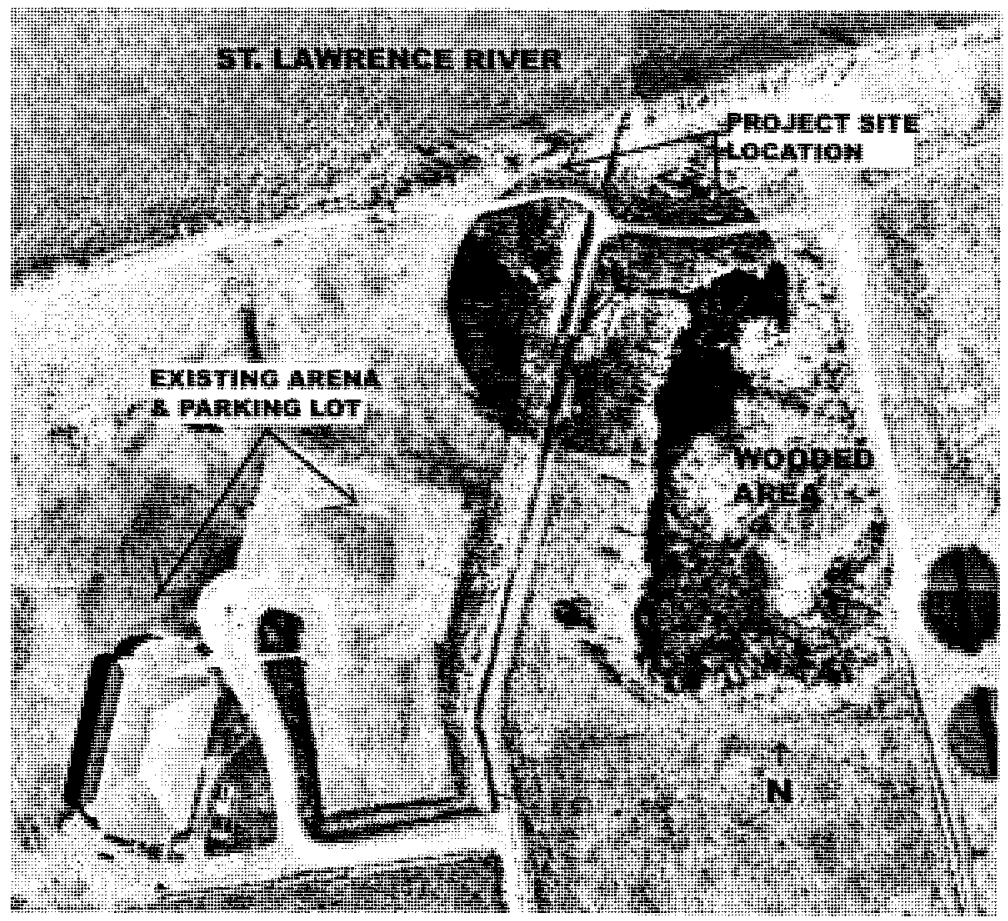




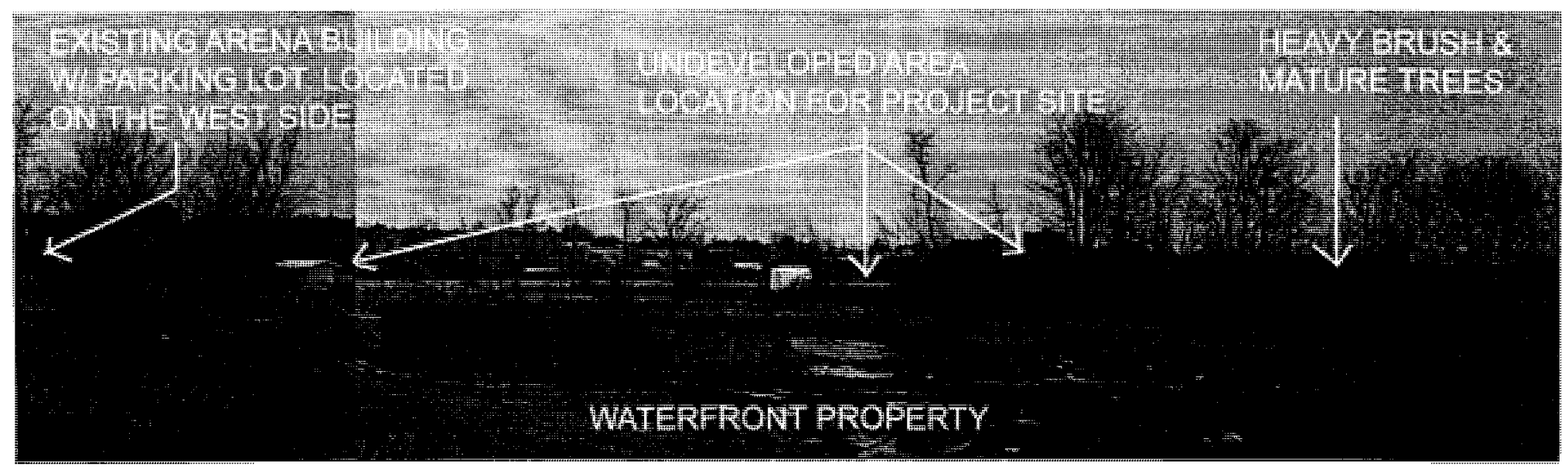

Fig.55. Location of Project site. Looking in north direction. (undeveloped area) Photo by Author 2007

The region is relatively flat with diverse areas of dense forests, marshes and agricultural vegetation. The site is accessed by a system of international bridges, highways and waterways crossing the St. Lawrence River and connecting the mainland with several of the islands.

The St. Lawrence River serves as one of the natural dividing lines between Canada and the United States. According to the history of the site, people were primarily farmers, relying on the river for food, medicines, commerce, trade and recreation. When the St. Lawrence Seaway power dam was introduced upstream from the reservation, it attracted additional industries to the American side, including the General Motors Corporation, Reynolds Metal and the Aluminum Company of America (ALCOA); and Domtar Paper Inc. on the Canadian side.

Several years later, the consequences of having industrial neighbors became evident as the quality of wildlife, vegetation and waterways were environmentally damaged. The effects on aquatic organisms, fish, and livestock, traditional sources of Native American food and livelihood, forced a dramatic change in lifestyles and traditions. 
By 1987, the community became aware of the environmental degradation occurring within the region. To help protect and repair the surrounding natural environment, several environmental programs were established within the vicinity of the community: the St. Regis Mohawk Tribe's Environment Division, the Mohawk Council of Akwesasne's Environment Division, the Akwesasne Task Force on the Environment, the First Environment Research Project, the First Environment Communication Project, and the E.A.G.L.E. Project (Effects in Aboriginals from the Great Lakes Environment, -studies on environmental contaminants in wildlife) These environmental agencies addressed environmental pollution cleanup, natural resource protection and solid-waste control.

Situating the building on waterfront property in the heart of the natural landscape provides an opportunity to showcase the region's accomplishments, celebrating environmental renewal and educating the public about the rich and diverse historical, cultural, and ecologically-sensitive knowledge that the community treasures. The design of the educational centre will include maintaining itself in balance and harmony with the natural environment while serving as a valued contribution to the communities' identity and future.

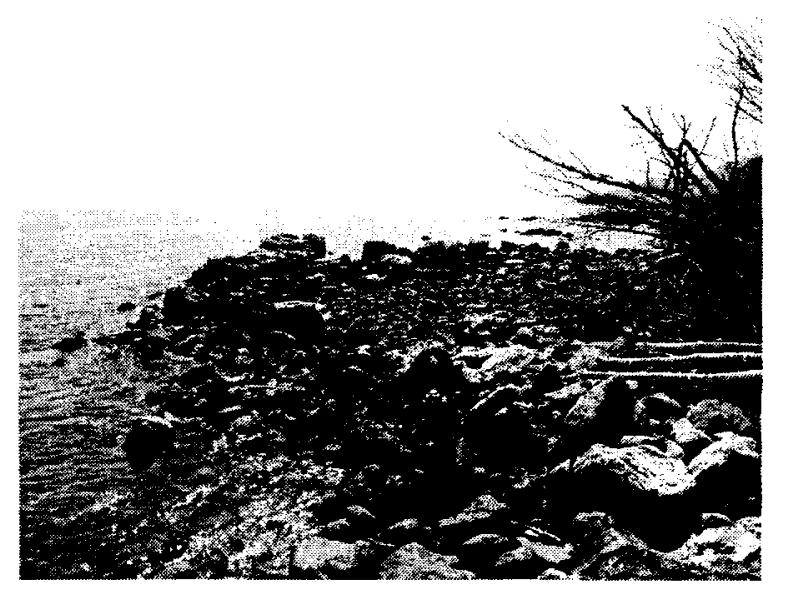

Fig.56. River bank at project site. Photo by Author. 2007

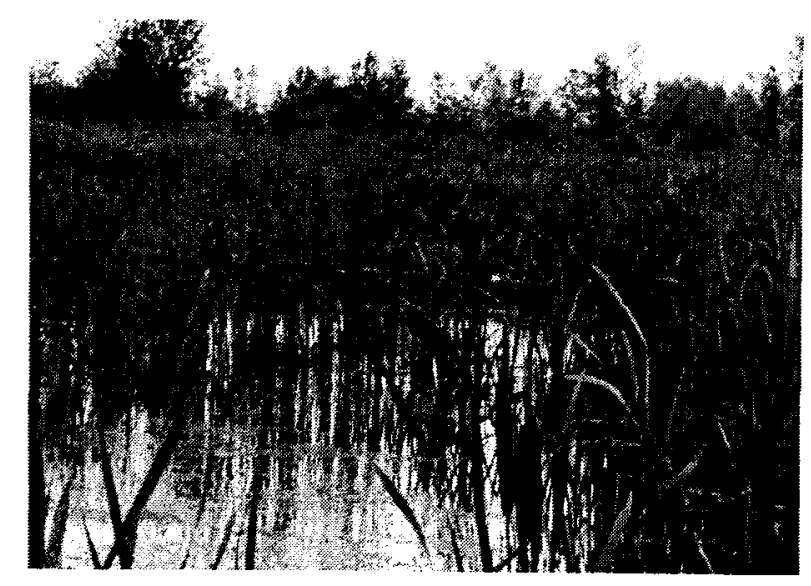

Fig.57. Marshland located east of project site. Photo by Author. 2007 
Previously, the identity of First Nations communities was disrupted and displaced as the Canadian and American governments initiated various programs, which resulted in the construction of universal building types and restrictive building guidelines ignoring the inherent diversity and identity for each First Nation's community. The buildings were identical in appearance, unrepresentative of any regional tradition or culture. Bill Woodworth, an architect and Native American traditionalist expressed concerns regarding appropriate design specific to native culture: "There is a profound overlook of cultural traditions and patterns that are inherent in native development. What I see is the imposition of European architecture and planning forms that don't fit in this landscape, they are out of step with the native traditions. In my experience ugly cities, bad design and plans come from confusion, imposition of foreign perspectives and ideas that are rootless and not place orientated." 84

It is apparent today that most reservations are composed of a bare minimum of buildings exhibiting very few advances in new building development. The allocation of funds to First Nations is developed through the Indian and Northern Affairs Canada (INAC) and funding for the tribal governments in the United States comes from a variety of sources including grants, taxable income from a tribal levy and casino profits. Funding is influenced by factors such as geographic location, distance from major population centres and local climatic condition.

However, most communities encompass a collection of houses, a church, a school, a band council, and a community hall. The sense of community is inhibited by this design. Houses comprise the principal fabric of a "typical" reservation as determined by government initiatives. This fabric is dominated by single detached homes -- repetitive, spatially isolated, set in a rural environment--- or by misrepresented new buildings designed without proper knowledge or input from its community. The native people have expressed their concern regarding the loss of ancestral languages, religious traditions, and architecture as connections to the pre-reservation generation slowly declines. The lack of connection to a historically strong culture has generated a disconnection resulting from the government planning initiatives discussed above.

\footnotetext{
${ }^{84}$ Peters, John. "Aboriginal Perspective on Planning in Canada -Decolonizing the Process: A discussion with Four Aboriginal Practitioners". Plan Canada vol3 no.2, 2003. p.23-41
} 

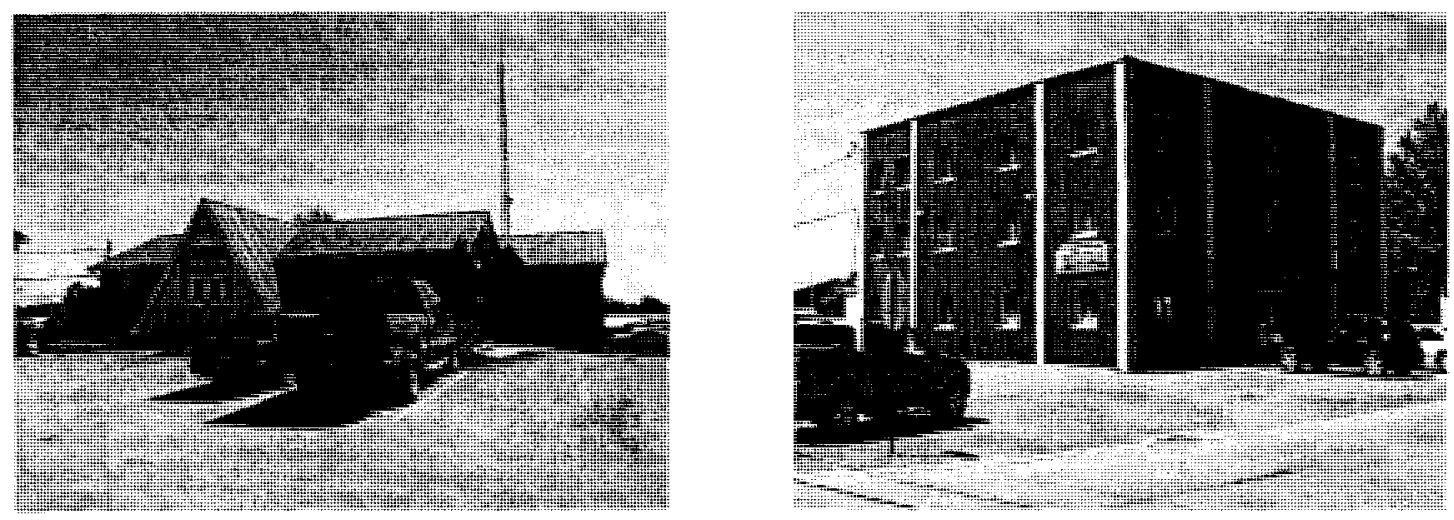

Fig.58 \&59. Administration Building (Left) \& Justice building (Right) located on the Akwesasne reserve. These buildings do not reveal any cultural connection to site, or its community.- Built by Indian and Northern Affairs Canada in the 1960's. Photo by Author. 2007

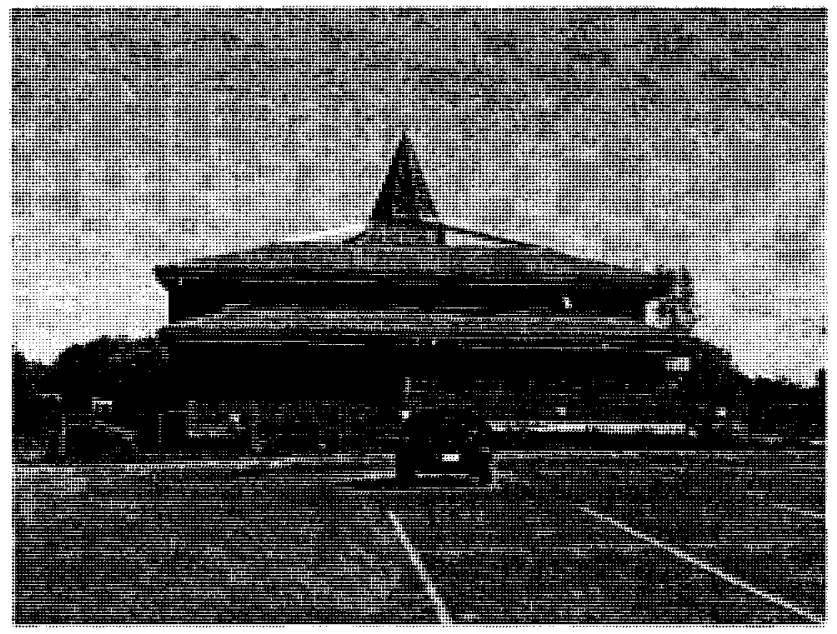

Fig.60. Health Facility built in 1992 and designed by an architectural firm. Did not consult extensively with the community: therefore there are several problematic issues with this building, including the "teepee" form skylight which does not reflect Iroquois tradition. Photo by Author. 2007

Research in the traditional structures of the Iroquoian culture led to an identified and considered organizational strategy which incorporated symbolism with the design process. This visual language of communication is a major learning and teaching tool, a language of "Stored knowledge" passed down for generations. 


\section{Design Concept: The Environmental Learning Centre}

The design of an appropriate architecture for a distinct culture must proceed with complete respect for that culture and without preconceptions derived from other cultures or landscape. Engagement with the local residents is crucial as a means of making informed decisions and testing new ideas.

After speaking with various community members about the proposed project, they were quite responsive and interested. They offered suggestions into design specifics as it related to the programmatic functions and various cultural elements that would be necessary for the success of the project. I was also reminded that certain values and beliefs were sacred within the traditional longhouse and therefore, it was forbidden to incorporate or portray these elements to the general public.

The design then developed through a series of preliminary studies aimed at gaining a better understanding of the fundamental elements of the landscape and historical cultural aspects. As a result the design incorporated spatial abstractions of Iroquois beliefs, which acknowledged the seasonal rhythms and patterns of the natural, followed with the careful review of traditional and contemporary materiality and insight into structural and formal solutions.

By means of the creation of an interactive learning atmosphere, the purpose of "The Environmental Learning Facility" is to educate and inspire the community and others about environmental responsibility, and historical cultural connections relative to the First Nation's Iroquois. The facility is a place for the community and the public to gather in celebration, through various cultural ceremonies, teachings, educational workshops and exhibits. Architectural considerations were carefully addressed, so that the visitor is able to experience and interact with their surroundings, by providing and promoting places of discovery, niches and natural features found through the interior and exterior spaces.

The Building resides as a focal point, for the community and surrounding areas. Built specific for the public to gather and belong to a place, creating a representational channel for the community for telling stories, teaching traditional knowledge, cultural preservation, and reestablishing humanity with the natural environment. 


\section{The Description: The Visitors Journey}

From the main east entrance, the visitor descends into the building and follows the cyclical orientation of the sun in a clockwise direction. At this point the visitor is located on the horizontal plane characterized as between heaven and earth.

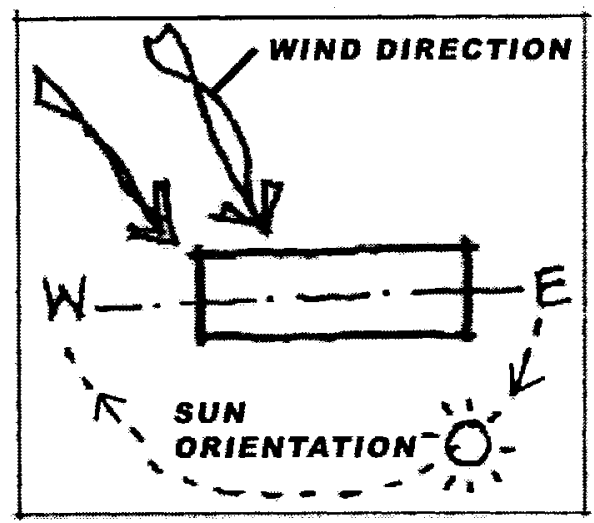

Fig.61 Sun \& wind orientation around building. Drawing by author. 2006

Illustrated panels describing the procession from the early historical ancient period through to modern times, information panels, wall murals, photos and exhibit cases enclosing cultural artifacts are found along a "pathway" transcending through various programmatic zones. The building's interior is diffused with natural light from the large clerestory windows on the south side and as one moves the window penetrations decrease on the north side, portrayed by the sunset. The building and its functional programs wrap around a large central glass encased courtyard open from below and open to the sky above. The circular courtyard transcends and blurs the boundaries between interior and exterior elements. Two large water filtration systems located on both sides of the courtyard, send rainwater from the roof to the central core water garden, which in turn descends underground and re-emerges within the landscape, funneling through streams and nourishing vegetation. The windows have operable louvers and screens in areas that receive direct sunlight that can be opened and closed. When opened, light funnels through and pierces the interior, and projects interior light to the interior, suggestive by the layering and light penetrations of the ancient longhouse dwellings. The viewer has now moved to the north side of the building to the suspended observation deck which overlooks the grounds and waterways of the St. Lawrence River. The observation deck is the main exhibit that holds permanent artifacts and affiliated information about the community. The viewer then proceeds and meets back to the east side. There are three 
options to descending to the next level, the elevator, circular stairs or the ramp which are all located in this area, and all still assemble in the clockwise direction. From the lower level, the landscape encases the building, and the viewer begins to experience the natural characteristics developed with the earth's texture, natural light, natural sounds and smell of the surrounding environment. (Flowers, plant life,) The central exterior courtyard is recessed in the ground and along its perimeter there are stepped seating areas where people can gather. It is at this central position that traditional teachings are recited to the listener. The Orator and Faithkeeper will initiate a purification ceremony, burning sacred tobacco and sweetgrass giving thanks and reinforcing the bond with earth's resources. It is at this location where the Orator and Faithkeeper account humanity's position with the universe, as being between the horizontal plane and situated along the vertical axis connecting the earth and sky. This location is the central gathering area, which Christian Norberg Shultz explains, The development of Schemata, that includes certain externalized centers, as points of reference in the environment. 85

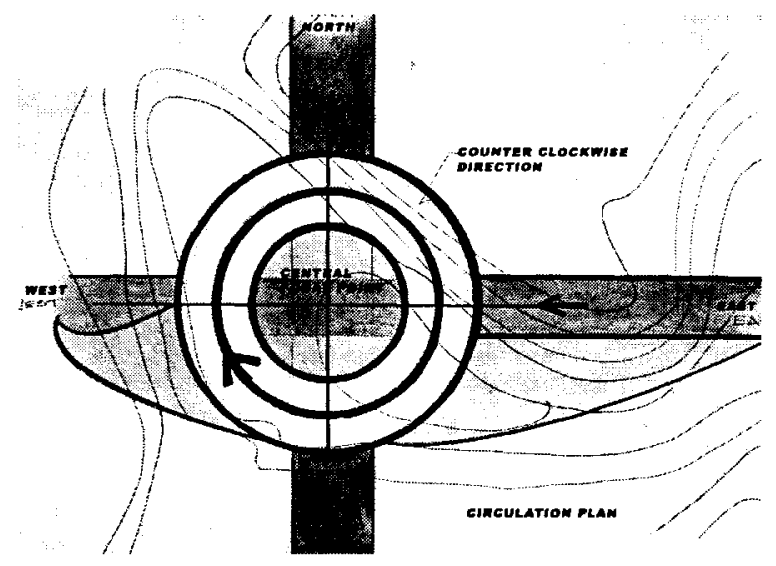

Fig.62 Circulation pattern through building. Drawing by author. 2008

The interior and exterior is linked by this central location combined with the building's program functions. The visitor has the option to proceed in four directions; the north direction connects to the riverbank and wind observatory, the east direction sends the visitor back to the main entrance, the south direction where light penetrates the interior, and to the west where the visitor travels through the building's interior and surfaces between the earth's embankment up to the horizontal plane.

\footnotetext{
${ }^{85}$ Norberg Schulz, Christian. "Existence, Space, and Architecture". Praeger Publishers. 1971.P.21.
} 
Earlier in the chapters, Author Douglas Kelbaugh provided six architectural features that supported and defined characteristics for a particular region. These features have been implemented to describe the project's intent.

\section{The Sense of Place:}

In meeting the needs of the community, development must be designed and built with an awareness of the local interrelationships between natural, cultural, social, and economic resources for its surrounding and immediate environment. The inspirational ideal is to imagine a building that has grown in place in intimate interaction with its surroundings, and with the deep roots in the accumulated wisdom of the local culture and its vernacular. This implied a spectrum of specific design approaches for the site. These ranged from the particular knowledge of the place, its local materials and building traditions, and drawing on the personal experiences and feedback from the community in which the building was designed for.

The environment provides an important sense of place for the Iroquois, both for historical and cultural reasons. The effect of natural resources is important when it comes to the optimal habitats for various traditional Iroquois plants (medicinal plants, traditional sweetgrass and tobacco). The project proposed planetariums inside and out, marshlands and water gardens that promoted specific plant life, protected and preserved for cultural continuity. In addition, natural vegetation, and marsh-lands grow undisturbed, streams and ponds flow through the building and site. Extensive use of local natural materials, new native vegetation planting areas, new growth forests, traditional agricultural fields and fish plantations are some areas where the public is able to interact with the site.

The climate in this location is marked by four distinct seasons, with extreme variations between long cold winters and hot humid summers. The annual cycle moves rapidly from the interminable damp cold of late winter, shifting abruptly to summer conditions.

This site-specific ecological analysis is part of the sustainable design awareness for the intended project. Passive solar design is a simple design and natural form of energy. The 
orientation of the building runs east and west and window penetrations are located in areas that take advantage of the solar movements of the sun.

The use of local materials contributes to a distinctive environmental and cultural characteristic. Sensitively placing the building on the site aids in its correspondence with the surrounding context. In environmental terms, the intersection between the physical site and the cultural place differentiation opens up the possibility of using the old in new ways.

\section{Sense of Nature:}

What makes a material natural? According to the encyclopedia Wikipedia it states that, "A natural material is any product or physical matter that comes from plants, animals, or the ground. Minerals and the metals that can be extracted from them (without further modification) are also considered to belong into this category. ${ }^{86}$

In addition the term "nature", in the broadest sense, is defined as being "equivalent to the natural world, physical universe, material world or material universe. "Nature" refers to the phenomena of the physical world, and also to life in general. Manufactured objects and human interaction are not considered part of nature unless qualified in ways such as "human nature" or "the whole of nature"', 87

\footnotetext{
${ }^{86} \mathrm{http}: / /$ en.wikipedia.org/wiki/Natural_material

${ }^{87}$ Ibid
} 


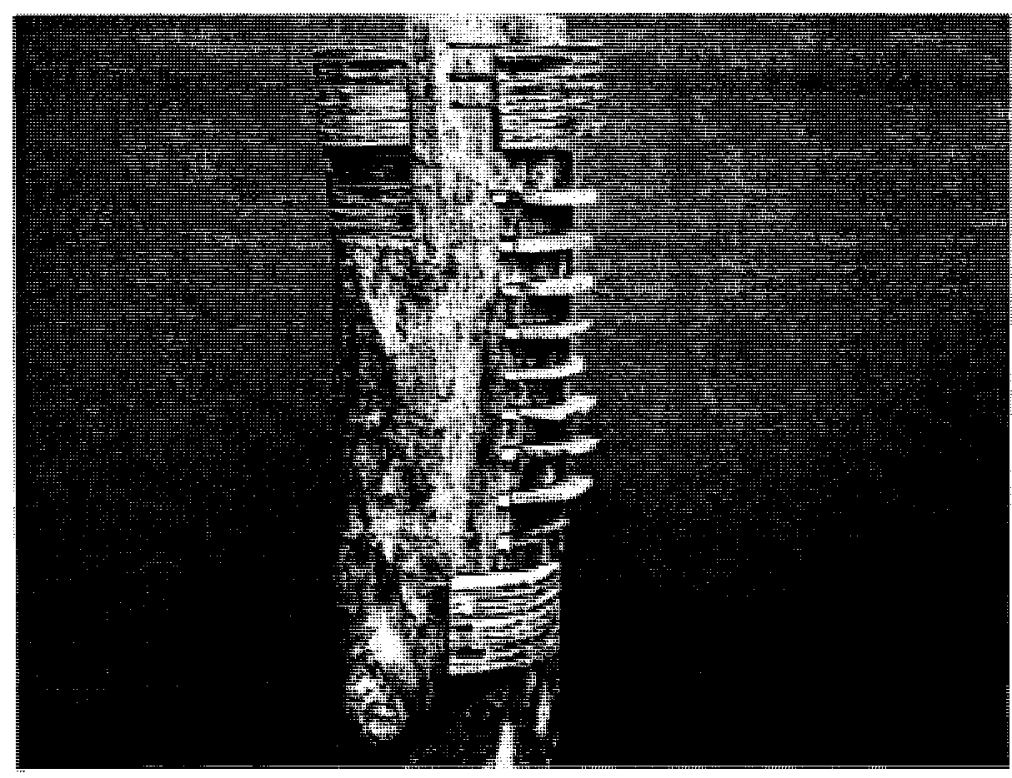

Fig.63 Conceptual study. The interchange of a natural material. Work by Author. 2006

The design for the facility is organized according to natures' resources: materials, water and energy --and their underlying principles and forces (earth, air, water, and fire). The Environmental learning centre should not only respond to the need for conservation, but be a model for others to build upon. The concept of earth sheltered design, green roofs, and landscape enhancement are earth-related strategies that enhances the sense of the natural for the facility design and being an interval of the landscape that respects the natural conditions of a place.

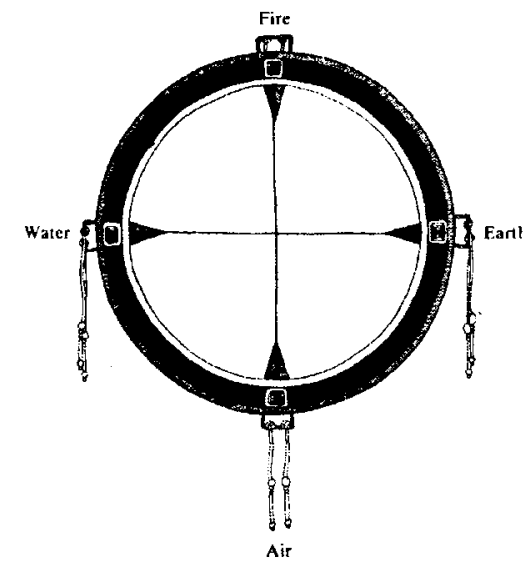

Fig.64. Nature's resources. Turtle Island Alphabet: A Lexicon of Native American Symbols and Culture p.20. 1992 Gerald Hausman 
The facility is embedded into the ground, designed as being part of the natural landscape and following the topographic contours of the land. Sections of the building become fully emerged into the site, where the roof becomes a sloping earth bank, encasing the building with natural vegetation. The earth bank mitigates storm water runoff by using scuppers that extend from the roof, and impel rainwater beyond the building's skin into a rocklined water garden bioswale.

\section{The earth:}

Within the building design there are two areas where the earth is revealed to the observer. Inside the interior of the building an earth wall reveals its layers and various materials of the earth and in other areas exposed cracks and crevices in the wall create niches for the buildup of soil and grasses on the surfaces of walls, allowing vegetation to grow. Additionally, a filtration wall located on an exterior wall, allows the user to become aware of the hidden layers of the earth and the water cycle's connectivity to the earth.

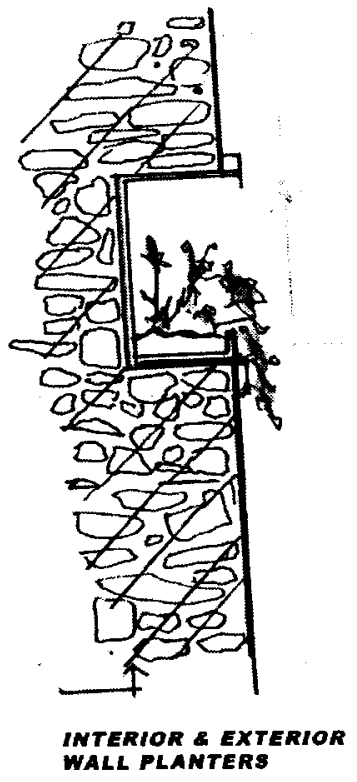

Fig. 65. Niche wall planter Detail by author. 2008

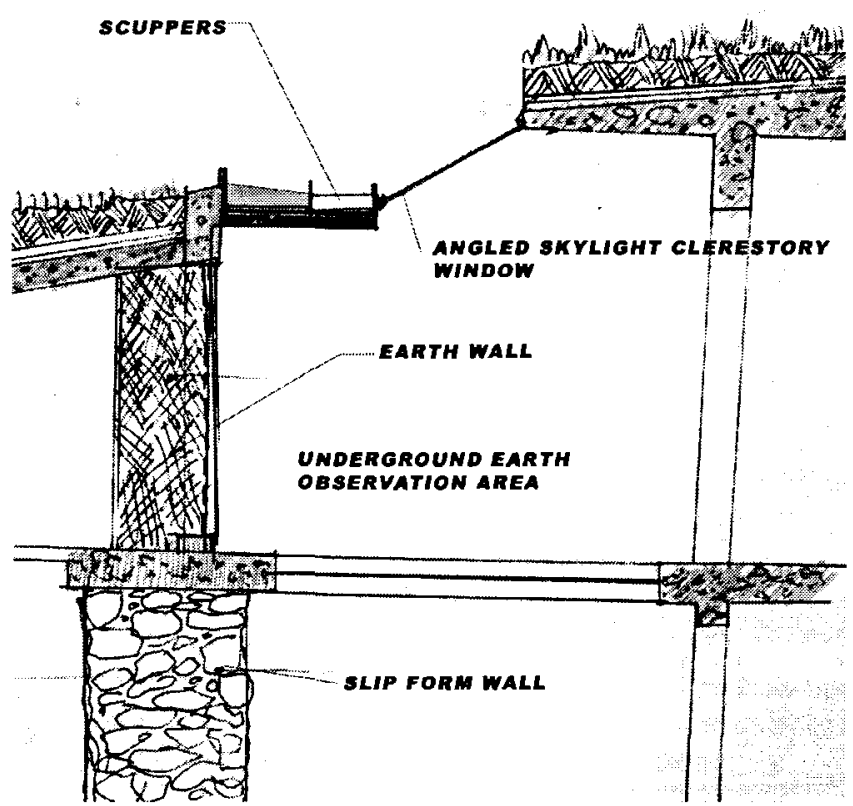

Fig.66. Earth wall \& Slip Form. Section -Conceptual detail by author. 2008 

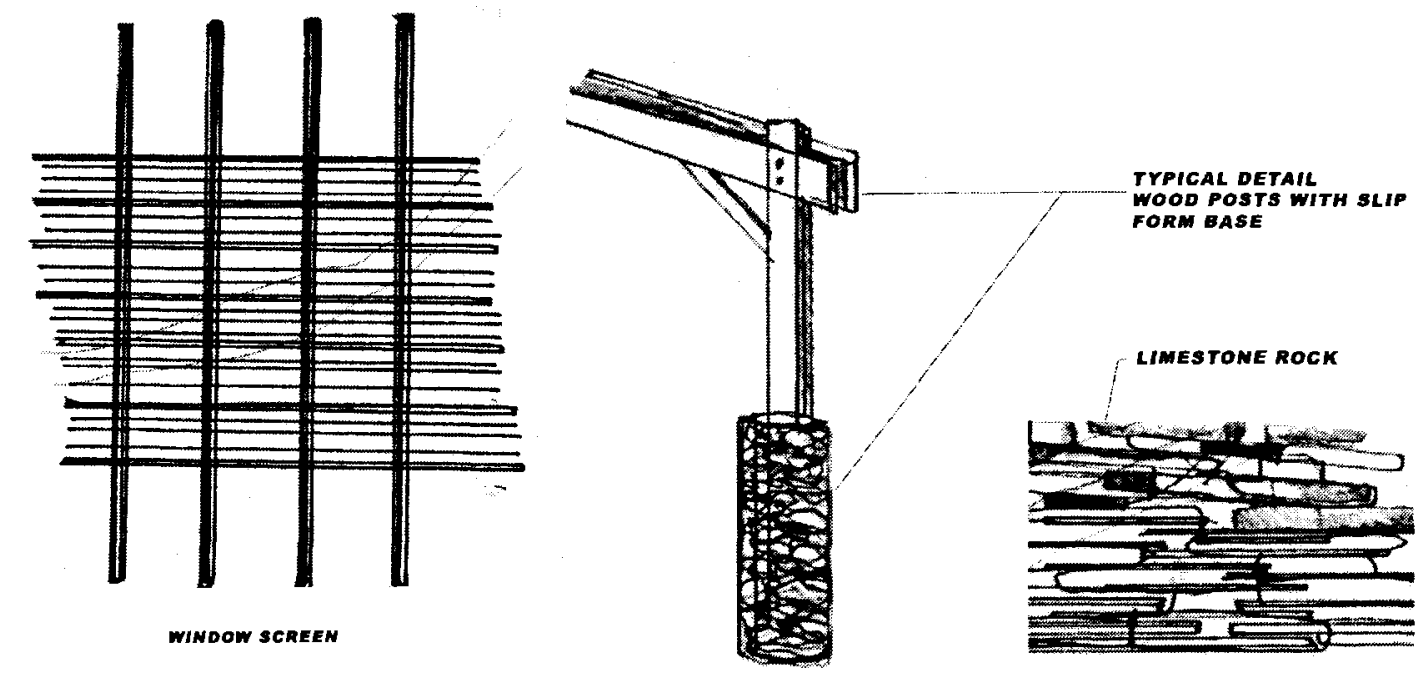

\begin{tabular}{l}
\hline $\begin{array}{l}\text { Fig.67. Wood window screen } \\
\text { detail. By author } 2008\end{array}$ \\
\hline
\end{tabular}

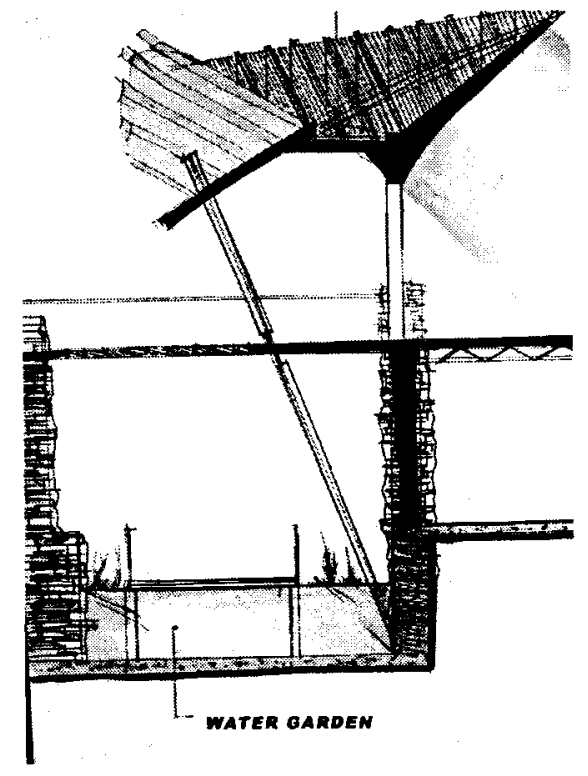

Fig. 69. Water garden and plantation
Fig. 68. Typ. Post detail., location for slip form. \& limestone rock (conceptual)

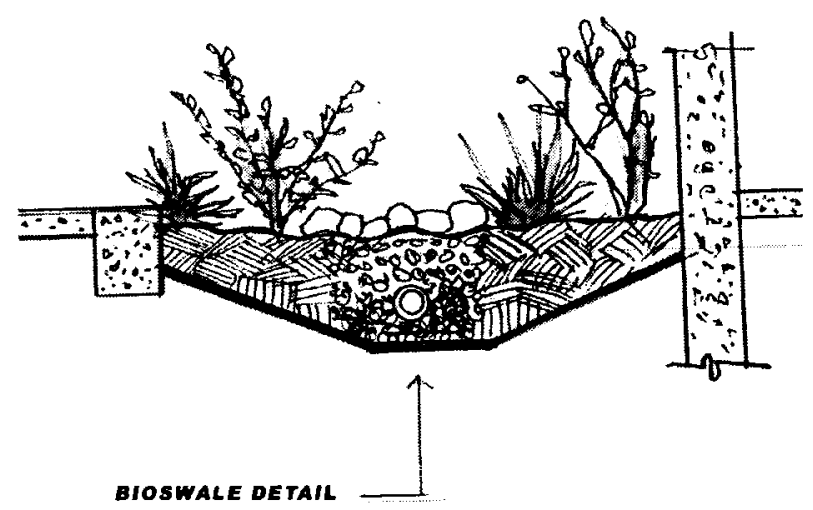

Fig. 70. Bioswale detail. 

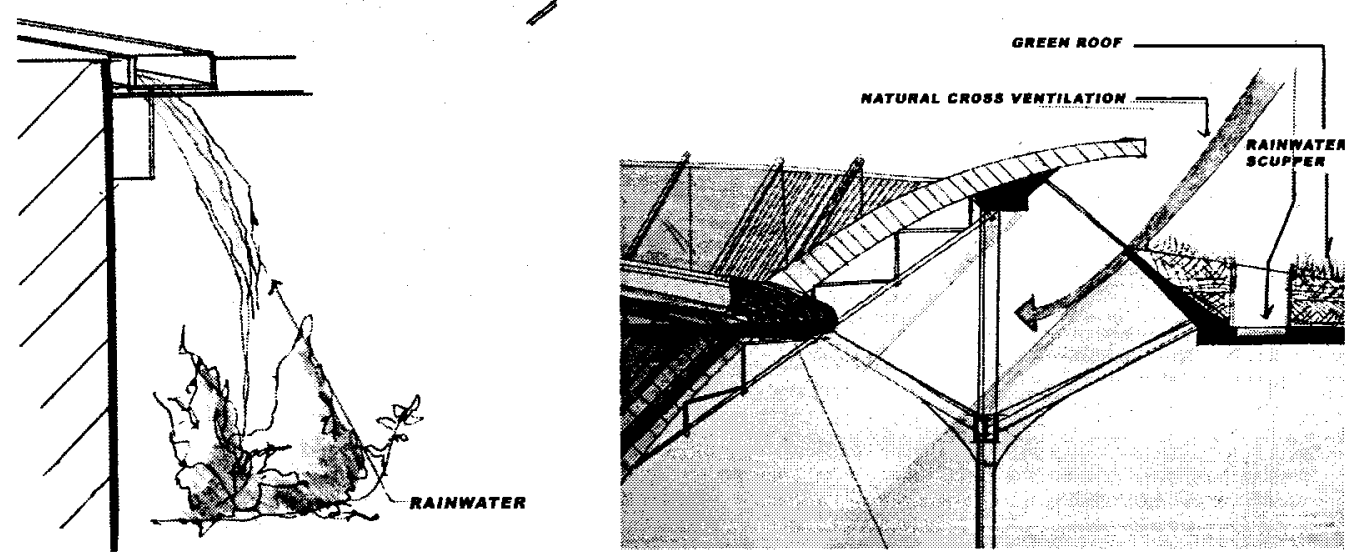

Fig. 71. Rainwater irrigation system. Drawing by Author

Fig.72.Cross Ventilation Diagram. Drawing by author.2008
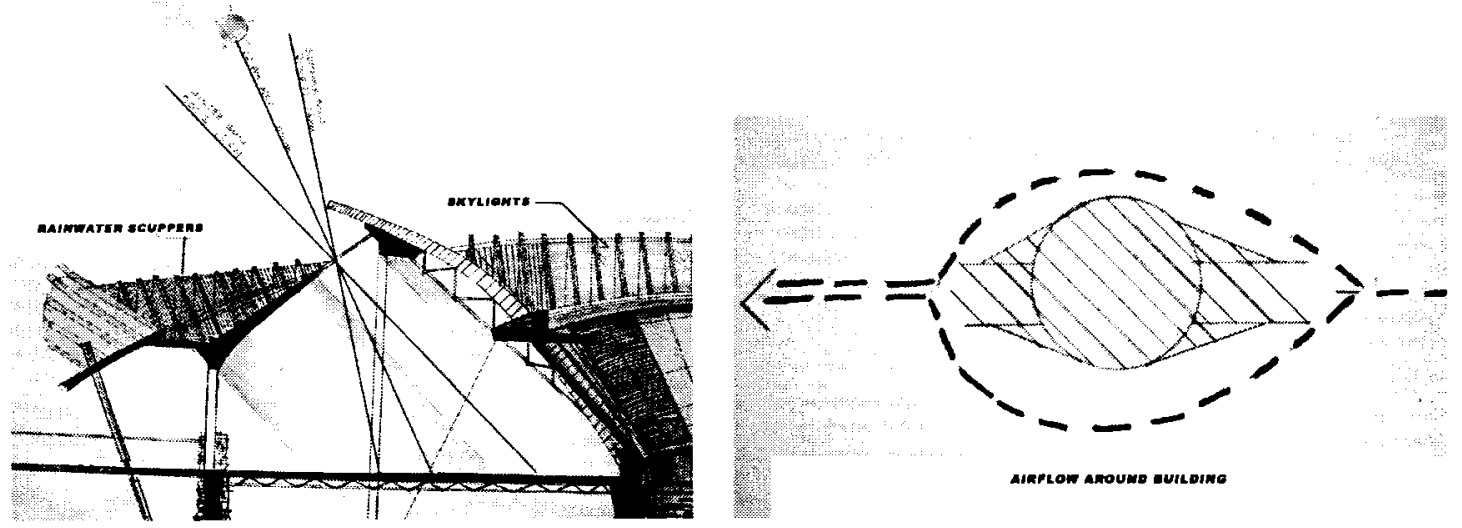

Fig.73. Sun angle projection. Drawing by Author

Fig.74. Air Flow diagram around Building

Air:

The ventilation air strategy in the interior of the building, capitalizes on the availability of fresh cool air. Operable double hung windows provide natural cross ventilation, and louvered shading-devices that provide protection against overheating in the summer. In addition, the experience of being suspended on the observation exterior deck near the water's edge allows air to funnel through and surround itself through hole penetrations in the natural rock and wood materials. 


\section{Water:}

Water offers itself as an ideal resource that can be integrated into the architecture and site. An on-site detention and retention strategy with the proper design emphasizes expresses the poetry of water by maximizing the features as the landscape form. This is executed by revealing instances where water runs through the interior and exterior of the building. In the central courtyard, rain-water is funneled through into the center. A water garden is shown at grade, and from below individuals can descend underneath the garden and observe water elements from below.

\section{Sun:}

Significant use of natural light is used to reduce the need for daytime artificial lighting. Sunlight enters through the glass of the exterior courtyard, and through the south facing windows diffusing light through the building interior.

\section{Materials:}

The structure for the centre is largely constructed of wood and stone. The stone technique is a slip-form style made up of natural concrete and stone. The slip-form is a readily available local material that can be made of recycled stone and stone byproducts presenting an earthly, durable aesthetic that is incorporated into the landscape and applied to features within the building. The slip-form walls reveal itself as a form of structural support along the perimeter of the building and acts as a standard wall barrier to other features of the landscape. Slip-form or "slipforming" is an old-fashioned style of masonry, resulting in a random or "rubble-stone" appearance that does not have uniform joints or sharp clean lines from modern masonry. The method of construction is to construct short forms on both sides of the wall to serve as a guide for the stone work. The stone and concrete is then poured into these crevices and cured. Following this, the forms are then removed and applied "slipped" up to the next level. Stone is used in areas where thermal mass is desired, especially in the interior of the building, where sunlight can serve to store heat or moderate temperature fluctuations. 
Natural wood construction is employed in various ways throughout the building. This is utilized by girders and structural support, finished boards for decking, flooring materials and woven strips for shading devices and aesthetic elements. Natural wood veneers are introduced in the form of structural beams which "conceptually" reinforce aesthetic qualities by exposing structural members for the central "tree" design. This type of product is by nature, not manufactured

\section{Form:}

Trees once of great importance to human survival, seem to have since become decorations to the buildings that subsume our land. Integrating trees into the landscape, not as mere foliage but as prominent history lesson in themselves, assures that they will be at the forefront of ecological conscience. In addition, the building's form is designed to mimic the growth of a tree. The "tree" situated as the focal point stretches its branches across the building's landscape, acting as a roof element, that embraces the programmatic layout, and metaphorically uniting the community. The symbol of the "tree" for example, within the Iroquoian tradition, symbolizes unity, peace and strength: binding the community together and symbolizing the Six Nations Confederacy.

Mircea Eliade in his book The Sacred and the Profane continued with this conception,

The cosmic tree, a symbol of a rich cultural mythos, the major archetype being that of the center, the beginning where sacred powers first originated. The tree is the navel of the world, the "cosmic axis" (Axis mundi)88 standing at the universe's center where it passes through the middle and unites the three great cosmic domains: the underworld, earth, and sky... additionally, the vertical direction includes the "sacred dimension of space. It represents a path towards a reality, which may be higher or lower than daily life, a reality that conquers gravity 89

\footnotetext{
${ }^{88}$ Eliade, $1959, \mathrm{p} 38$

${ }^{89}$ Roth, Stephanie. "The Tree of Life, The Ecologist". Jan. 2000 v30il. 18 Aug. 2003. p.11.
} 


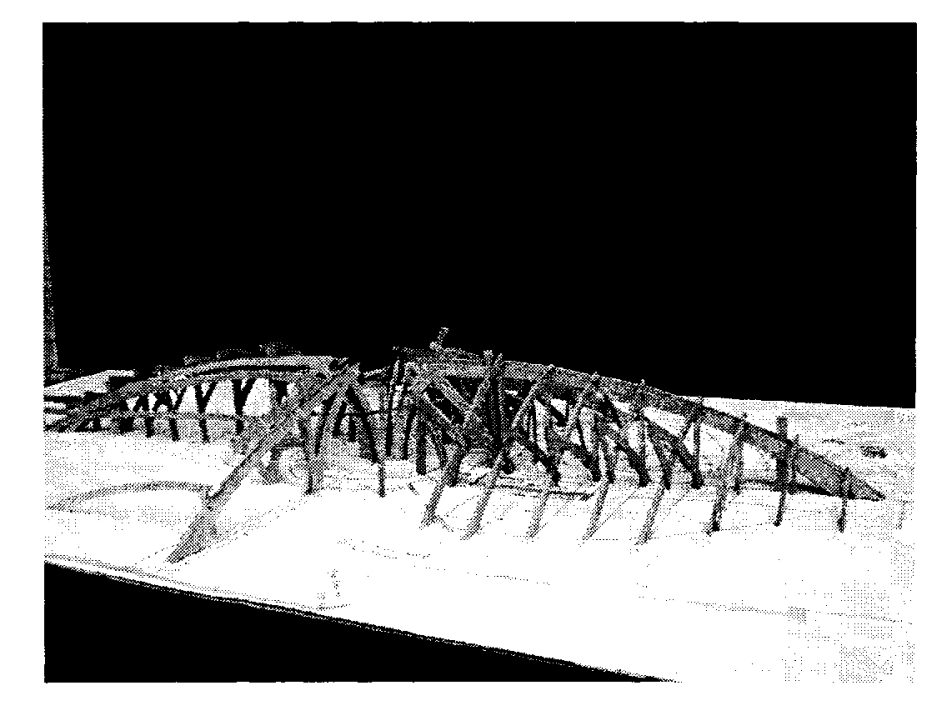

Fig.75 The structural tree. Conceptual model by author.2006

\section{Wind:}

The location of the site near the riverbank, allows the opportunity to take advantage of the properties of wind. Surveillance of the wind's process is located to the north side of the site at the cantilevered deck. Positioned on the eastside is a screened wood fabricated wall with various openings creating a tunnel effect and sound diffusion as the wind channel through this zone.

\section{Sense of History:}

The design aims to emphasize and reinforce Iroquois culture while acknowledging culture as an evolving entity that links itself with traditional knowledge, culture and contemporary western society, by taking elements from historical measures, symbolism, building orientation, environmental aspects, post and beam structure, and the use of natural materials that correspond with the local natural resources provides a viable design solution for the Iroquois community.

"Buildings that invite participation can help acquire knowledge, discipline, and useful skills that cannot be acquired other than by doing." 90

\footnotetext{
${ }^{90}$ Orr, David W. The Nature of Design: Ecology, Culture, and Human Intention. Oxford University Press.2002.p.114
} 
The facility accommodates and exhibits artistic and cultural collections from the community that convey the story of the communities' history, as well as address its current contemporary state. It is important to incorporate significant features of the landscape and nature's resources that enhance the building's program and functional requirements. The concept of seasonal cycles, plant cycles, sun and wind orientation, water cycles and built spaces include interior and exterior gathering areas correspond with the initial traditional teachings and beliefs set forth by the Iroquois Thanksgiving Address. This address is a prayer that is still spoken at Iroquois ceremonial and governmental gatherings and is based on teachings of how one is to conduct one's self in harmony with the natural world. For example:

The water gardens; " The Waters: We give thanks to all the Waters of the world for quenching our thirst and providing us with strength. Water is life. We know its power in many forms - waterfalls and rain, mists and streams, rivers and oceans. With one mind, we send greetings and thanks to the spirit of water. Now our minds are one.....

The plant gardens; The Food Plants- With one mind, we turn to honor and thank all the Food Plants we harvest from the garden. Since the beginning of time, the grains, vegetables, beans and berries have helped the people survive. Many other living things draw strength from them too. We gather all the Plant Foods together as one and send them a greeting and thanks." 91 These teachings form the basis for the arrangement and variety of gardens, water tables, plantations, marshlands etc.

The Traditional longhouse ceremonies, is a sacred conduct, and therefore governed to only be performed within the longhouse. These ceremonies follow the natural seasonal events, and can only be performed by it members, therefore it is not appropriate to execute these events to the public. As a result, the new facility will provide traditional dance socials and gatherings within the site's context and teachings will be conducted in the theatre, in celebration of seasonal events. These activities are extended to the public, allowing the visitors to participate, learn and experience specific celebrations and cultural actions.

\footnotetext{
91 Stokes, John. "Thanksgiving Address, Greeting to the Natural World". Six Nations Indian Museum Tracking Project. Tree of Peace Society.1993.
} 


\section{Sense of Craft}

Architecture should be made to last. Efficient architecture that has an essential character remains steadfast against modern society's changing developments.

The quality of a building is in part derived from the quality if intention by the designer, and also derived from the nature of the workmanship employed.

Built with materials that endure and improves with age and integrating sustainable selfsufficient design principles is an easy way to accommodate change and be aesthetically pleasant in character so that people will prefer to conserve them.

Vernacular architecture is still relevant today, because it has always addressed sustainability. It is that of necessity in most cases where local craftsmanship and building materials were vital and where Spaces always mirrored the true and practical lifestyles of their inhabitants. The relevance of good traditional building is that it not only allows us to celebrate our past technological achievements but also to study and understand the primary mechanisms, which guarded the design of the particular building.

\section{Sense of limits}

Instances within the site context initiate physical and temporal boundaries as it pertains to programmatic functions. For example the exterior central courtyard is wrapped by the building's façade, which accentuates an intimate experience and enforces a spatial boundary. Rock boulders were removed from the site during construction, is strategically placed near pedestrian pathways. The procession to the building is set to the east side of the building along a tree-lined path. The end of the path is marked by the reveal of a low stone wall that follows the topography of the site until it unites with the building. The buildings' visibility to the water below and to the City of Cornwall located across the St. Lawrence River establishes a visual connection. The exhibition areas located within the interior of the building and in areas along the exterior pathways of the ecological grounds, informs the public about the narrative story of the Iroquois history, as well as addressing its current state and identity. The spatial organization of the building, allows new relationships across and between art, moments in history, and ecological knowledge. And lastly, by enlarging the opening to the north and south, creates an open plan with a visual connection in all directions. 


\section{Cultural Identity}

The Environmental Learning Centre is a cultural artifact that gains its identity through the community in which the building is designed for. It is their culture that reveals the dominant role by maintaining "sense of place" manifested through their cultural qualities of different textures, form and meaning.

Thus, in order to make an integrated connection with the land, one must redefine man's relationship with the natural environment. To promote change, architecture should not only re-connect to the natural environment, but also act as a vehicle to promote awareness and understanding of natural systems. Architecture must carefully address the experience of each individual as he or she interacts with the environment. It must promote a sense of discovery, allowing the user to develop a deep intuitive understanding of place, the natural environment and the philosophy behind Native American culture.

The process of appreciating the project is through exploration, experiential learning, and interaction with the site, through the building circulation, exposed structures, penetrations, and by integrating natural elements that allow the natural elements to grow within the "ecosystem" of the building.

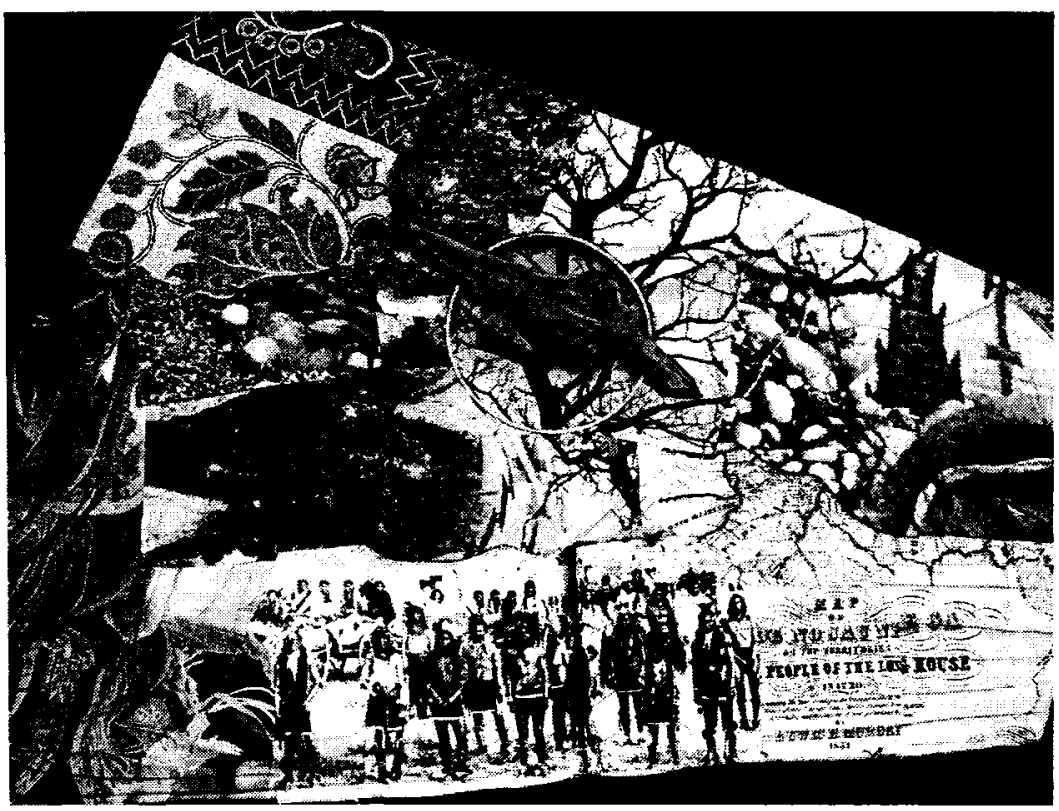

Fig.76 Conceptual Montage Study. Revealing the layers of culture, landscape and nature's resources. By Author. 2008 


\section{Model \& Drawings}

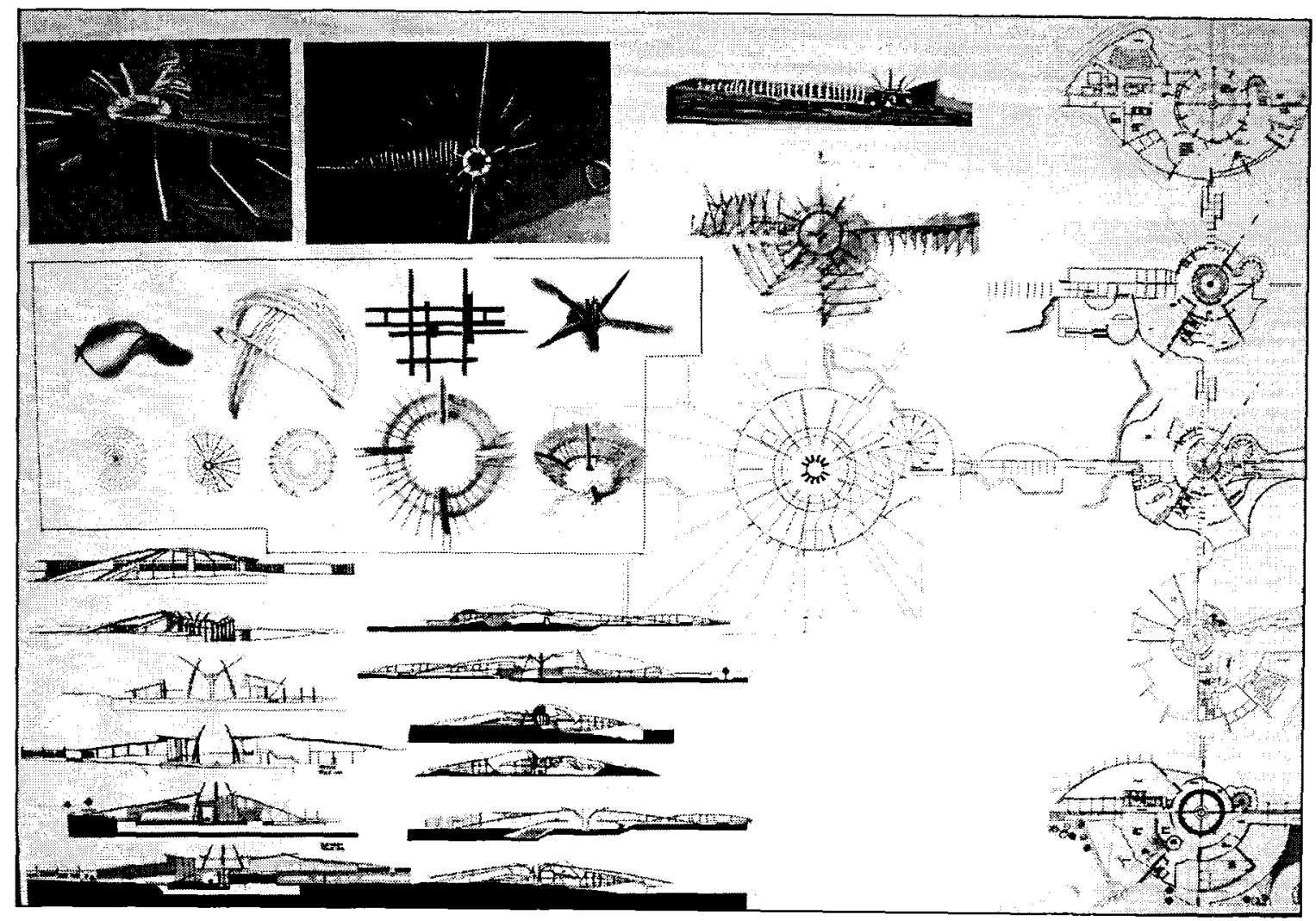

Fig.77Panel showing preliminary stages of design concept. By author. 2008
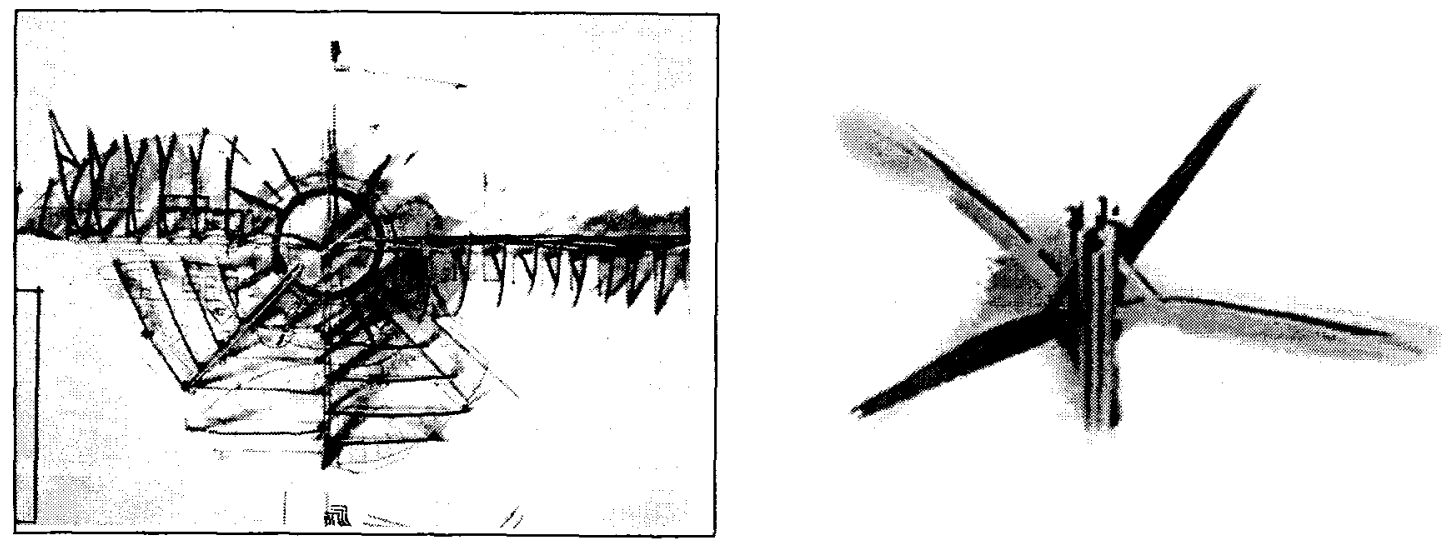

Fig 78 Preliminary structural tree detail. Model by author. 2006

Fig.79. Preliminary structural tree detail. Model by author 2007 


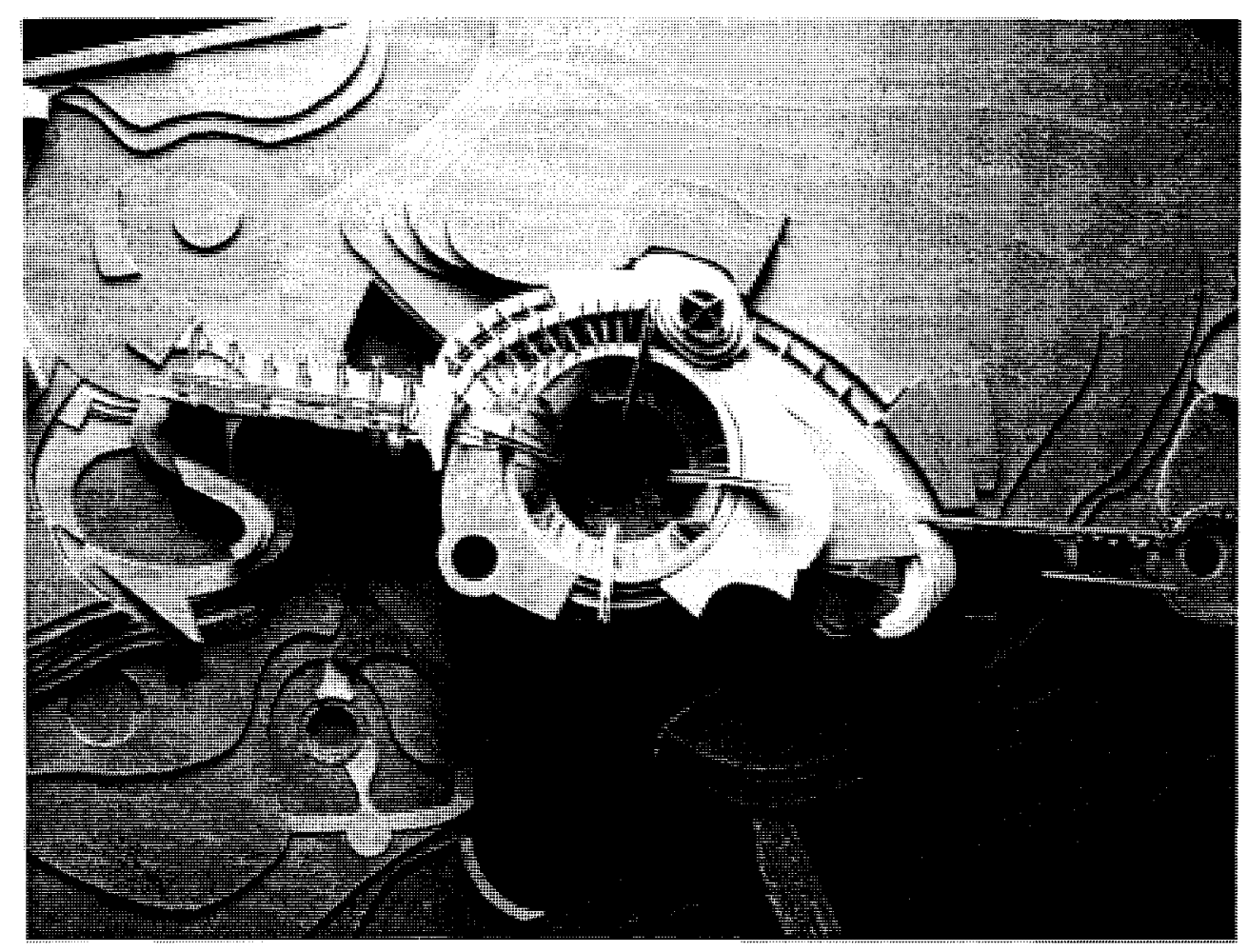

Fig.80 Top Aerial view of site model. Model by Author. 2008

Fig.81. Perspective view of site model. Model by author. 2008

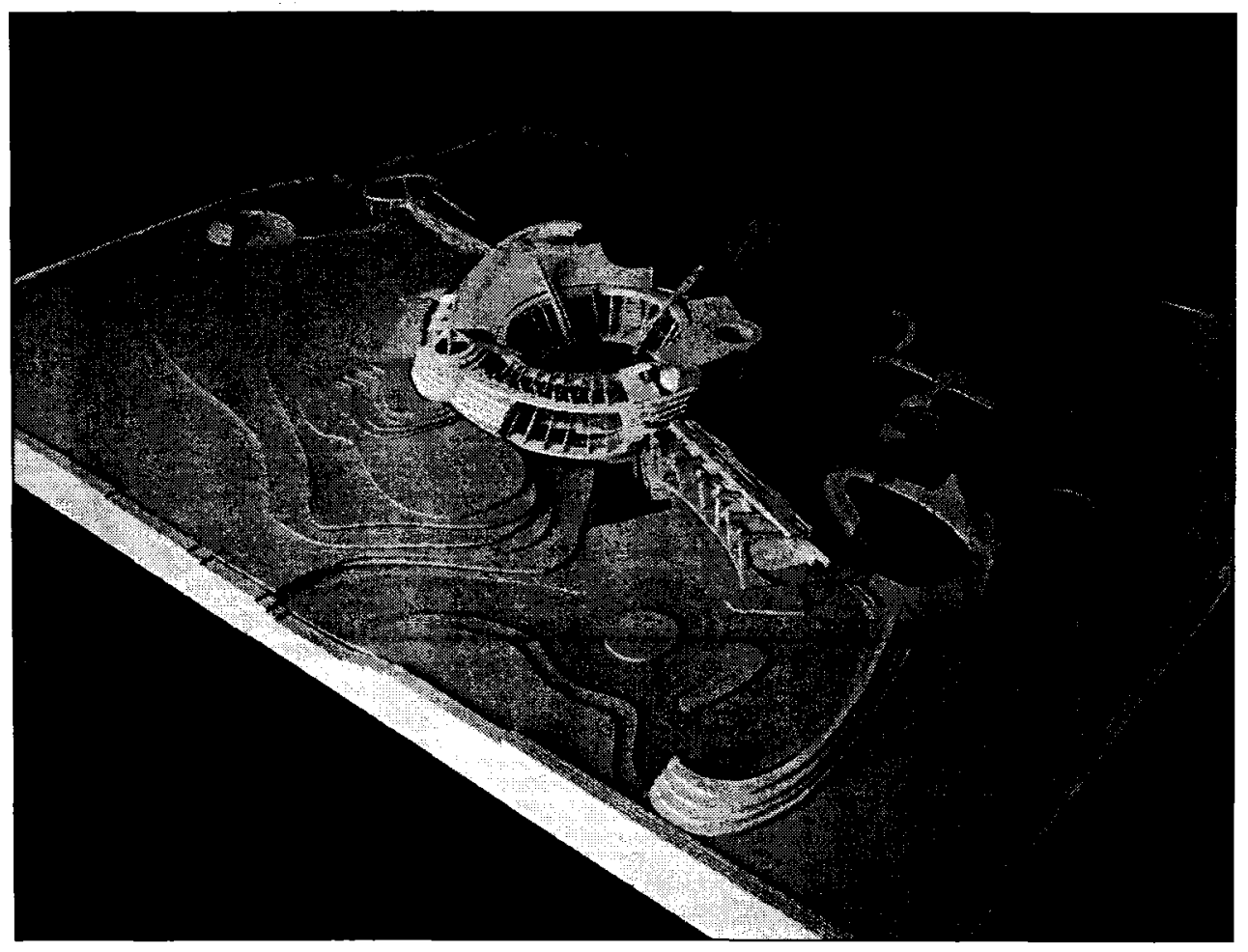




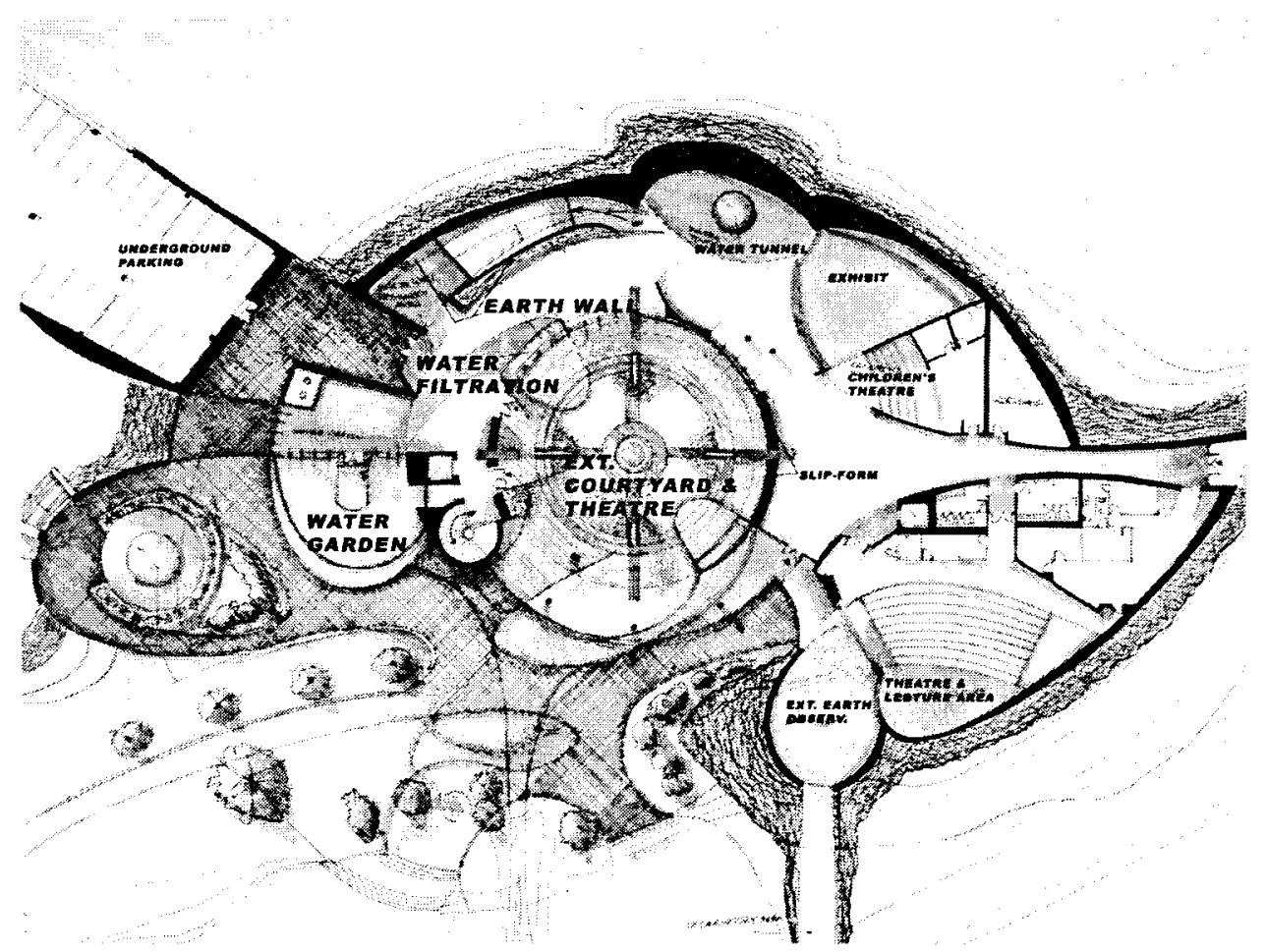

Fig.82. Ground Floor plan. - Conceptual. Drawing by author. 2008

Fig.83. Main floor plan-Conceptual drawing. Drawing by author. 2008

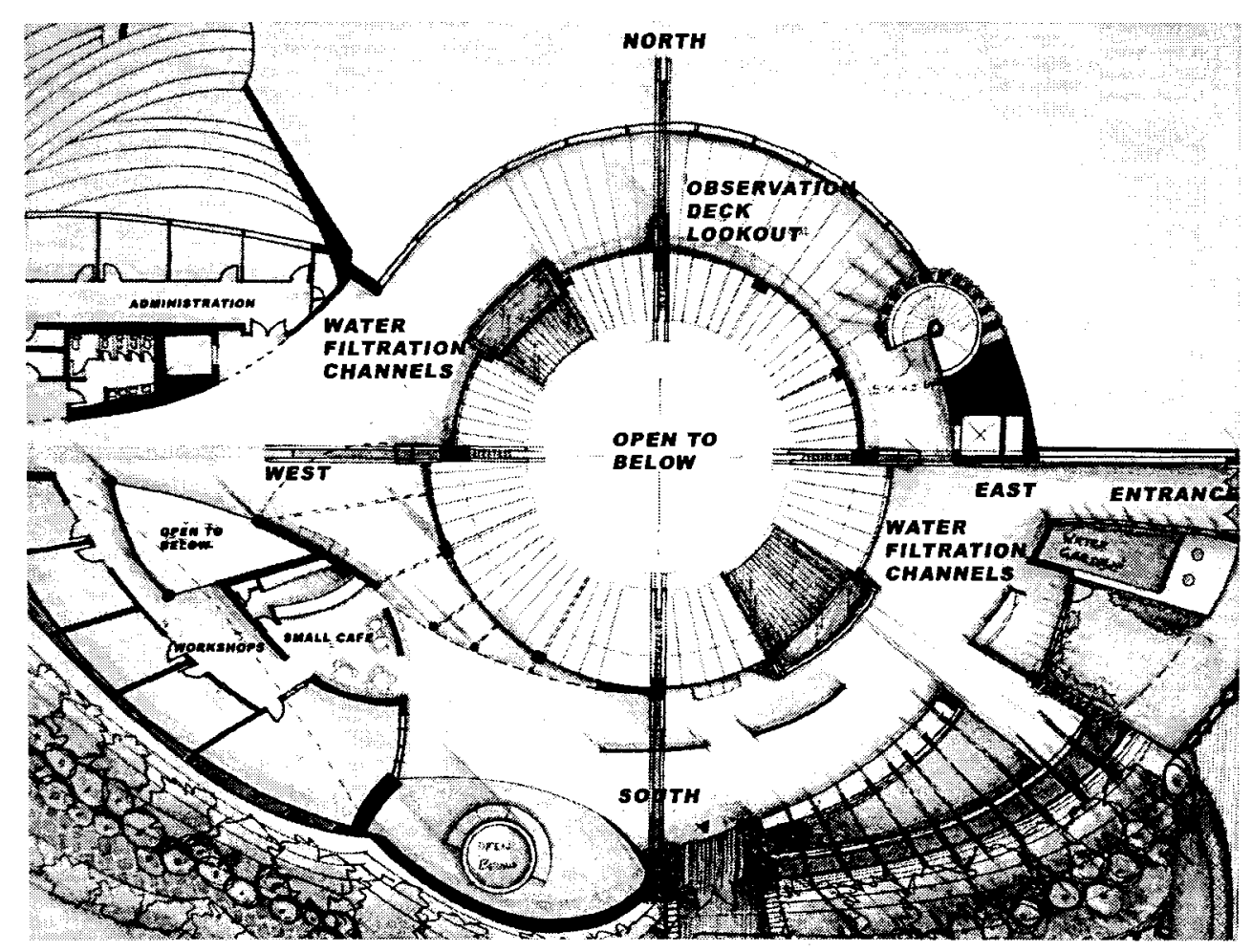




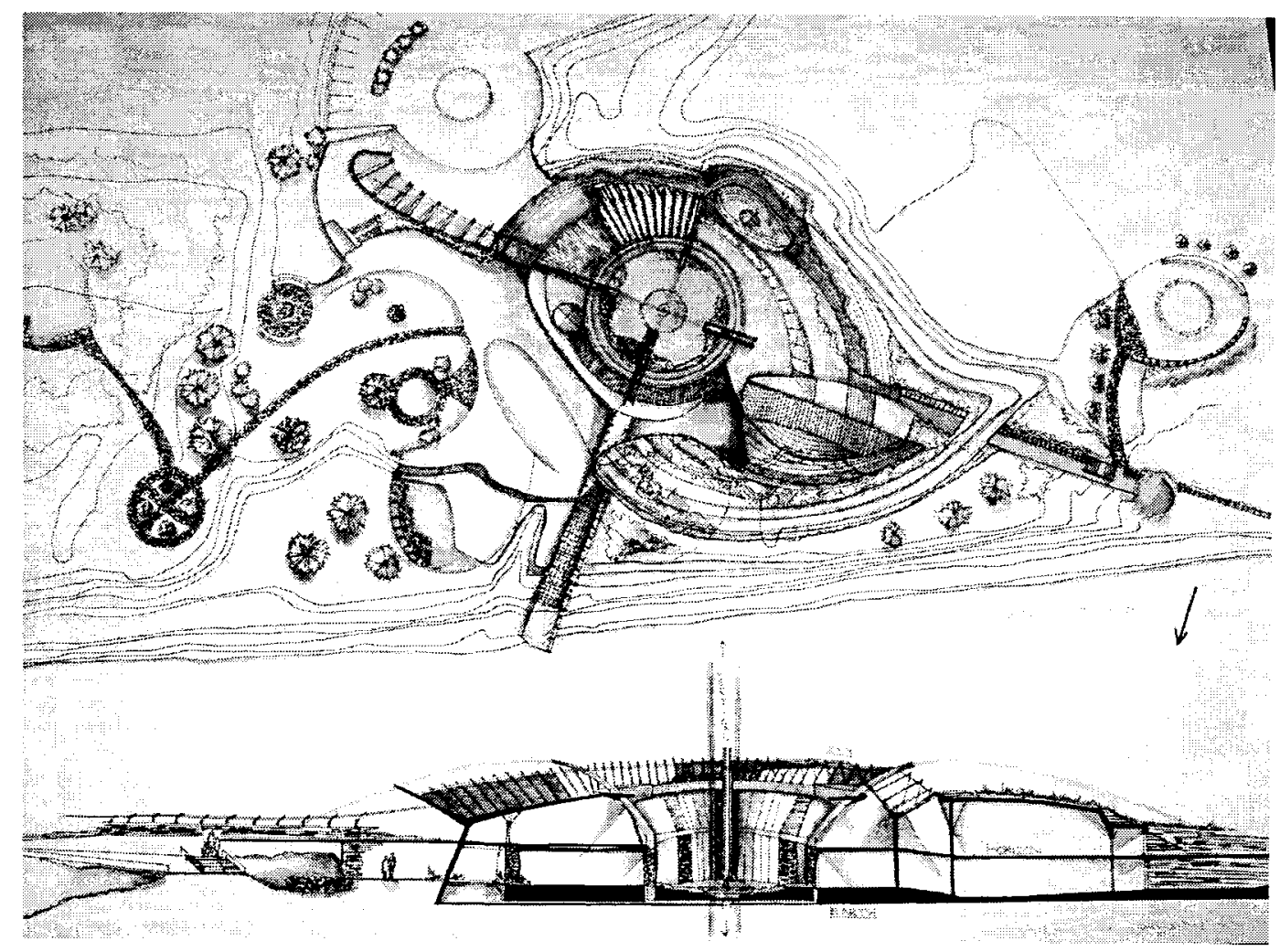

Fig.84. Site plan \& Section - Conceptual. Drawing by author. 2008

Fig.85. Elevation drawings -Conceptual drawing. Drawing by author. 2008

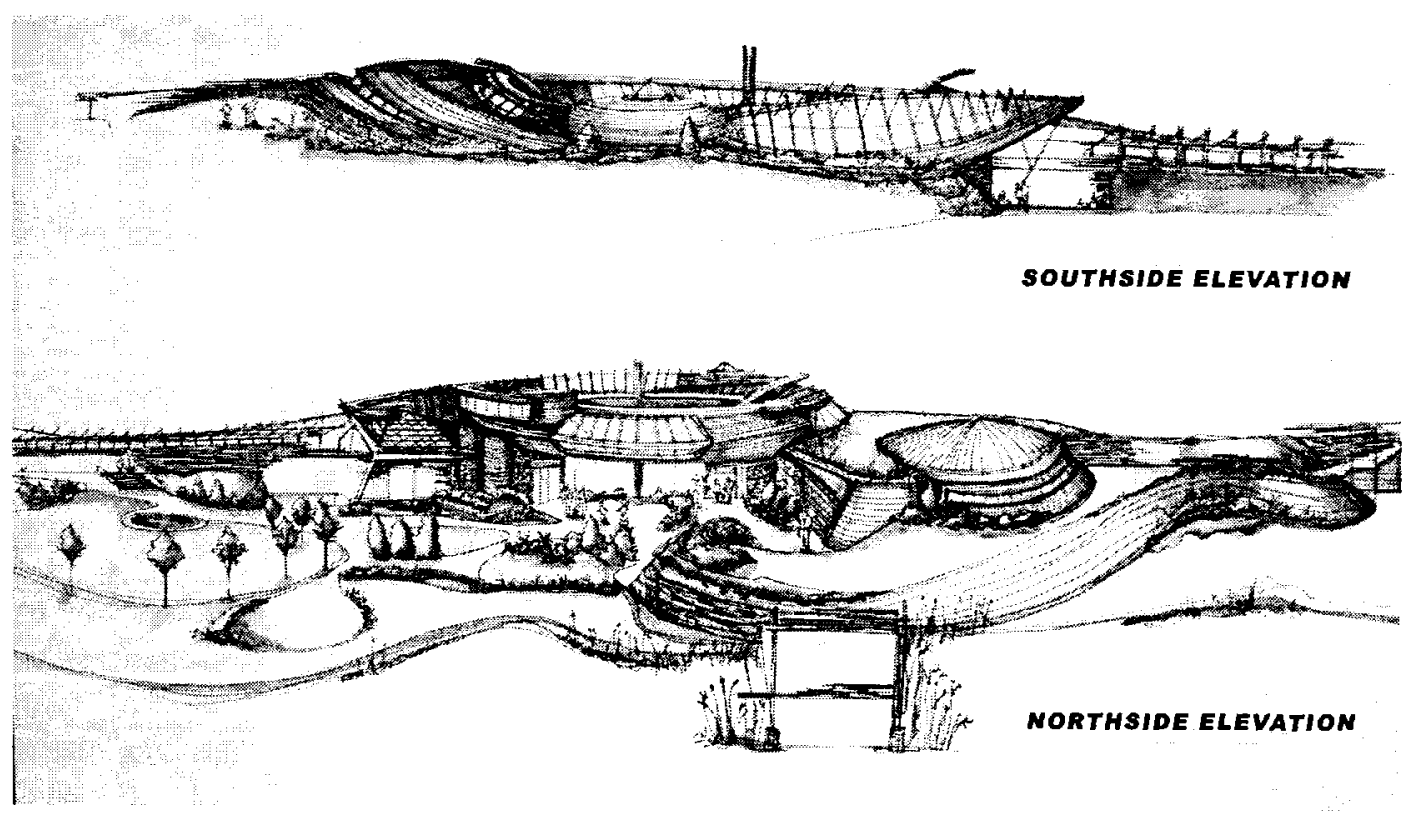




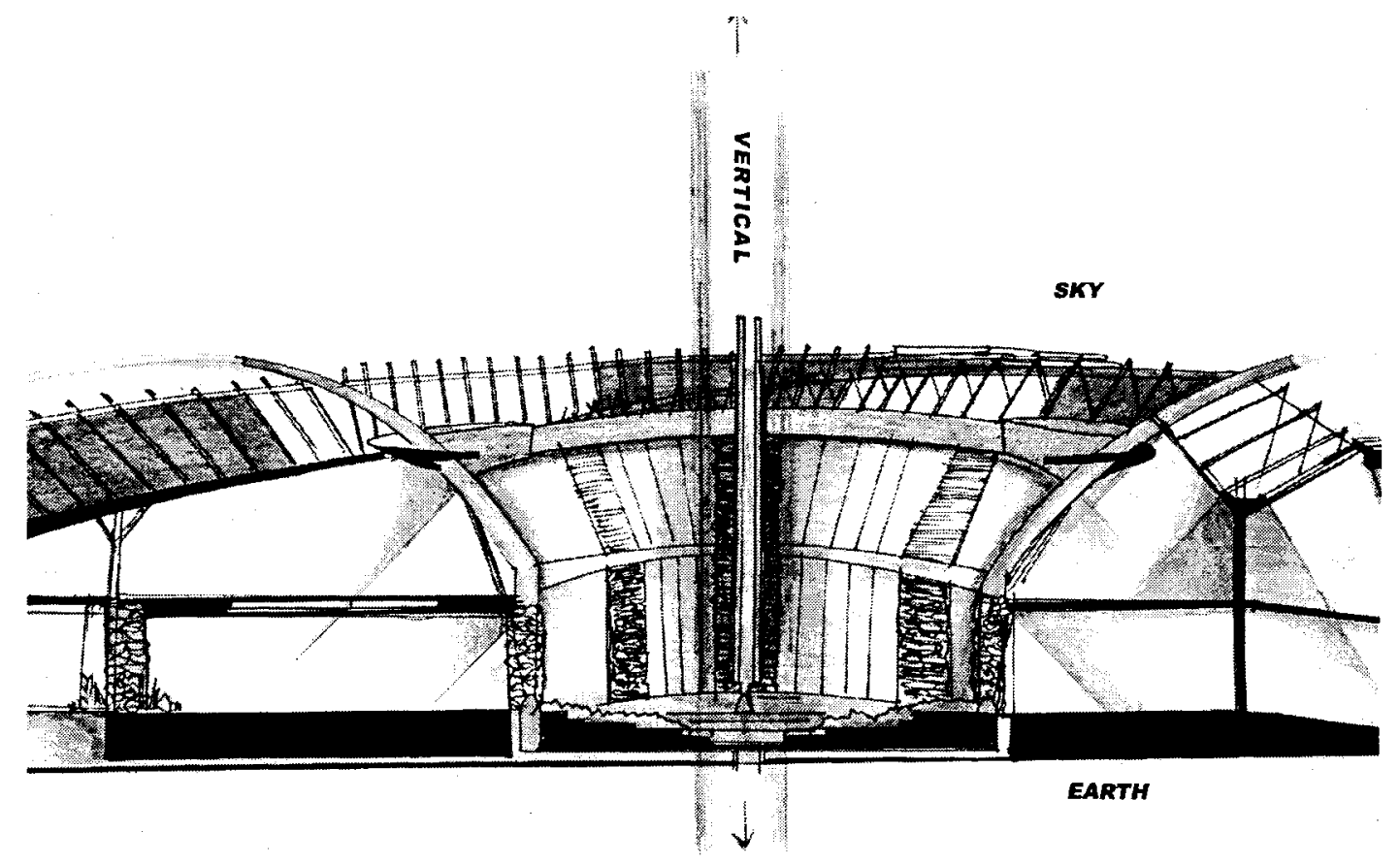

Fig.86. Section detail. - Centre courtyard- conceptual Drawing by author. 2008

Fig.87. Section detail-Centre courtyard indicating scale. Drawing by author. 2008

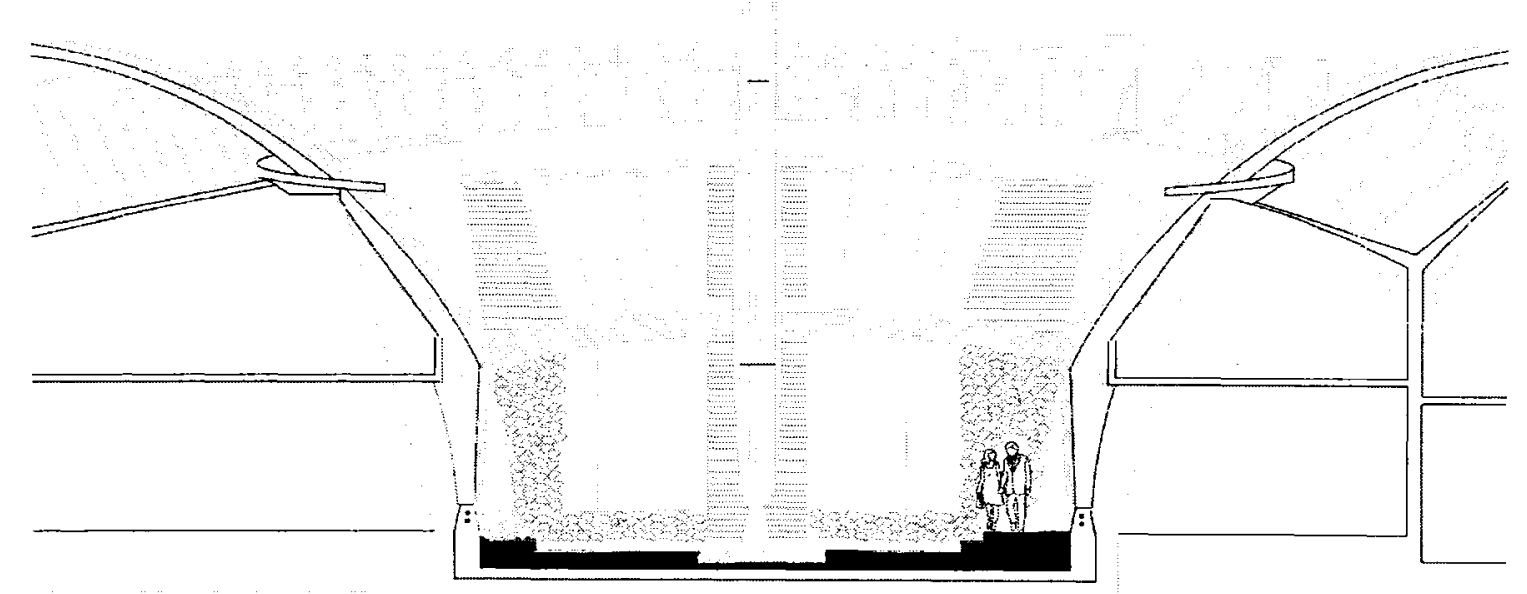

SECTION DETAIL AT CENTRAL COURTYARD 


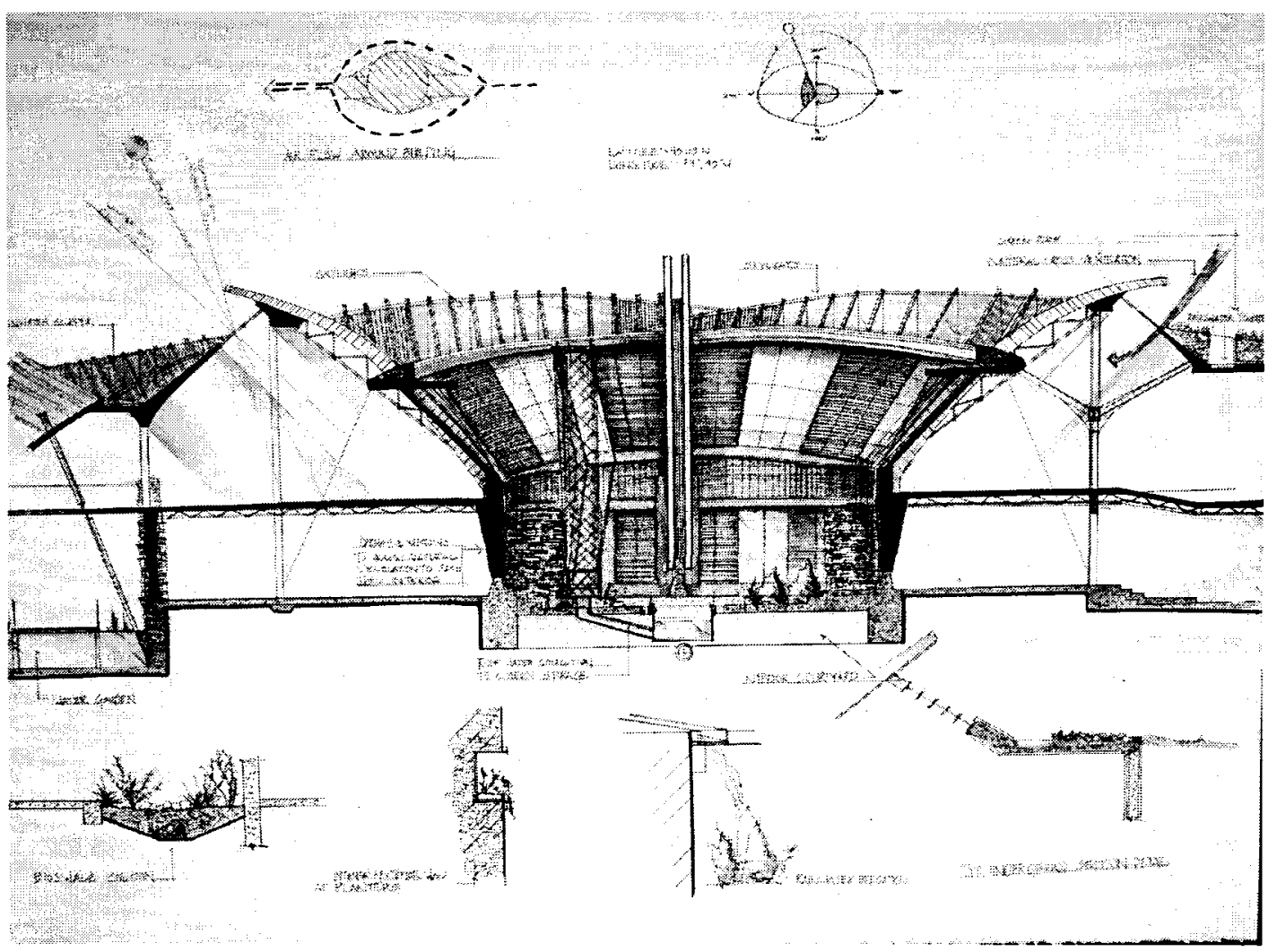

Fig.88. Panel diagram. - Conceptual. Drawing by author. 2008

Fig.89 Conceptual image showing building on site. by author. 2008

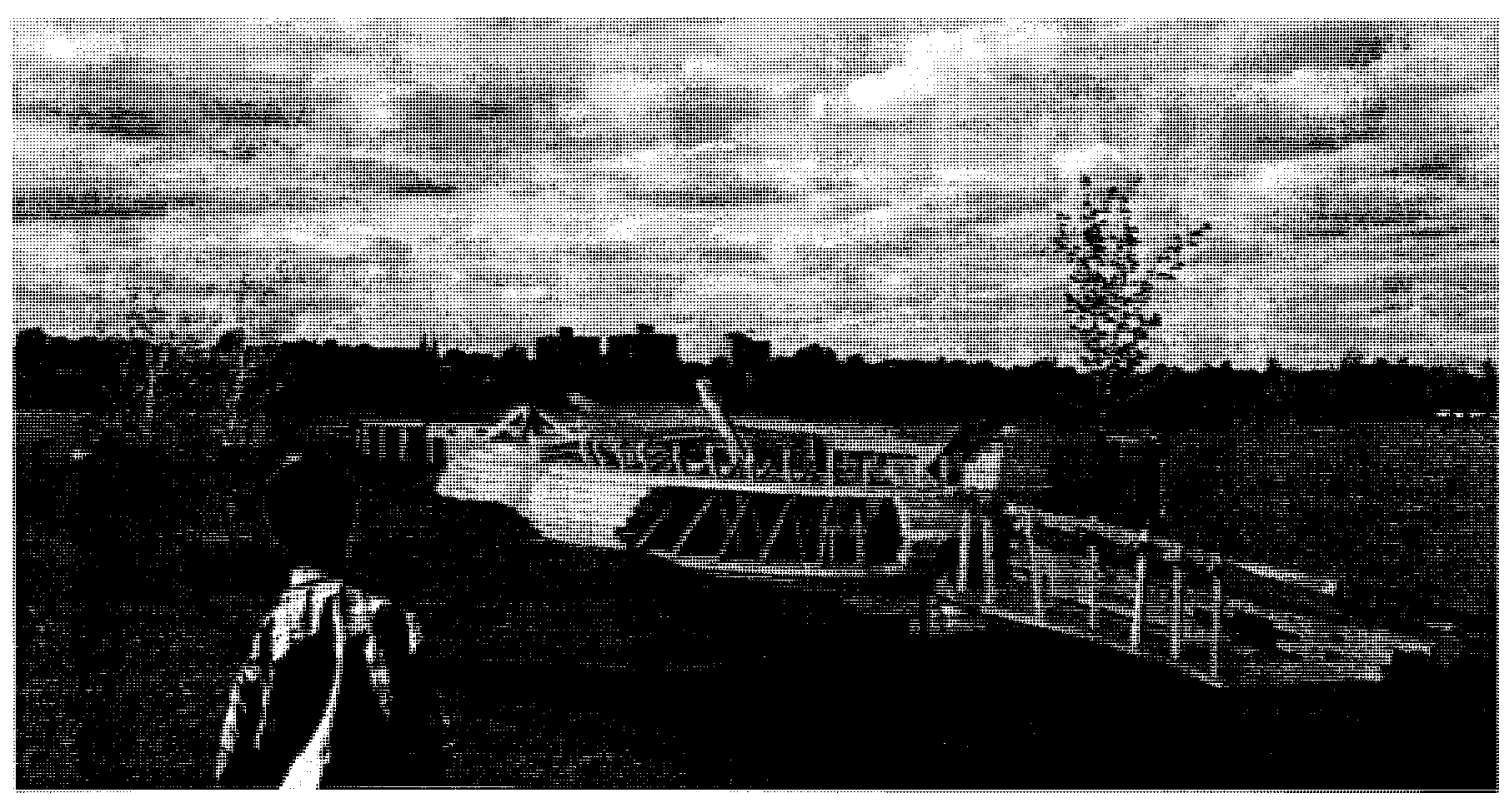




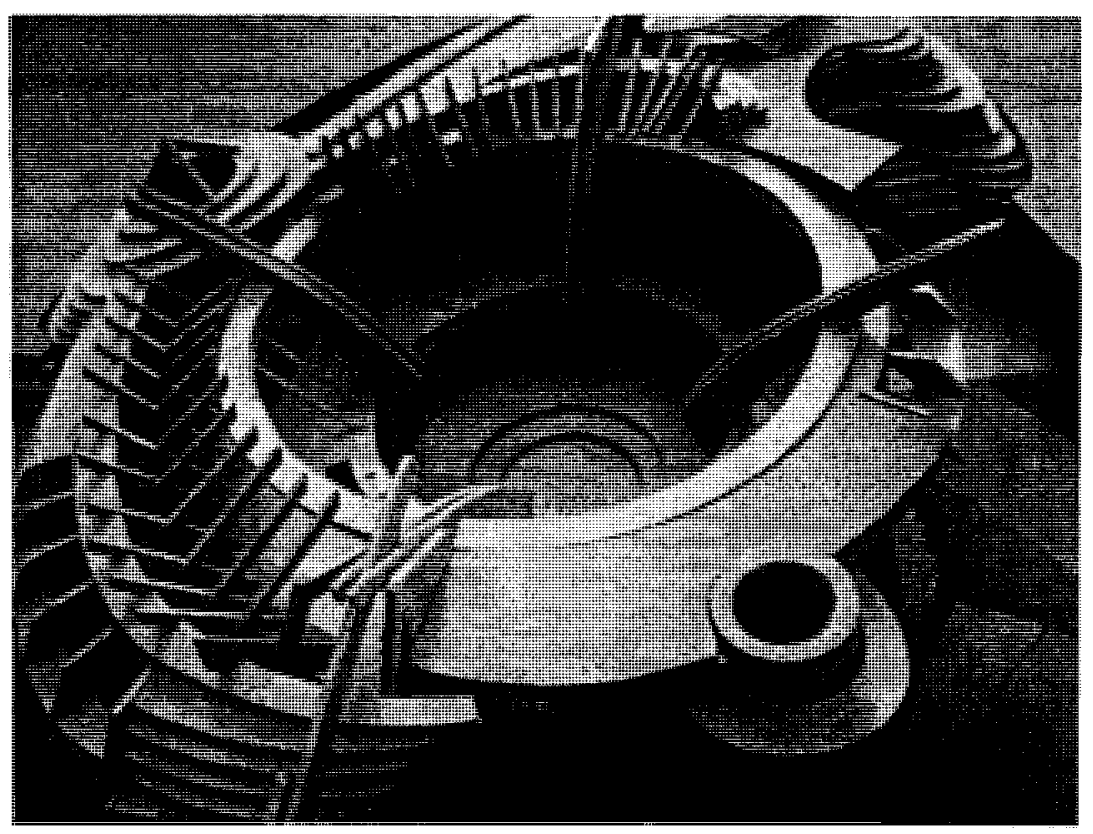

Fig.90. Central view of model. Photo by author. 2008

Fig.91. Conceptual drawing. Drawing by author. 2007

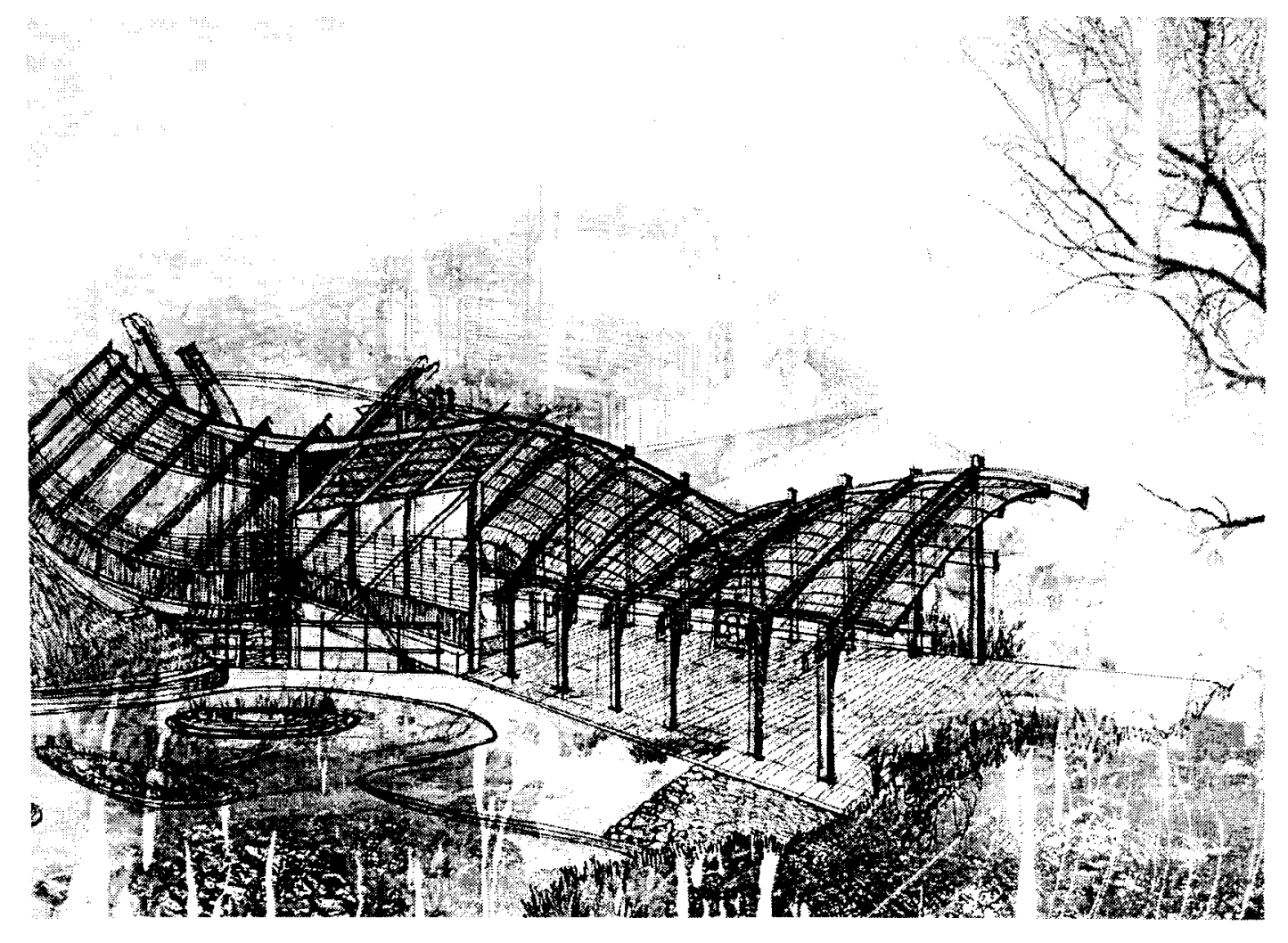




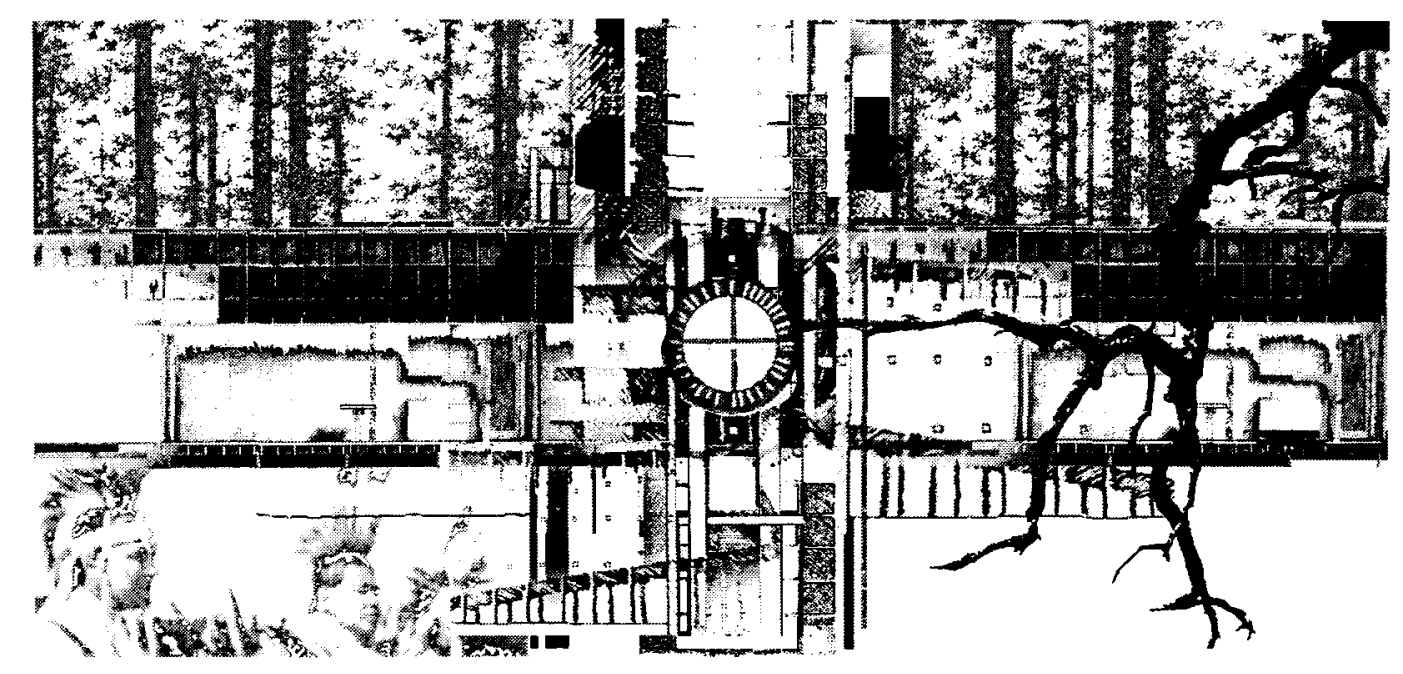

Fig.92 Figure Ground exercise. Drawing by author. 2008

\section{Final Conclusion:}

The negative actions from global measures have weakened the relationship towards the distinct character of building design when speaking in terms of "place specific". The vernacular became forgotten, as mass of standardized prototypes became the trend. But what happened when a culture's traditional vernacular architecture was lost as it pertained to a specific place?

Therefore the answer positioned itself by looking back to the past to review man's initial relationship with nature. By including the philosophies behind Native American Iroquoian culture, provides an example of a culture with a deep respect for environmental awareness and sensitivity to nature's resources.

The First Nation's Iroquois' early traditional vernacular longhouse was the primary expression of their culture and beliefs. However, this structure no longer exists today. The study of historical precedents lends a deeper understanding and appreciation for the significance of culture in shaping the landscape of the built environment. The project used architecture as a means of commemorating the events of the past and incorporating them into the present. The building is physically, culturally and ecologically embedded in the landscape. It reconstructs the landscape, remembers and reveals its history, while responds to its environment. It reinforces the sense of place by interpreting and reinterpreting the site. The building unravels the complexities of the surrounding 
landscape and widens our perception of the context. Through this example, a more profound relationship and deeper understanding is initiated in our relationship with nature and its resources.

Having outlined the history of the traditional longhouse structure and current trends within architectural theory and practice, I believe the inherent properties affiliated with the vernacular architecture, regional site context, cultural values and local natural resources provide the framework of an appropriate architectural design strategy. Specifically, the thesis questioned whether the design for an environmental learning center can intuitively represent the First Nations people and their community. The answer to this is that it is possible. There is a possibility to construct an architecture with a specific link and meaning to a particular place. Native American architecture must address the contemporary product while at the same time be able to identify the uniqueness of a specific context. Thus, specific considerations of place infiltrate the design process, which included explorations of site, material and experience that generated specific responses to the exigencies of place. These responses influenced the building assembly, and rendered it specific rather than general. The building thus became expressive of place.

As noted in the thesis, Kenneth Frampton's intent was to place specific local architecture close to the theoretic stance for critical regionalism. However, it is important to note that critical regionalism advocated mediation between regionalist and universal positions. The separation and, consequently, opposition of these two stances made the architecture a type of moderator in search of a middle ground. As this thesis proposes, the two are inseparable. Thus, regional or universal measures are taken only when it is appropriate to the meaning of the place and its cultural fabric. Additionally, critical regionalism did not address the meanings attached to vernacular architectural traditions.

In the end, it is imperative that architecture became again a means to reconnect the user to the environment and natural, elemental, and physical forces. The objective was to attempt to bridge the distances among the natural landscape, the vernacular, and tectonics 
measures that present a powerful metaphor for cultural and social rejuvenation, in turn provide an interactive, culturally appropriate form of architecture.

Therefore, the philosophies that we espouse, the buildings we apply them to, and the setting in which they are presented all influence the quality and importance of how we build our society. Without history we will only repeat our mistakes; without nature we will not be able to survive. Nature aims to teach us about connectedness, holism, beauty and restoration. Whether we choose to listen or not is our decision. 


\section{Bibliography:}

Barreiro, Jose ed; Indigenous Economics Toward a Natural World Order. Akwekon Press at Cornell University. Plenty Canada. Vol.IX, No.2, Summer 1992.

Breisch, Kenneth A...Constructing Image, Identity, and Place: Perspectives in Vernacular Architecture, Volume IX, edited with. Knoxville: University of Tennessee Press, 2003.

Boddy, Trevor. The Architecture of Douglas Cardinal. Edmonton NeWest Press, 1989.

Cardinal, Douglas and Jeannette Armstrong, eds., The Native Creative Process: A collaborative Discourse Between Douglas Cardinal and Jeannette Armstrong. Penticton, British Columbia: Theytus Books, 1991.

Crowe, Norman. Nature and the Idea of a Man-Made World: An Investigation into the Roots of Form and Order in the Built Environment. MIT Press. Cambridge Massachusetts. London. 1999.

Douglas Cardinals Website: http://www.djcarchitect.com

Farmer, John. Green Shift.: Towards a Green Sensibility in Architecture. Butterworth Architecture, WWF-UK Oxford.1996.

Foster, Hal. The Anti-Aesthetic: Essays on Postmodern Culture. Bay Press. Port Townsend, Washington. 1983.

Hughs, Donald J., American Indian Ecology. Texas Western Press. The University of Texas. 1983.

Krinsky, Carol Herselle. Contemporary Native American architecture : cultural regeneration and creativity / Oxford University Press, New York : 1986.

Moore, Jerry D. Visions of culture : an introduction to anthropological theories and theorists. Walnut Creek, Calif. : AltaMira Press, c1997.

Morgan, Lewis H., Houses and House Life of the American Aborigines. The university of Chicago Press. Chicago.1965.

Nabokov, Peter \& Robert Easton. Native American architecture Oxford University Press, New York : 1989

Norberg-Schultz, Christian. Intensions in Architecture. Massachusetts Institute of Technology.Cambridge Massachusetts. 1965.

Norberg-Schultz, Christian, Existence, Space \& Architecture. Praeger. New York. 1971.

Norberg-Schulz, Christian, Genius Loci: Towards a Phenomenology of Architecture. New York: Rizzoli International Publications, Inc., 1980.

Norberg-Schulz, Christian. Architecture: Presence, Language, Place. Skira editore, Milan. 2000. 
Rapoport, Amos. The Meaning of the Built Environment: A Nonverbal Communication. Approach. Tucson, AZ: University of Arizona Press.1990.

Rapoport, Amos. House Form and Culture. Prentice Hall Inc. Englewood Cliffs, N.J. 1969.

Ricour, Paul.Universal Civilization and National Cultures, 1961 in Kenneth Frampton's Modern Architecture: a Critical History. London: Thames and Hudson Ltd., 1992.

Rudofsky, Bernard. Architecture without Architects: A Short Introduction to Non-Pedigreed Architecture. Doubleday \& Company, Inc. Garden City, New York. 1964. 


\section{Appendix A}

\section{THANKSGIVING ADDRESS: GREETINGS TO THE NATURAL WORLD}

\section{Words Before All Else ${ }^{92}$}

The People: Today we have gathered and we see that the cycles of life continue. We have been given the duty to live in balance and harmony with each other and all living things. So now, we bring our minds together as one as we give greetings and thanks to each other as People. Now our minds are one.

The Earth Mother: We are all thankful to our Mother, the Earth, for she gives us all that we need for life. She supports our feet as we walk about upon her. It gives us joy that she continues to care for us as she has from the beginning of time. To our Mother, we send greetings and thanks. Now our minds are one.

The Waters: We give thanks to all the Waters of the world for quenching our thirst and providing us with strength. Water is life. We know its power in many forms - waterfalls and rain, mists and streams, rivers and oceans. With one mind, we send greetings and thanks to the spirit of water. Now our minds are one.

The Fish: We turn our minds to all the Fish life in the water. They were instructed to cleanse and purify the water. They also give themselves to us as food. We are grateful that we can still find pure water. So, we turn now to the Fish and send our greetings and thanks. Now our minds are one.

The Plants: Now we turn toward the vast fields of Plant life. As far as the eye can see, the Plants grow, working many wonders. They sustain many life forms. With our minds gathered together, we give thanks and look forward to seeing Plant life for many generations to come. Now our minds are one.

The Food Plants: With one mind, we turn to honor and thank all the Food Plants we harvest from the garden. Since the beginning of time, the grains, vegetables, beans and berries have helped the people survive. Many other living things draw strength from them too. We gather all the Plant Foods together as one and send them a greeting and thanks. Now our minds are one.

The Medicine Herbs: Now we turn to all the Medicine herbs of the world. From the beginning, they were instructed to take away sickness. They are always waiting and ready to heal us. We are happy there are still among us those special few who remember how to use these plants for healing. With one mind, we send greetings and thanks to the Medicines and to the keepers of the Medicines. Now our minds are one.

\footnotetext{
${ }^{92}$ Stokes, John. Thanksgiving Address, Greetings to the Natural World. Six Nations Indian Museum, 1993
} 
The Animals: We gather our minds together to send greetings and thanks to all the Animal life in the world. They have many things to teach us as people. We see them near our homes and in the deep forests. We are glad they are still here and we hope that it will always be so. Now our minds are one.

The Trees: We now turn our thoughts to the Trees. The Earth has many families of Trees who have their own instructions and uses. Some provide us with shelter and shade, others with fruit, beauty and other useful things. Many peoples of the world use a Tree as a symbol of peace and strength. With one mind, we greet and thank the Tree life. Now our minds are one.

The Birds: We put our minds together as one and thank all the Birds who move and fly about over our heads. The Creator gave them beautiful songs. Each day they remind us to enjoy and appreciate life. The Eagle was chosen to be their leader. To all the Birds - from the smallest to the largest - we send our joyful greetings and thanks. Now our minds are one.

The Four Winds: We are all thankful to the powers we know as the Four Winds. We hear their voices in the moving air as they refresh us and purify the air we breathe. They help to bring the change of seasons. From the four directions they come, bringing us messages and giving us strength. With one mind, we send our greetings and thanks to the Four Winds. Now our minds are one.

The Thunderers: Now we turn to the west where our Grandfathers, the Thunder Beings, live. With lightning and thundering voices, they bring with them the water that renews life. We bring our minds together as one to send greetings and thanks to our Grandfathers, the Thunderers. Now our minds are one.

The Sun: We now send greetings and thanks to our eldest Brother, the Sun. Each day without fail he travels the sky from east to west, bringing the light of a new day. He is the source of all the fires of life. With one mind, we send greetings and thanks to our Brother, the Sun. Now our minds are one.

Grandmother Moon: We put our minds together and give thanks to our oldest grandmother, the Moon, who lights the night-time sky. She is the leader of women all over the world, and she governs the movement of the ocean tides. By her changing face we measure time, and it is the Moon who watches over the arrival of children here on Earth. With one mind, we send greetings and thanks to our Grandmother, the Moon. Now our minds are one.

The Stars: We give thanks to the Stars who are spread across the sky like jewelry. We see them in the night, helping the Moon to light the darkness and bringing dew to the gardens and growing things. When we travel at night, they guide us home. With our minds gathered together as one, we send greetings and thanks to all the Stars. Now our minds are one.

The Enlightened Teachers: We gather our minds to greet and thank the enlightened Teachers who have come to help throughout the ages. When we forget how to live in 
harmony, they remind us of the way we were instructed to live as people. With one mind, we send greetings and thanks to these caring Teachers. Now our minds are one.

The Creator: Now we turn our thoughts to the Creator, or Great Spirit, and send greetings and thanks for the gifts of Creation. Everything we need to live a good life is here on this Mother Earth. For all the love that is still around us, we gather our minds together as one and send our choicest words of greetings and thanks to the Creator. Now our minds are one.

Closing Words: We have now arrived at the place where we end our words. Of all the things we have named, it was not our intention to leave anything out. If something was forgotten, we leave it to each individual to send such greetings and thanks in their own way. Now our minds are one. 